\title{
DETERMINING THE OPTIMUM OPERATING PARAMETERS OF A UNIPOLAR PWM INVERTER
}

\author{
A Thesis \\ Presented to the \\ Faculty of California Polytechnic State University, \\ San Luis Obispo \\ In Partial Fulfillment \\ of the Requirements for the Degree \\ Master of Science in Electrical Engineering
}

by

Michael James McCarty

May 2010 
(C) 2010

Michael James McCarty

ALL RIGHTS RESERVED 


\section{Committee Membership}

TITLE:

Determining the Optimum Operating Parameters of a

Unipolar PWM Inverter

AUTHOR: $\quad$ Michael McCarty

DATE SUBMITTED: $\quad$ May 2010

COMMITTEE CHAIR: $\quad$ Dr. Taufik, Professor

COMMITTEE MEMBER: Dr. Bill L. Ahlgren, Associate Professor

COMMITTEE MEMBER: Dr. Dale Dolan, Assistant Professor 


\author{
Abstract \\ DETERMINING THE OPTIMUM OPERATING \\ PARAMETERS OF A UNIPOLAR PWM INVERTER
}

Michael McCarty

May 2010

This study presents a determination of the optimum operating parameters of a unipolar PWM inverter through theoretical and experimental analysis. The inverter is investigated in its simplest form without input DC-DC conversion or output filtering. The intent of this study is to understand the core of the inverter thoroughly before adding peripheral elements such as output filtering. Variations on the input voltage level and switching frequency were investigated to determine their impacts on the operation of the inverter and harmonics produced. Theoretical modeling and calculations confirmed by experimental measurements and analysis allow determination of the inverter operating conditions which allow highest converter efficiency with lowest distortion. Results suggest highest efficiency and lowest harmonic distortion is achieved at the lowest input voltage (just above the peak of the desired fundamental component) and lowest switching frequency independent of output power. 


\section{Acknowledgements}

This document is the culmination of my educational experience thus far and, therefore, I believe it is important to not only thank people for their assistance and support with regards to this study, but also for my college education in general. I would like to thank my parents for their continual support of my education. The strong values and work ethic that I have obtained throughout my life are rooted in what they have instilled in me. I would also like to thank my sister for her emotional support throughout college. In the last five years, the two of us have had to deal with some life changing situations and I could not have gotten through them without her support and guidance.

Outside of my immediate family, I cannot go without thanking God. I would also like to thank Dr. Taufik. He gave me my first interest in power and that is where it all began. He has offered guidance throughout my college years and the many successes I have had at Cal Poly are owed to the special attention he has given me. It is this same special attention that he gives to many of his students showing that he genuinely cares for their education and them as people and friends. I would like to thank Dr. Shaban for the education I have received in power systems and I cannot go without thanking the many friends in electrical engineering that I have gained over the years.

Lastly, I must thank my wife-to-be. With reference to this thesis, her assistance in editing many of the photos was very helpful, but her emotional support was more important. At times when the task seemed overwhelming and things were not going as planned, she was the positive encouragement that helped me through it. It is this same encouragement that has gotten me through many challenges at Cal Poly and I could not have done it all without her. 


\section{Table of Contents}

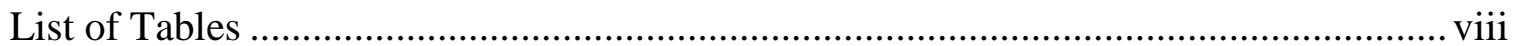

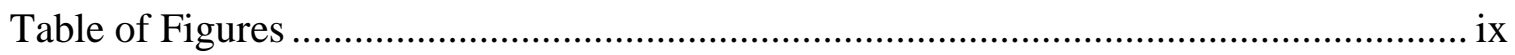

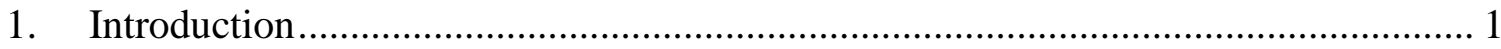

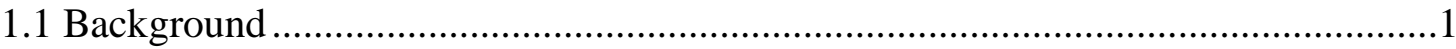

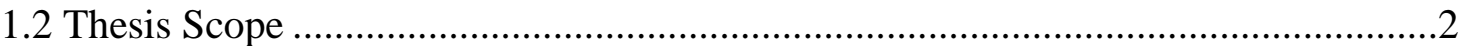

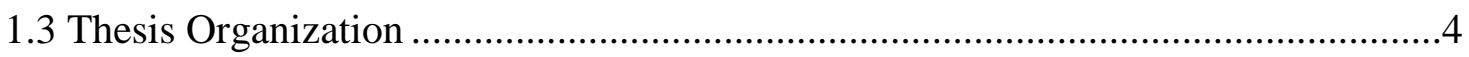

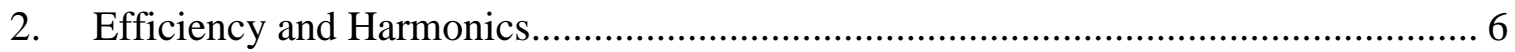

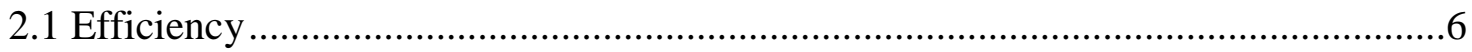

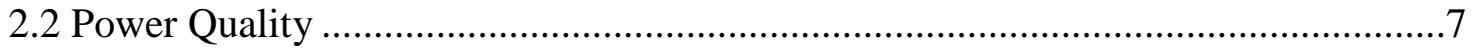

2.3.1 Harmonics ................................................................................... 7

3. Power Electronic Devices ............................................................................ 12

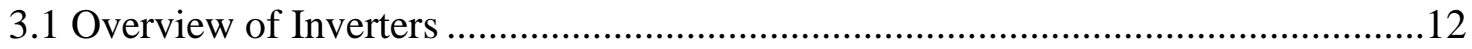

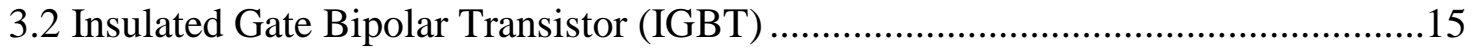

3.3 The Powerex Intelligent Power Module .............................................................. 17

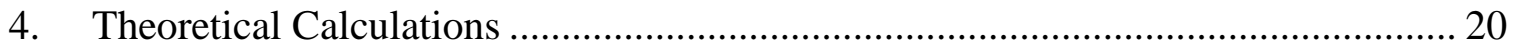

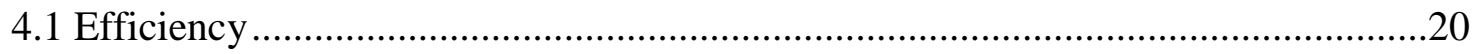

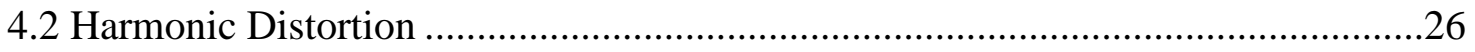

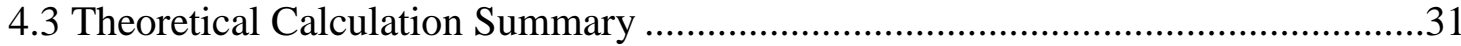




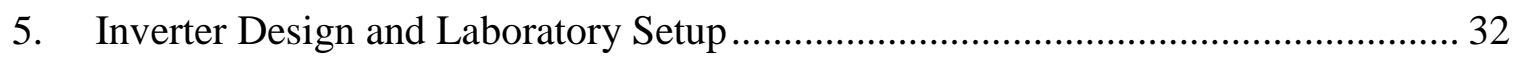

5.1 Lab Procedure ............................................................................................ 32

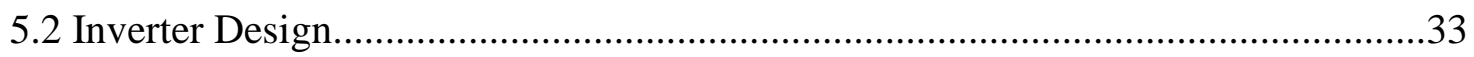

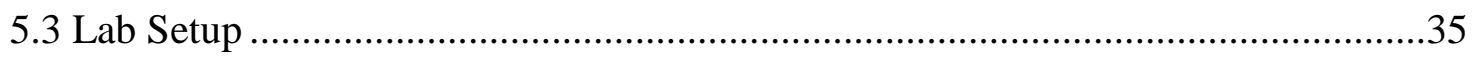

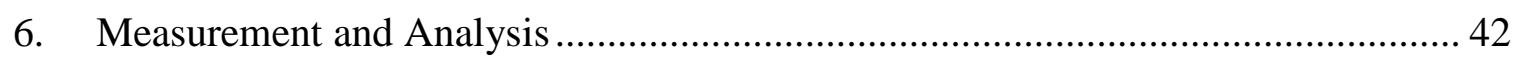

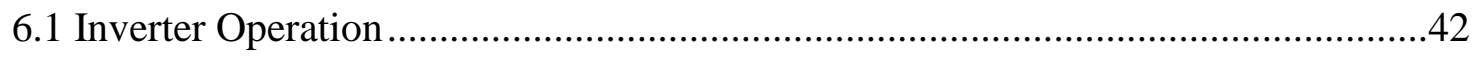

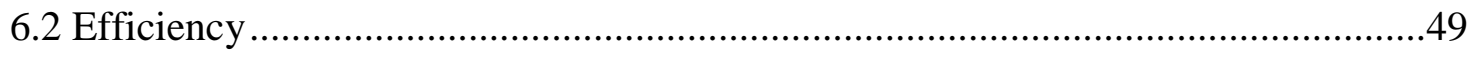

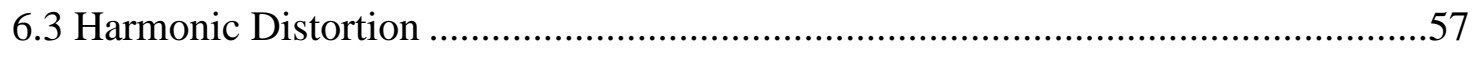

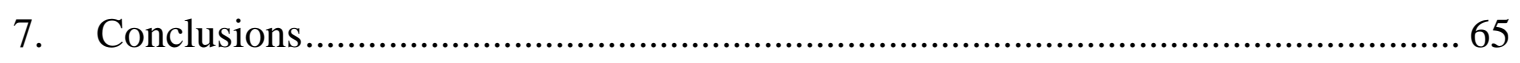

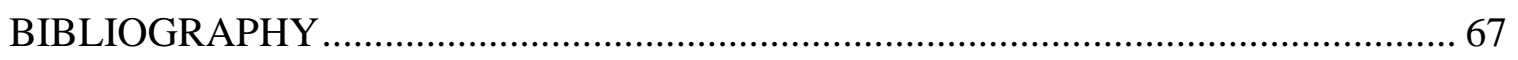




\section{List of Tables}

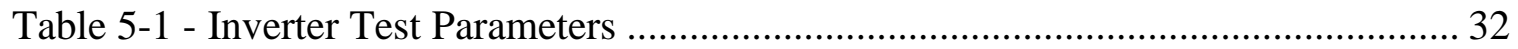




\section{Table of Figures}

Figure 2-1 - Summation of the First Three Harmonics of a Triangular Waveform 9

Figure 2-2 - Summation of the First 100 Harmonics of a Triangular Waveform.............. 9

Figure 2-3 - IEEE 519 - Low-Voltage System Classification and Distortion Limits [23] 11

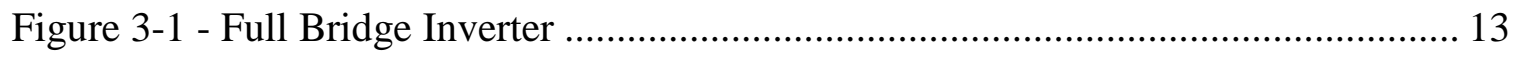

Figure 3-2 - Triangular and Sinusoidal Waveforms ................................................... 14

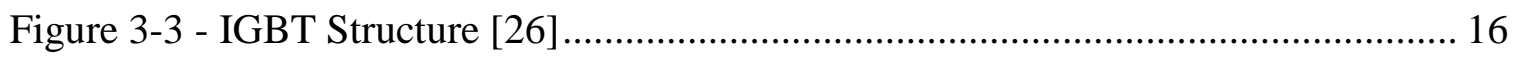

Figure 3-4 - Powerex PM50CLA060 Intelligent Power Module.................................... 18

Figure 3-5 - Powerex BP7B Interface Circuit............................................................ 19

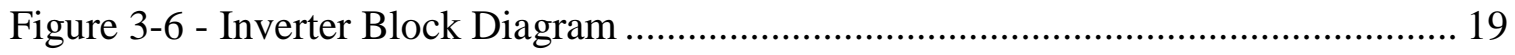

Figure 4-1 - Collector-Emitter Saturation Voltage Characteristics (Typical) [28] .......... 21

Figure 4-2 - Free-Wheel Diode Forward Characteristics (Typical) [28] ...................... 22

Figure 4-3 - Switching Loss (On) Vs. Collector Current (Typical) [28] ......................... 22

Figure 4-4 - Switching Loss (Off) Vs. Collector Current (Typical) [28] ....................... 23

Figure 4-5 - Melcosim Loss Simulator for Calculated Condition ................................. 24

Figure 4-6 - Theoretical Efficiency vs. Input Voltage and Switching Frequency at 500 W

Figure 4-7 - Theoretical Efficiency vs. Output Power and Switching Frequency for a

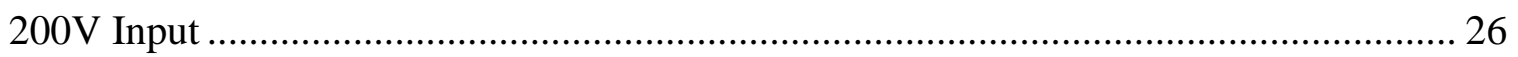

Figure 4-8 - Output Waveform for Mathcad THD Calculation ..................................... 28

Figure 4-9 - Theoretical Total Harmonic Distortion vs. Switching Frequency and Input

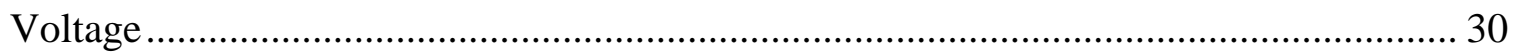




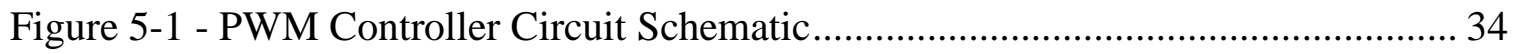

Figure 5-2 - Detailed Block Diagram of Test Setup ................................................. 36

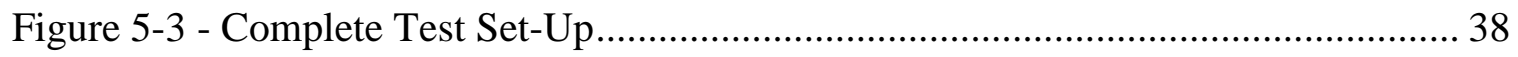

Figure 5-4 - Test Set-Up Primary Bench (Inverter) ................................................. 39

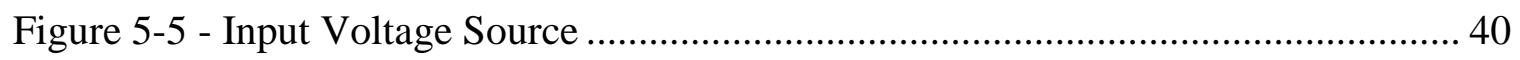

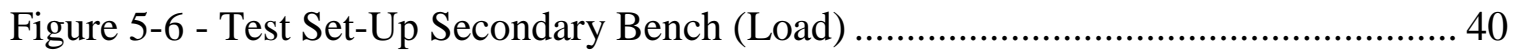

Figure 5-7 - Intelligent Power Module, Interface, and Control ................................... 41

Figure 6-1 - Switching Signals at 2 kHz Switching Frequency ................................ 43

Figure 6-2 - Output Voltage at $2 \mathrm{kHz}$ Switching Frequency $(5 \mathrm{~ms} / \mathrm{div})$.......................... 44

Figure 6-3 - Output Voltage at $2 \mathrm{kHz}$ Switching Frequency (1ms/div) ........................ 44

Figure 6-4 - Switching Signals at 18 kHz Switching Frequency ................................ 45

Figure 6-5 - Output Voltage at $18 \mathrm{kHz}$ Switching Frequency (5ms/div) ...................... 46

Figure 6-6 - Output Voltage at 18 kHz Switching Frequency (1ms/div) ...................... 46

Figure 6-7 - Output Voltage at 18 kHz Switching Frequency $(200 \mu \mathrm{s} / \mathrm{div})$.................... 47

Figure 6-8 - Switching Signals and Input Current of Inverter Shoot Through................ 48

Figure 6-9 - Theoretical (Blue) and Experimental (Red) Efficiency for a $300 \Omega$ Load ... 50

Figure 6-10 - Experimental Output Power for a $300 \Omega$ Load....................................... 51

Figure 6-11 - Theoretical (Blue) and Experimental (Red) Efficiency for a $150 \Omega$ Load . 52 Figure 6-12 - Theoretical (Blue) and Experimental (Red) Efficiency for a $75 \Omega$ Load ... 52 Figure 6-13 - Theoretical (Blue) and Experimental (Red) Efficiency for a $50 \Omega$ Load ... 53 Figure 6-14 - Theoretical (Blue) and Experimental (Red) Efficiency for a $42.85 \Omega$ Load 53 
Figure 6-15 - Comparison of Different Output Voltage Measurements at $300 \Omega$ and $210 \mathrm{~V}$ 55

Figure 6-16 - Theoretical (Top) and Experimental (Bottom) THD for a $300 \Omega$ Load ..... 58

Figure 6-17 - Theoretical (Top) and Experimental (Bottom) THD for a $150 \Omega$ Load ..... 59

Figure 6-18 -Theoretical (Top) and Experimental (Bottom) THD for a $75 \Omega$ Load ........ 59

Figure 6-19 - Theoretical (Top) and Experimental (Bottom) THD for a $50 \Omega$ Load ....... 60

Figure 6-20 - Theoretical (Top) and Experimental (Bottom) THD for a $42.85 \Omega$ Load .. 60

Figure 6-21 - Experimental THD for 300 (Red), 150 (Orange), 75 (Yellow), 50

(Green), 42.85 (Blue) $\Omega$ Loads 61

Figure 6-22 - Calculated and Measured Frequency Spectrum of Output Voltage at 210

$\mathrm{V}$ and $2 \mathrm{kHz}$ up to 50th Harmonic. 63

Figure 6-23 - Calculated Frequency Spectrum of Output Voltage at 210 V and 2 kHz... 64 


\section{Introduction}

\subsection{Background}

Due to the growing interest in renewable and efficient energy use, inverters are gaining more attention in their industrial, commercial, and residential applications in converting a Direct Current (DC) input into an Alternating Current (AC) output. While to the unfamiliar it is not obvious by the name, inverters often convert a DC input voltage into an AC output voltage by switching it in such a way as to produce a sinusoidal waveform. The inverter got its name by the manner in which it was first implemented. This was done by operating the early mechanical rectifiers (having been in use for over two decades) in reverse or "inverting" them [1]. Currently all inverters use semiconductor parts and provide the same basic function, however it is the manner in which they provide this function that makes them unique. This includes both their design topology and switching scheme. The two main design topologies are full bridge and half bridge and the main switching schemes include square wave, bipolar pulse width modulated (PWM), and unipolar PWM. Depending on the application, any of these topologies and schemes can be used.

Inverters are used for a number of reasons. The first of these reasons is to simply use a DC source. Many forms of renewable energy generation produce a DC voltage that must be converted for use in the AC power grid. This is done on both a small and large scale. In residential applications, solar panels are used on top of homes while in the electric utility, entire solar farms use photovoltaic cells to produce a DC voltage. Fuel cells are another potential renewable resource that has a DC output. Another use of 
inverters is in batteries. Many homes use batteries to keep the power on when the sun goes down, but they are also used in uninterruptable power supplies (UPS) to prevent short term power loss and in electric vehicles to power the vehicle's motor. Inverters are also used to change the frequency of an $\mathrm{AC}$ source. This is done by first rectifying an $\mathrm{AC}$ input to $\mathrm{DC}$ and then inverting it back to $\mathrm{AC}$ at a different frequency. This is how variable frequency drives (VFD) and induction heaters work. The electric utility uses inverters for a number reasons. When connecting two power grids of different frequencies a method of rectification and inversion is used. Also, inverters are used for Static Synchronous Compensators (STATCOMs) and Unified Power Flow Controllers (UPFCs).

\subsection{Thesis Scope}

Many studies have been conducted on the efficiency and harmonic distortion of inverters. However, all of these studies do not involve the inverter in its simplest form. Inverter efficiency is investigated in a variety of forms. In [2] and [3], high efficiencies are obtained, however a DC-DC converter stage is used. In [4], [5], [6], and [7], the effect of wide input voltage ranges are specifically investigated, but once again this is done through the use of a DC-DC converter stage that steps the voltage up or down to the desired DC inverter input. In [8], [9], and [10], soft switching topologies are used to increase efficiency by reducing switching losses. Harmonic distortion studies have also been conducted. In [11] and [12], the harmonic content of the output is investigated, and in [13] and [14] IEEE 519 standards and recommendations for harmonic content are addressed and met. However, in all of these studies a filtering stage is used. Whether investigating efficiencies or harmonics, the basic inverter topology is not used by itself. 
One major use of inverters is in photovoltaic applications, especially those of grid-tied. Photovoltaic arrays and their relationship with inverters has also been studied. A photovoltaic module's maximum power point voltage can range anywhere from 23 to $38 \mathrm{~V}$ [15]. Modules can be arranged in many different combinations of series and parallel to meet the needs of the converter and load. In [16] several different combinations of photovoltaic arrays in series and parallel are analyzed to determine the maximum possible output power. Traditionally a central inverter topology is used with respect to module configuration where all modules are connected to a main centralized inverter. In [17] and [18] string, multi-string, and team configurations are discussed where modules are connected in parallel and in turn connected to several inverters in parallel. This allows for the use of fewer inverters during lighter irradiation improving efficiency and mismatch. However, all of these studies focus on the voltage and configuration that yields the maximum possible output power of the array and they do not address the desired input voltage of the inverter to give the maximum efficiency of the inversion process.

The goal of this study will be to see what effect different input and output variables have on a basic inverter topology's efficiency and harmonic content. These changing variables will include the DC input voltage, switching frequency, and output load. The control signals can be adjusted for each input voltage and switching frequency to produce the same output voltage at the fundamental frequency. Input current, output voltage, and total harmonic distortion (THD) will be measured for every constraint. The loads used will be resistive therefore voltage and current will be related to each other through Ohm's law and allows simple power calculations based on the output voltage. 
This study will ultimately culminate in determining the optimum input voltage and switching frequency of an inverter based on its load. This would be a vital resource for engineers designing inverters for the highest possible efficiency and lowest possible harmonic distortion. The switching frequency could be set as a fixed parameter or adjusted on the fly for optimum conditions. The input voltage constraint could be used to appropriately configure photovoltaic modules in any number of series and parallel as well as to appropriately design a DC-DC converter stage to output this desired voltage.

As previously mentioned, study involves an inverter in its simplest form. Since a good portion of the harmonic content can be filtered out, it would be difficult to determine the effect of different variables on the THD after filtering. Therefore, output filtering will not be used. Also, since this study could be used to appropriately size DCDC converters' output, a step-up or step-down stage will not be used at the input.

\subsection{Thesis Organization}

Chapter 1 of this thesis begins with a discussion of the background of inverters and why they are important. The scope of the thesis is then discussed with special emphasis on why it is important and what it could be used for. Chapter 1 is concluded with a summary of the organization of the thesis. Chapter 2 focuses on the details of the quantities to be measured. This includes a review of efficiency, power quality, and harmonics. Their details and importance are mentioned. Chapter 3 focuses on the power electronic devices of this study. The operation of inverters and design topologies are mentioned. The insulated gate bipolar transistor (IGBT) is addressed specifically as well as the Powerex Intelligent Power Module (IPM) used in the experimental portion of this study. Chapter 4 consists of the theoretical calculations of efficiency and harmonics. 
The two are derived and calculated using Mathcad from Parametric Technology, Inc. Chapter 5 consists of the measurement and analysis portion. Experimental results are measured, discussed, and analyzed. Differences between theoretical and experimental results are addressed and recommendations are made on determining the optimum operating parameters of the specific inverter topology. The study is concluded in Chapter 6 with conclusions about the study, recommendations, problems and solutions, as well as future work that could be conducted. 


\section{Efficiency and Harmonics}

\subsection{Efficiency}

Efficiency in electrical engineering is the ratio of the average output power in watts to the average input power in watts (useful output power per unit input power.) In most cases outside of power electronics this should not be confused with effectiveness or usefulness. However, the main objective of power electronics is to convert one form of electricity into another as efficiently as possible. Therefore, the effectiveness of a power electronic device is directly coupled to its efficiency. This is why efficiency is so important in this field.

From drilling for oil to plugging a device into the wall, there are many energy losses along the energy supply chain. While the majority of this energy is lost in primary energy transport and power generation, significant losses occur in both the electrical conversion process and end-user equipment [19]. These two stages are where power electronics can play a significant role in efficient electric energy conversion. If power electronic technology was applied throughout the world it would result in a $35 \%$ reduction in energy consumption [20].

This efficiency is not just important because of the added cost of waste energy, but also because it directly translates to heat. If power electronic devices are switching while current is flowing through and voltage is across their switches, power is lost. Devices have to dissipate this heat, which can be a difficult task. Power electronics focuses on minimizing this wasted energy to output power as close to the input power as possible. 


\subsection{Power Quality}

Power electronics and power quality come hand in hand. Due to the nature of power electronics interrupting the natural flow of current, it is often both the cause and solution to power quality problems. While power quality has been discussed since the dawn of AC electricity, more recently in the last several decades the invention of the semiconductor has increased the amount of non-linear loads. In the distant past these loads were predominantly owned by the utility and industrial world, but now power electronics has brought them into residential homes.

Power quality as defined in [21], "[Stretches] from the generation plant to the utility customer, [it] is a measure of how the elements affect the system as a whole." Devices with poor power quality can lead to problems with the operation of other equipment as well as its life expectancy. Ironically, the power electronic devices that create these problems are often most sensitive to its repercussions.

Power quality can be organized into many different categories including steadystate voltage magnitude and frequency, voltage sags, grounding, harmonics, voltage fluctuations and flicker, transients, and monitoring and measurement [22]. However, due to this study's focus on harmonics, the other categories will not be discussed.

\subsubsection{Harmonics}

As defined in IEEE 519-1992, IEEE Recommended Practices and Requirements for Harmonic Control in Electrical Power Systems [23], a harmonic is, "a sinusoidal component of a periodic wave or quantity having a frequency that is an integral multiple of the fundamental frequency." In the United States, the fundamental frequency is 60 $\mathrm{Hz}$ so harmonics occur at multiples of $60 \mathrm{~Hz}$. Waveforms of $120 \mathrm{~Hz}, 180 \mathrm{~Hz}$, and $240 \mathrm{~Hz}$ 
are referred to as harmonics two, three, and four respectively. A device is said to be nonlinear if its voltage or current is anything other than a $60 \mathrm{~Hz}$ sinusoidal waveform and therefore all of these devices have harmonic content.

From this, the importance of breaking a waveform down into a summation of sine waves is evident and can be done using the mathematical technique discovered by the famous mathematician Jean Baptiste Joseph, Baron de Fourier. Fourier series analysis can be used by performing several simple integrals and the equations below demonstrate how the $\mathrm{n}^{\text {th }}$ harmonic of a voltage waveform, $\mathrm{V}_{\text {out }}$, of frequency $\mathrm{f}$ can be determined.

$$
\begin{aligned}
& a_{n}=2 f \int_{0}^{\frac{1}{f}} V_{\text {out }}(t) \cos (2 \pi f n t) d t \\
& b_{n}=2 f \int_{0}^{\frac{1}{f}} V_{\text {out }}(t) \sin (2 \pi f n t) d t \\
& V_{\text {out }, n}=a_{n} \cos (2 \pi f n t)+b_{n} \sin (2 \pi f n t)
\end{aligned}
$$

With some work, these principles can be applied to a triangle waveform to produce the equation

$V_{t r i, n}=\frac{8}{\pi} \frac{(-1)^{n-1}}{(2 n-1)^{2}} \sin [2 \pi f t(2 n-1)]$

Figure 2-1 shows the first three harmonics of a $2 \mathrm{kHz}$ triangular wave and their sum. Already, the waveform takes its shape, but has difficulty with the sharp edges. Figure 2-2 shows the summation of the first 100 harmonics. Here the triangle is much more obvious. 


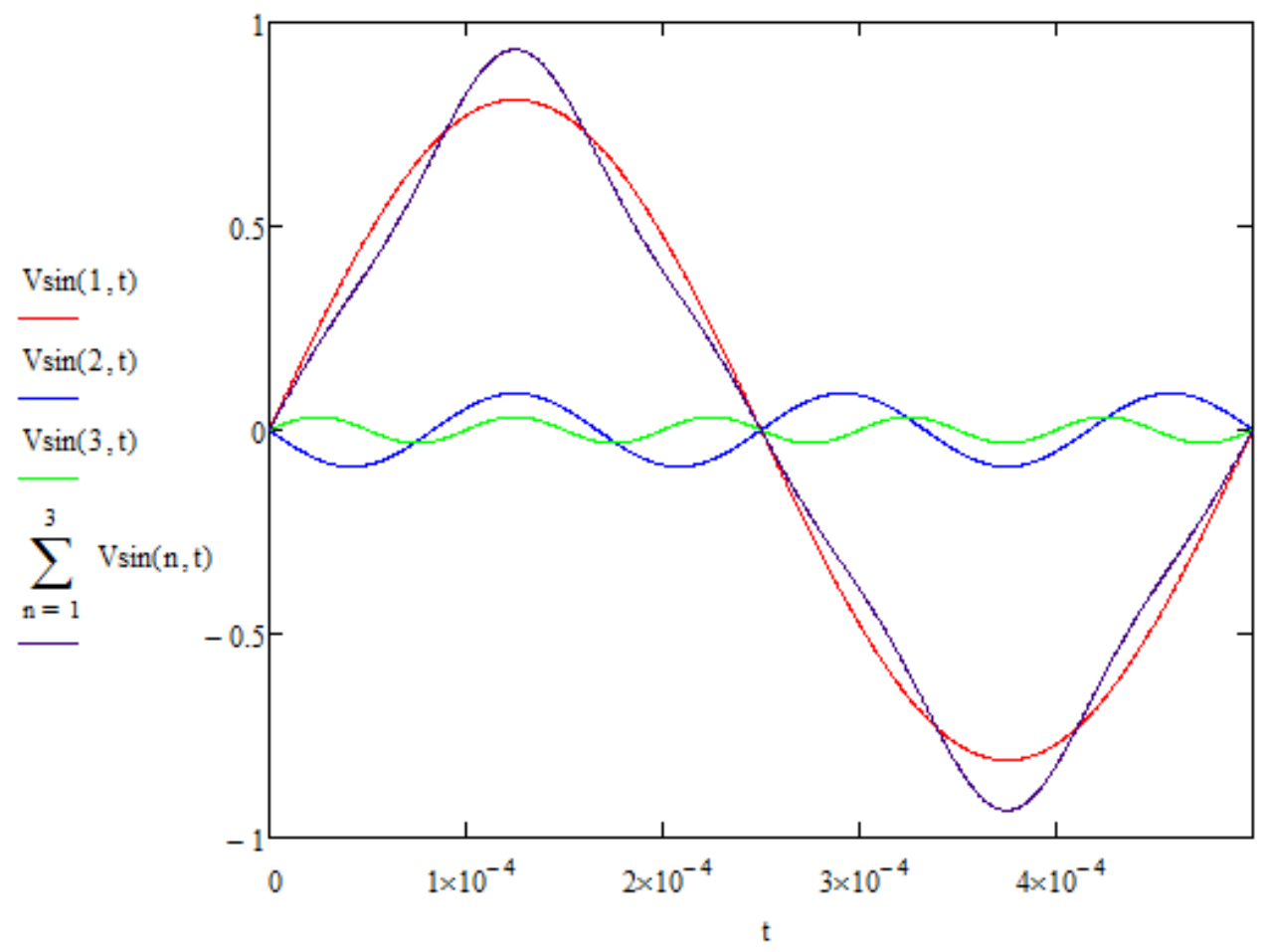

Figure 2-1 - Summation of the First Three Harmonics of a Triangular Waveform

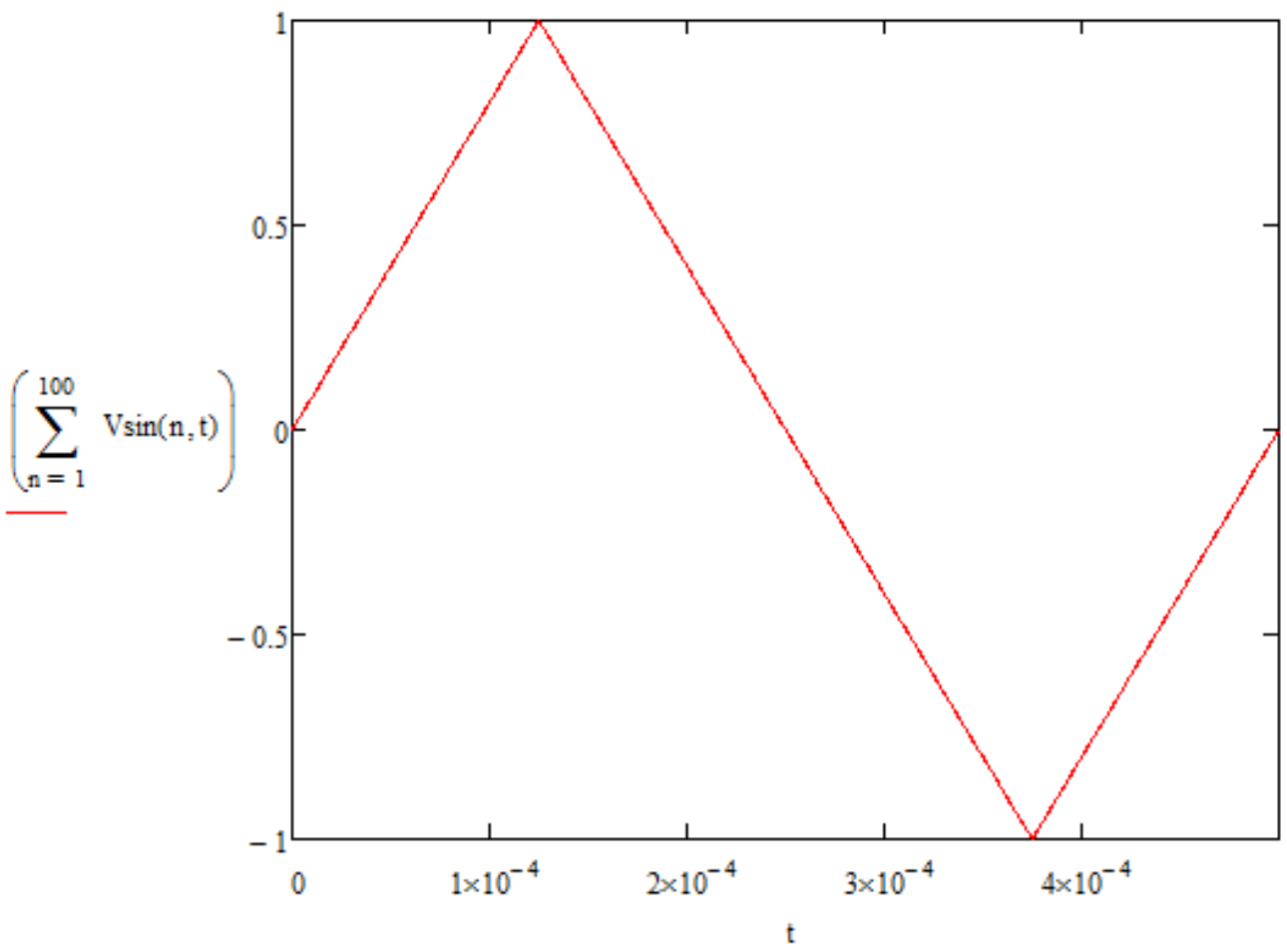

Figure 2-2 - Summation of the First 100 Harmonics of a Triangular Waveform 
It is important in this study to understand Total Harmonic Distortion (THD) as a measurement of the harmonic content of a waveform. The two equation below define THD.

$T H D_{V}=\frac{\sqrt{V_{D C}^{2}+\sum_{n=2}^{\infty} V_{n, r m s}^{2}}}{V_{1, r m s}}$

$T H D_{v}=\frac{\sqrt{V_{r m s}^{2}-V_{1, r m s}^{2}}}{V_{1, r m s}}$

These two equations calculate the same THD of the voltage. Equation 2-5 calculates THD by summing up the DC voltage and all harmonics, while Equation 2-6 calculates THD by subtracting the fundamental voltage from the total voltage. In order to prevent calculating and measuring an infinite number of harmonics, Equation 2-6 is used throughout this stud.

These harmonics typically come from non-linear power electronic loads including linear and switching power supplies, UPS's, and Adjustable Speed Drives (ASD). but can also come from the non linearity of magnetic material in large engines as well as unloaded and overloaded transformers [24]. These harmonics can cause harmful effects to conductors with the increase in heating by the skin effect. In the three phase power system, negative and zero sequence voltages and currents can occur at different harmonic multiples. More specifically, triplen harmonics, multiples of three, can cause zero sequence currents to flow into undersized neutral conductors. Additional losses in transformers can cause overheating. And power factor correction capacitors can also 
cause harmonic amplification if their frequency occurs close to the capacitors resonant frequency with the line inductance [25]. To summarize, the effect of harmonics and the additional equipment required to handle them simply make the power system more inefficient economically and hence their mitigation becomes important.

Due to the growing concerns of harmonics, IEEE has established a standard of recommended practices and requirements in reference to harmonics [23]. In this standard maximum limits are set for both utilities and customers. Figure 2-3 below shows and example of THD voltage limits for different types of systems. This can be found in Table 10.2 of the document.

\section{Low-Voltage System Classification and Distortion Limits}

\begin{tabular}{|c|c|c|c|}
\hline & $\begin{array}{c}\text { Special } \\
\text { Applications }\end{array}$ & $\begin{array}{l}\text { General } \\
\text { System }\end{array}$ & $\begin{array}{c}\text { Dedicated } \\
\text { System }^{\dagger}\end{array}$ \\
\hline Notch Depth & $10 \%$ & $20 \%$ & $50 \%$ \\
\hline THD (Voltage) & $3 \%$ & $5 \%$ & $10 \%$ \\
\hline Notch Area $\left(A_{\mathbb{N}}\right)^{\ddagger}$ & 16400 & 22800 & 36500 \\
\hline \multicolumn{4}{|c|}{$\begin{array}{l}\text { NOTE: The value } A_{N} \text { for other than } 480 \mathrm{~V} \text { systems should be multiplied by } \\
\text { V/ } 480\end{array}$} \\
\hline
\end{tabular}

Figure 2-3 - IEEE 519 - Low-Voltage System Classification and Distortion Limits [23] 


\section{Power Electronic Devices}

\subsection{Overview of Inverters}

Inverters convert DC into $\mathrm{AC}$ from either a $\mathrm{DC}$ source or a rectified $\mathrm{AC}$ source. The source can be either a current source or a voltage source corresponding to a current source inverter (CSI) or a voltage source inverter (VSI) respectively. Switched mode inverters convert this DC input into an AC output by controlling when switches operate. The manner in which the switches turn off and on depends on the switching method and topology as well as the desired output magnitude and frequency.

There are two different topologies for voltage source inverters. One is the half bridge topology that utilizes two switches and two capacitors. The other more common topology is full bridge utilizing four switches seen in Figure 3-1. These switches can operate in a number of ways depending on the switching method used. There are two main switching methods--square wave and pulse width modulated (PWM). Square wave inverters simply produce a square wave with a magnitude of the DC voltage at the desired frequency. While square wave inverters are probably the easiest to implement, they come with the disadvantage of having harmonic content close to the fundamental frequency. This makes it more difficult and expensive to filter. PWM inverters operate by comparing a sinusoidal control signal at the fundamental frequency to a triangular signal at the carrier or switching frequency. Each of the four switches operates under a different comparison of the two control signals. This method has the disadvantage of more complex control circuitry, however it makes up for it with its harmonic content. PWM inverters move the undesired output frequency components to multiples of the 
carrier frequency which is significantly larger than the control frequency. This makes it easier and less expensive to filter.

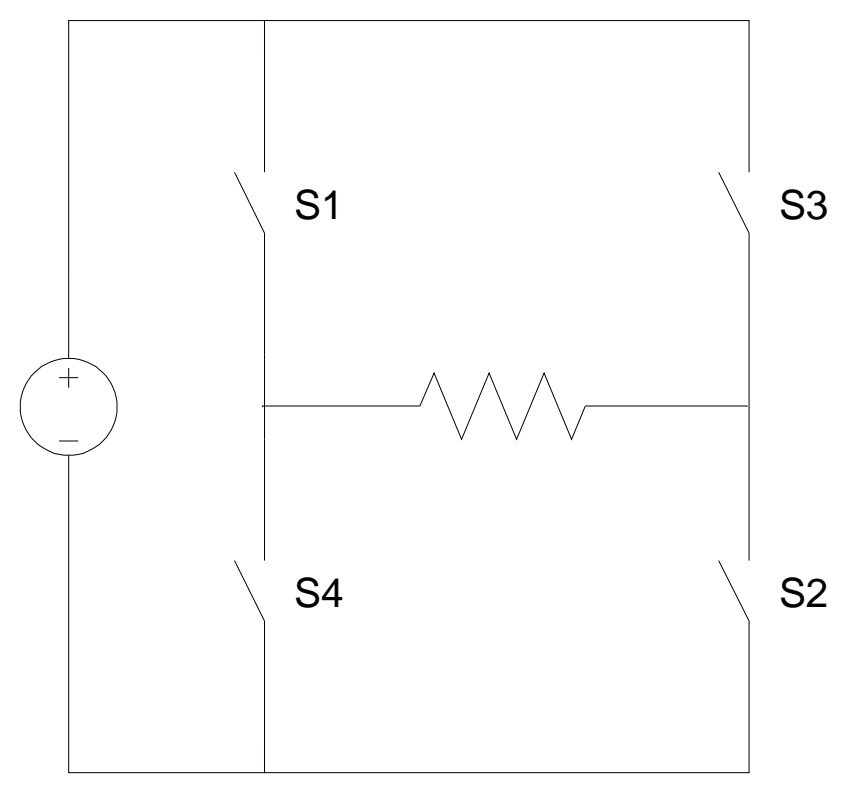

Figure 3-1 - Full Bridge Inverter

Within PWM inverters there are two different types--unipolar and bipolar. Unipolar inverters switch between the positive dc voltage, negative DC voltage, as well as neutral. They are referred to as unipolar because of the single common reference. Bipolar inverters switch only between the positive and negative DC voltage giving them their name. This thesis will focus on unipolar inverters due to their more obvious periodic nature and because they are most the most commonly used method in commercially available inverters; especially for photovoltaic and ASD applications. There are two different types of switching schemes within unipolar inverters. The first scheme can be seen below and will be referred to throughout this report as Type 1 
Unipolar. Figure 3-2 shows the sine and triangle waveforms and the nature in which switching occurs can be interpreted from their relationship.

$S_{1}$ Conducts: $V_{\text {Sine }} \geq \mathrm{V}_{\text {Tri }}$

$\mathrm{S}_{2}$ Conducts: $-\mathrm{V}_{\text {Sine }}<\mathrm{V}_{\text {Tri }}$

$\mathrm{S}_{3}$ Conducts: $\quad-\mathrm{V}_{\text {Sine }} \geq \mathrm{V}_{\text {Tri }}$

$\mathrm{S}_{4}$ Conducts: $\mathrm{V}_{\text {Sine }}<\mathrm{V}_{\mathrm{Tri}}$

This scheme has all four switches operating at the carrier (high) frequency. Switches $\mathrm{S}_{1}$ and $\mathrm{S}_{4}$ as well as switches $\mathrm{S}_{2}$ and $\mathrm{S}_{3}$ are complementary in that when one is turned on the other one is turned off. This is to prevent arm shoot through where the DC source is shorted.

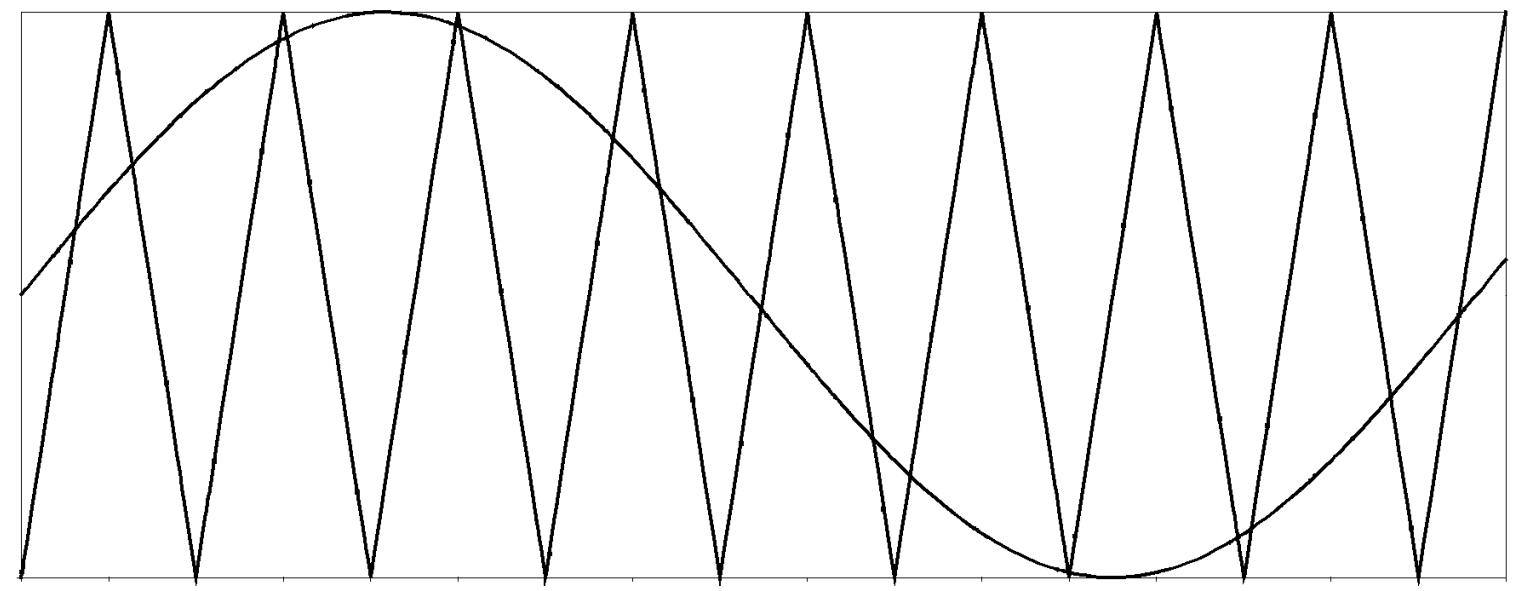

Figure 3-2 - Triangular and Sinusoidal Waveforms

The other unipolar switching scheme can be seen below and will be referred to throughout this report as Type 2 Unipolar.

$S_{1}$ Conducts: $V_{\text {Sine }} \geq \mathrm{V}_{\text {Tri }}$

$\mathrm{S}_{2}$ Conducts: $\mathrm{V}_{\text {Sine }}>0$

$\mathrm{S}_{3}$ Conducts: $\mathrm{V}_{\text {Sine }} \leq 0$

$\mathrm{S}_{4}$ Conducts: $\mathrm{V}_{\text {Sine }}<\mathrm{V}_{\text {Tri }}$

This scheme has the switches operating at both the control (low) and carrier (high) frequency. This scheme is used more often due to only two switches operating at high 
frequencies making the switching losses less than Type 1 Unipolar. It is for this reason that Type 2 Unipolar switching was implemented in this study.

For PWM inverters the input voltage has to be greater than the peak value of the desired output voltage. However, the amplitude of the fundamental frequency is linearly proportional to the amplitude modulation, $\mathrm{m}_{\mathrm{a}}$. This value is defined as the ratio of the sinusoidal amplitude to the triangular amplitude. The amplitude of the fundamental frequency of the output is thus the DC input voltage multiplied by the amplitude modulation or $\mathrm{V}_{1}(\mathrm{t})=\mathrm{m}_{\mathrm{a}} \mathrm{V}_{\mathrm{dc}} \sin \omega_{1} \mathrm{t}$. This value can be adjusted to produce the desired amplitude of the fundamental component. For instance, if an input voltage of $300 \mathrm{~V}$ is used to produce a desired RMS output voltage of $120 \mathrm{~V}$, the amplitude modulation can be adjusted to 0.567 producing an amplitude of $170 \mathrm{~V}$.

\subsection{Insulated Gate Bipolar Transistor (IGBT)}

First seen in the early 1980's, the insulated gate bipolar transistor (IGBT) is a semiconductor device used in power because of its high efficiency and fast switching. The fast switching makes it suitable in power electronics because of its ability to be controlled by complex PWM waveforms. The IGBT combines the advantages of the bipolar junction transistor (BJT) and the insulated gate field effect transistor, commonly referred to as the MOSFET, while eliminating most of the disadvantages. These advantages include the voltage control and fast switching of the MOSFET and the low on-state voltage drop and high current capability of the BJT [26]. 


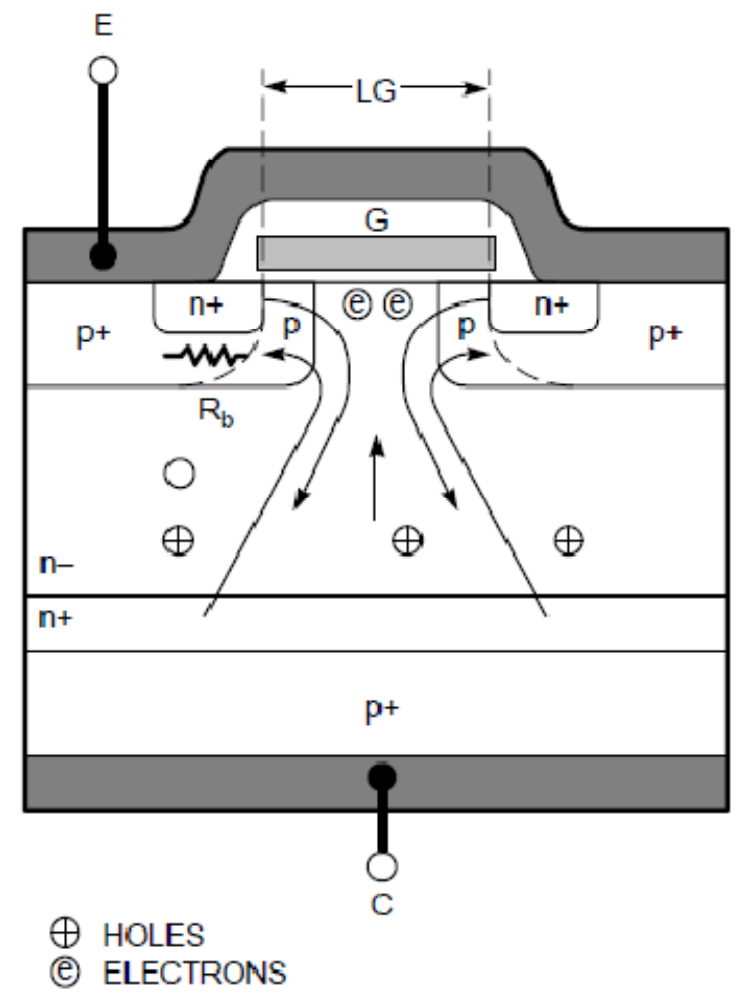

Figure 3-3 - IGBT Structure [26]

Figure 3-3 shows the structure of the IGBT. An actual IGBT would consist of many such structures in parallel. When a positive voltage is applied on the gate, electrons are attracted to the surface underneath the gate. Directly under the gate an ntype region is made from these electrons creating a path from the n-type region of the collector to the n-type region of the emitter. When no or negative voltage is applied this path is inhibited, turning the device off. Current can only flow in the forward direction so a free-wheeling diode is usually added in order to allow the reverse flow. The IGBT has one more junction than the MOSFET allowing for higher blocking voltage and conductivity modulation, the variation in conductivity through charge carrier density variations. However, this comes at the price of a slower switching frequency causing increased switching losses [26]. 


\subsection{The Powerex Intelligent Power Module}

To simplify the design process in this study a Powerex Intelligent Power Module (IPM) was used. Powerex IPMs combine high speed, low loss IGBTs with gate drive and protection circuitry. The devices are designed to respond to short circuits, over temperature, as well as under-voltages. These devices are made specifically to reduce system size and time to market [27]. For this study, they served that exact purpose.

Figure 3-4 shows the PM50CLA060. This device comes from the L-Series of Powerex power devices for medium level applications. The device has absolute maximum ratings of $600 \mathrm{~V}$ from the collector to the emitter and $50 \mathrm{~A}$ for the collector current. The gate drive and protection circuitry is made to run off of a $15 \mathrm{~V}$ supply and the control pins operate at active low. The device has six main pins. The two on the side are for the DC input voltage ( $\mathrm{N}$ and $\mathrm{P})$. This device is a three phase device, therefore three of the four pins $(\mathrm{U}, \mathrm{V}$, and $\mathrm{W})$ in the front are for the three different phases. For the purpose of this study, the device will be used to produce a single phase output and therefore only two of the three phase pins (U and V) will be used. The fourth pin (B) is for a break circuit. This device does not have a break circuit, but shares the same package as its sister part that does, therefore this pin has no connection to the IPM inside. The control pins on the top of the device include control signals, isolated supply voltages for high and low side drives, and fault output signals. The low side gate drive and protection circuits run off the same supply while the high side has three separate supplies [28]. 


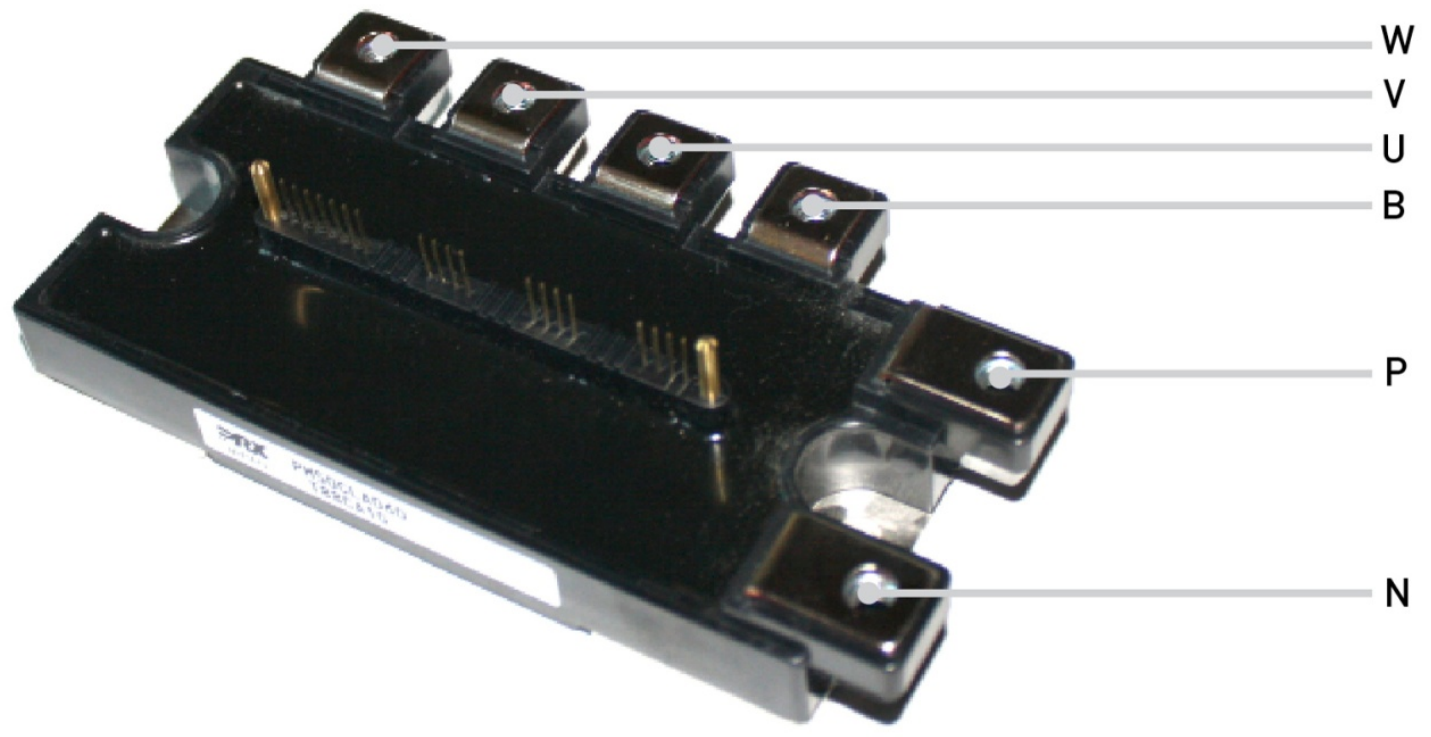

Figure 3-4 - Powerex PM50CLA060 Intelligent Power Module

In order to further simplify the process the BP7B - L-Series IPM Interface Circuit will be used. This module (see Figure 3-5) features Powerex devices that isolate control signals and voltage supplies. It includes fault feedback signals sent to LEDs, $2500 \mathrm{~V}_{\text {rms }}$ isolation of control signals and voltage supplies, and it is powered by a single $24 \mathrm{~V}$ supply [29]. This simplifies the process by allowing the control signals to be directly connected to the IPM. 


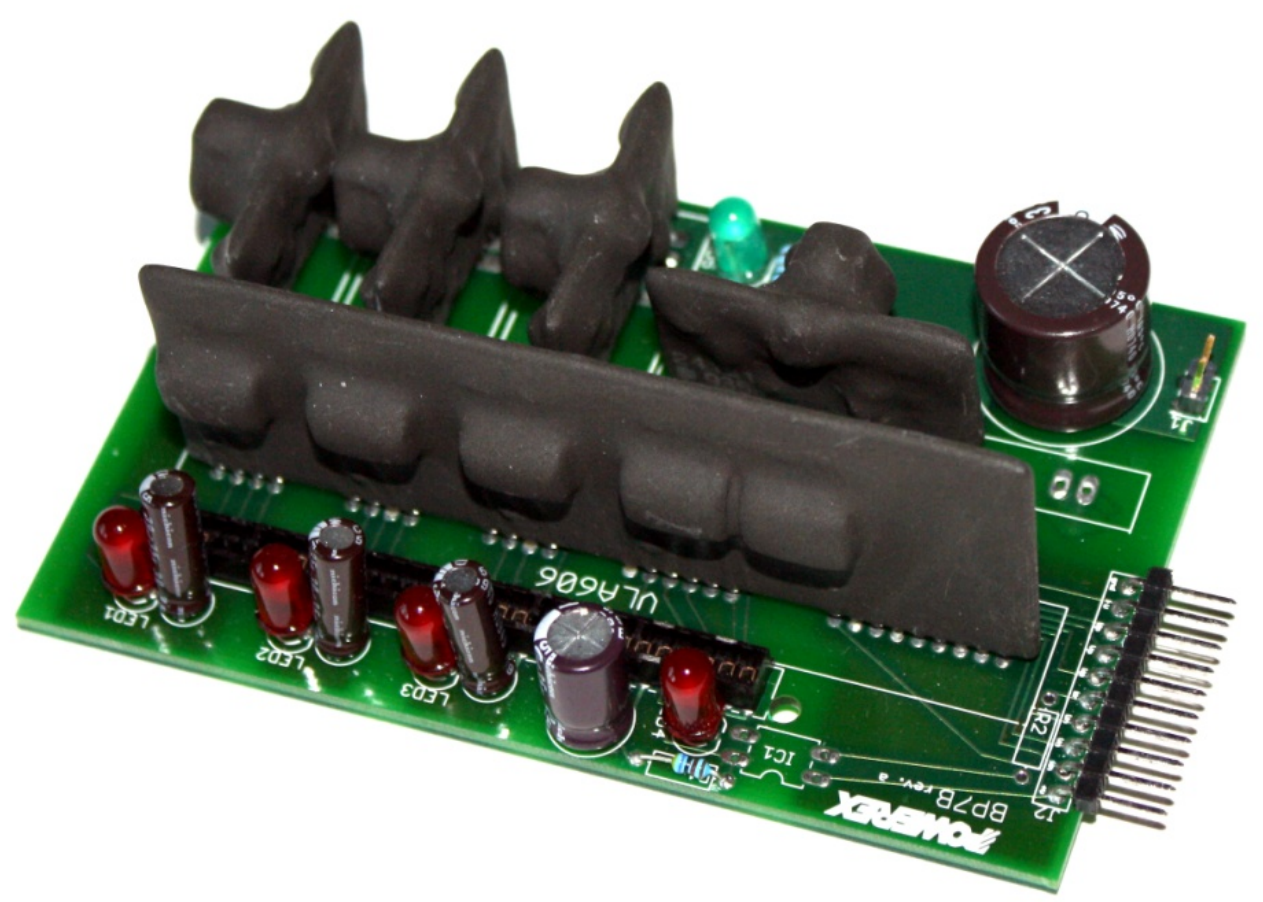

Figure 3-5 - Powerex BP7B Interface Circuit

Lastly, Figure 3-6 illustrates the block diagram of the inverter system set-up used for this thesis. A detailed design for this system will be explained in Chapter 5 .

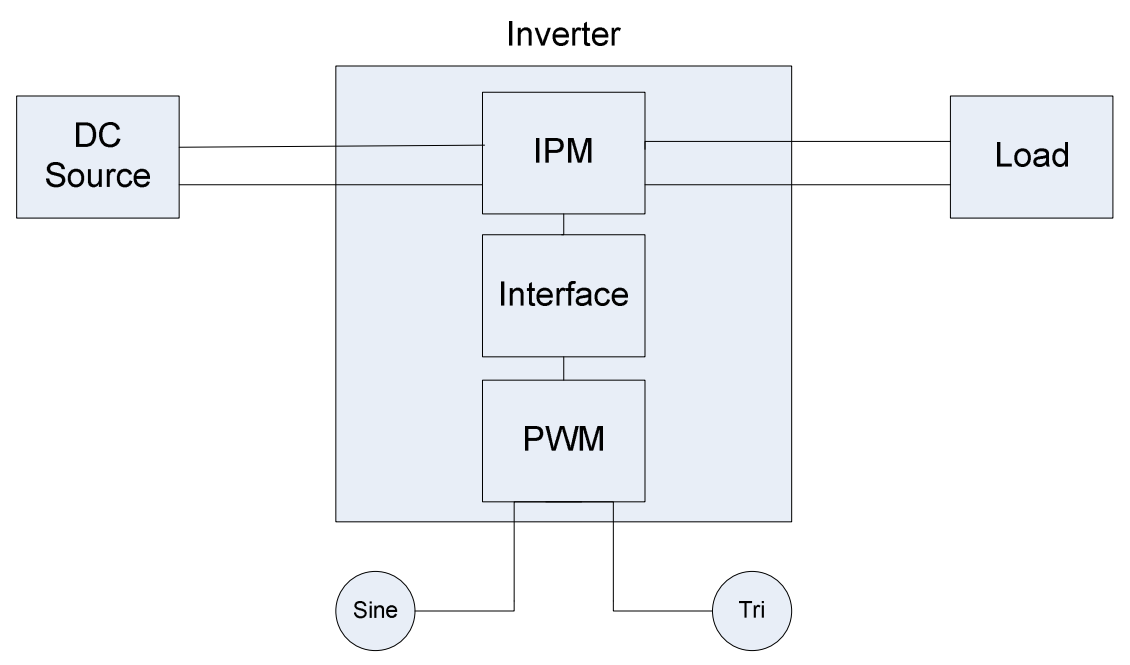

Figure 3-6 - Inverter Block Diagram 


\section{Theoretical Calculations}

Theoretical calculations for this study are performed using Mathcad from Parametric Technology Corporation. This simplifies the calculation process and limits human error. The ability to graph functions and data in three dimensions is also added. This will allow the trends in theoretical and experimental results to easily be seen. Trends previously displayed in ten different figures can conveniently be seen in one. Mathcad is also more proficient in determining certain theoretical results than some circuit simulation software programs. This will be discussed in more detail in section 4.2.

\subsection{Efficiency}

The following section consists of a calculation of the losses and temperature rise of the IGBTs. In order to calculate these losses a calculation of the peak and rms current at the load must precede it.

$$
\begin{aligned}
& \text { Let } P=500 \mathrm{~W} \\
& \text { Let } V_{r m s}=120 \mathrm{~V} \\
& \text { Let } p f=1 \\
& I_{r m s}=\frac{P}{V_{r m s} p f}=\frac{500}{120 * 1}=4.167 \mathrm{~A}
\end{aligned}
$$

Assuming a perfect sinusoidal waveform the peak value of this current is equal to:

$$
I_{\text {peak }}=\sqrt{2} I_{r m s}=\sqrt{2} * 4.167=5.893 \mathrm{~A}
$$


However, the average current through each IGBT is that of a half-wave rectifier.

$I_{A V G}^{I G B T}=\frac{5.893}{2 \pi} \int_{0}^{\pi} \sin (\omega t) d(\omega t)=\frac{5.893}{2 \pi}[-\cos (\pi)+\cos (0)]=\frac{5.893}{\pi}=1.876 \mathrm{~A}$

Taking this value as the collector current, relevant information was taken from the Powerex PM50CLA060 Intelligent Power Module datasheet. From Figure 4-1 at a collector current of $1.876 \mathrm{~A}$ the collector-emitter voltage was determined to be $\mathrm{V}_{\mathrm{CE}}=$ $0.625 \mathrm{~V}$.

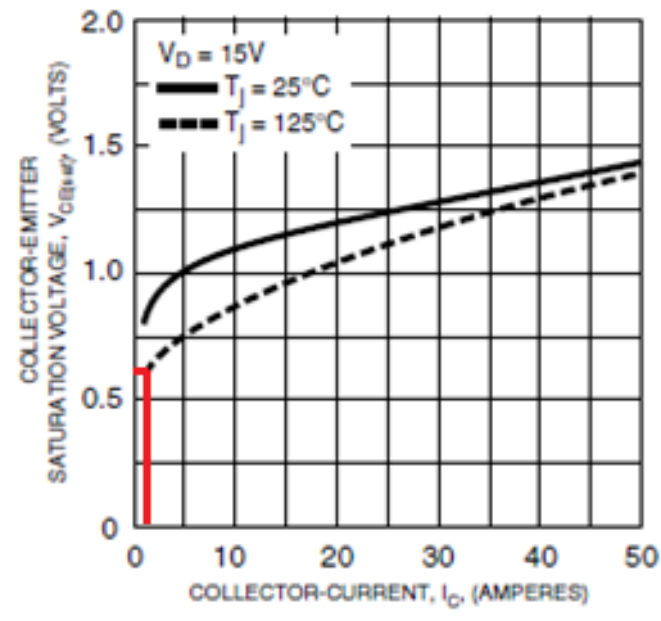

Figure 4-1 - Collector-Emitter Saturation Voltage Characteristics (Typical) [28]

From Figure 4-2, the forward voltage characteristics of the free-wheel diode was determined to be $\mathrm{V}_{\mathrm{F}} \approx 0.75 \mathrm{~V}$ at $\mathrm{I}_{\mathrm{c}}=1.876 \mathrm{~A}$. 


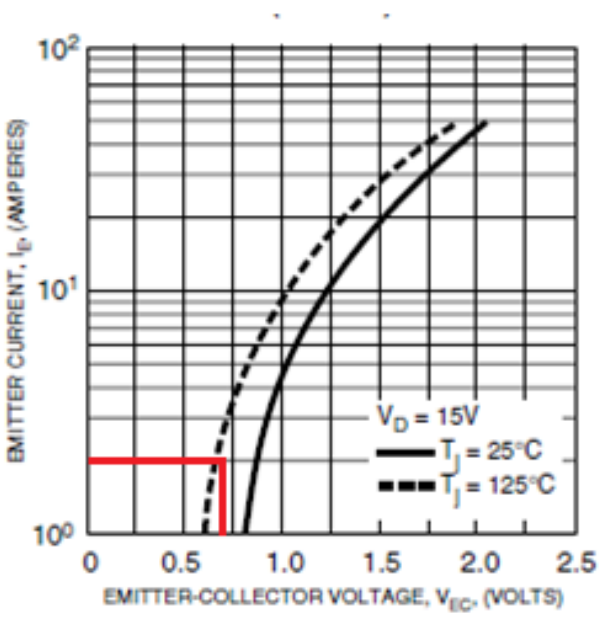

Figure 4-2 - Free-Wheel Diode Forward Characteristics (Typical) [28]

From Figure 4-3, the turn on energy of the IGBT was determined to be $\mathrm{E}_{\mathrm{on}}=0.13$ $\mathrm{mJ} /$ Pulse at $\mathrm{I}_{\mathrm{c}}=1.876 \mathrm{~A}$.

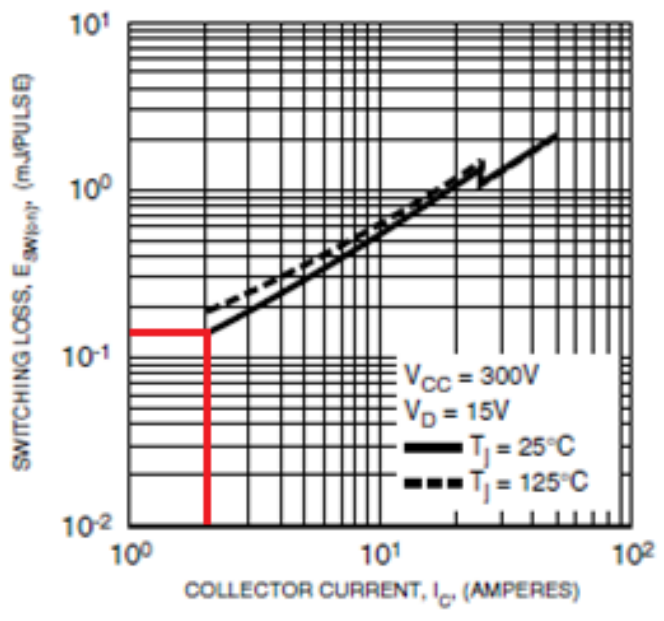

Figure 4-3 - Switching Loss (On) Vs. Collector Current (Typical) [28]

Figure 4-4, the turn on energy of the IGBT was determined to be $E_{\text {off }}=0.03$ $\mathrm{mJ} /$ Pulse at $\mathrm{I}_{\mathrm{c}}=1.876 \mathrm{~A}$. The collector-emitter resistance of the IGBT, the forward resistance of the free-wheel diode, and the recovery energy of the diode were assumed to be zero for the sake of this calculation. These values were not available in the manufacturer datasheet. 


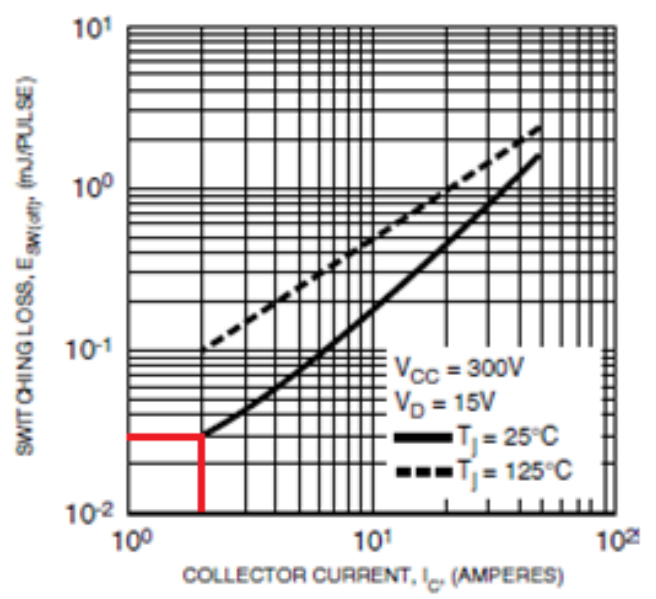

Figure 4-4 - Switching Loss (Off) Vs. Collector Current (Typical) [28]

The following equations were used to calculate the conduction and switching losses for a switching frequency of $20 \mathrm{kHz}$. These were made available in [30]. A DC input voltage of $250 \mathrm{~V}$ was assumed giving a modulation index of $\mathrm{M}=170 / 250=0.68$.

$$
\begin{aligned}
& P_{C}^{I G B T}=\frac{V_{C E} I_{\text {Peak }}}{2 \pi}\left[1+\frac{M \pi}{4} p f\right]+\frac{r_{c e} I_{r m s}^{2}}{2 \pi}\left[\frac{\pi}{4}+M\left(\frac{2}{3} p f\right)\right] \\
& =\frac{0.625 * 5.893}{2 \pi}\left(1+\frac{0.68 \pi}{4} 1\right)+0=0.9 \mathrm{~W} \\
& P_{S}^{I G B T}=\frac{1}{\pi} f_{S}\left(E_{\text {on }}+E_{\text {off }}\right) \frac{V_{D C}}{V_{\text {ref }}} \frac{I_{\text {peak }}}{I_{\text {ref }}}=\frac{1}{\pi} 20 k(0.13 \mathrm{~m}+0.03 \mathrm{~m}) \frac{250}{300} \frac{5.893}{5}=2.667 \mathrm{~W} \\
& P_{C}^{\text {Diode }}=\frac{V_{f} I_{\text {peak }}}{2 \pi}\left(1-\frac{M \pi}{4} p f\right)=\frac{1 * 5.893}{2 \pi}\left(1-\frac{0.68 \pi}{4} 1\right)=0.328 \mathrm{~W} \\
& P_{S}^{\text {Diode }}=\frac{1}{\pi} f_{S} E_{\text {rec }} \frac{V_{D C}}{V_{\text {ref }}} \frac{I_{\text {peak }}}{I_{\text {ref }}}=0 \\
& P_{\text {Loss } / I G B T}=P_{C}^{I G B T}+P_{S}^{I G B T}+P_{C}^{\text {Diode }}+P_{S}^{\text {Diode }}=3.894 \mathrm{~W}
\end{aligned}
$$

For the given conditions, Mitsubishi's Melcosim Loss Simulator was used to simulate the losses of the exact Intelligent Power Module used. The results can be seen 
in Figure 4-5. A total loss per IGBT was simulated as $3.9 \mathrm{~W}$ for a percent difference of $0.15 \%$.

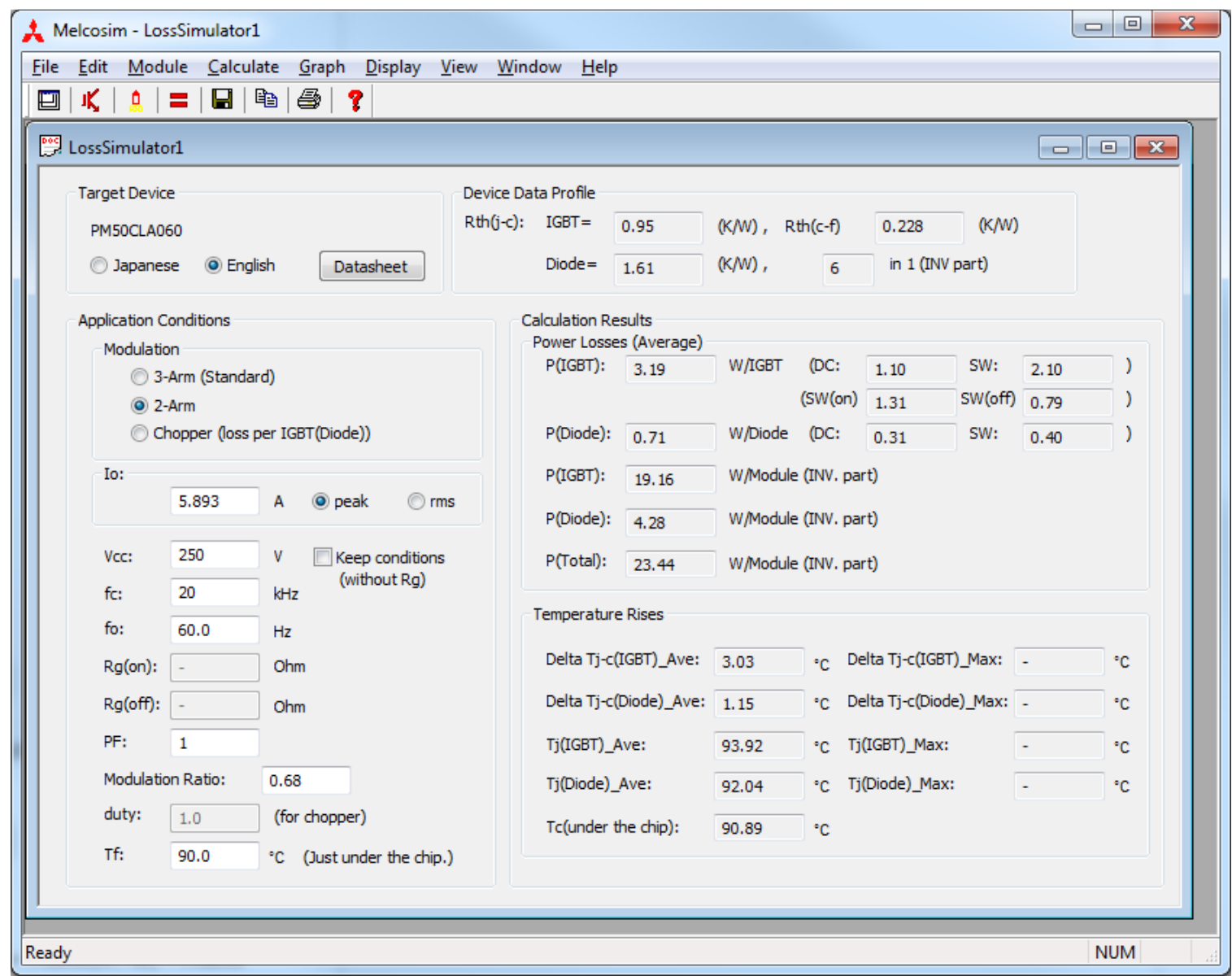

Figure 4-5 - Melcosim Loss Simulator for Calculated Condition

Due to the symmetry in the calculations the temperature from the thermal resistance was taken from the loss simulator and it was found that the average IGBT temperature was $93.92^{\circ} \mathrm{C}$ when initially $90^{\circ} \mathrm{C}$. The datasheet for the module states a maximum rated temperature of $150^{\circ} \mathrm{C}$ suggesting that the use of a heatsink is not necessary.

This loss per IGBT can be multiplied by four to produce total IGBT losses and to determine efficiency. Figure 4-6 shows the inverter efficiency variation with respect to 
input voltage and switching frequency. The input voltage ranges from 200 to $280 \mathrm{~V}$ and the switching frequency ranges from 2 to $18 \mathrm{kHz}$ (the reason for this will be discussed in a later section). A slight decrease in efficiency can be seen as the input voltage is increased however a more obvious decrease in efficiency can be seen as switching frequency is increased.

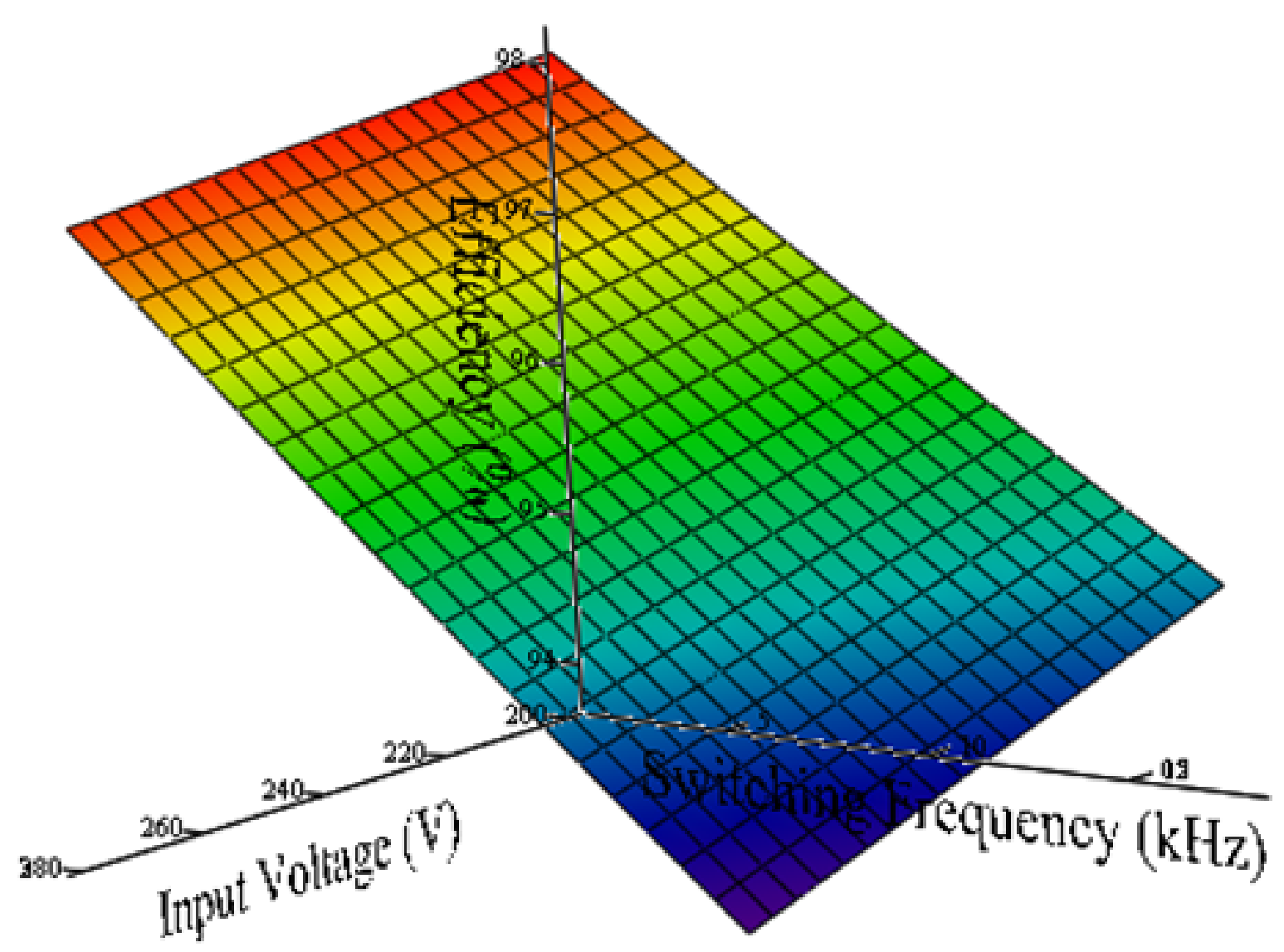

Figure 4-6 - Theoretical Efficiency vs. Input Voltage and Switching Frequency at 500 W

Figure 4-7 shows a more familiar trend--the efficiency variation with respect to output power and switching frequency for a fixed $200 \mathrm{~V}$ input. The output power is varied from 50 to $500 \mathrm{~W}$. The familiar asymptotic curve of efficiency can be seen while the switching frequency still varies linearly with efficiency. 


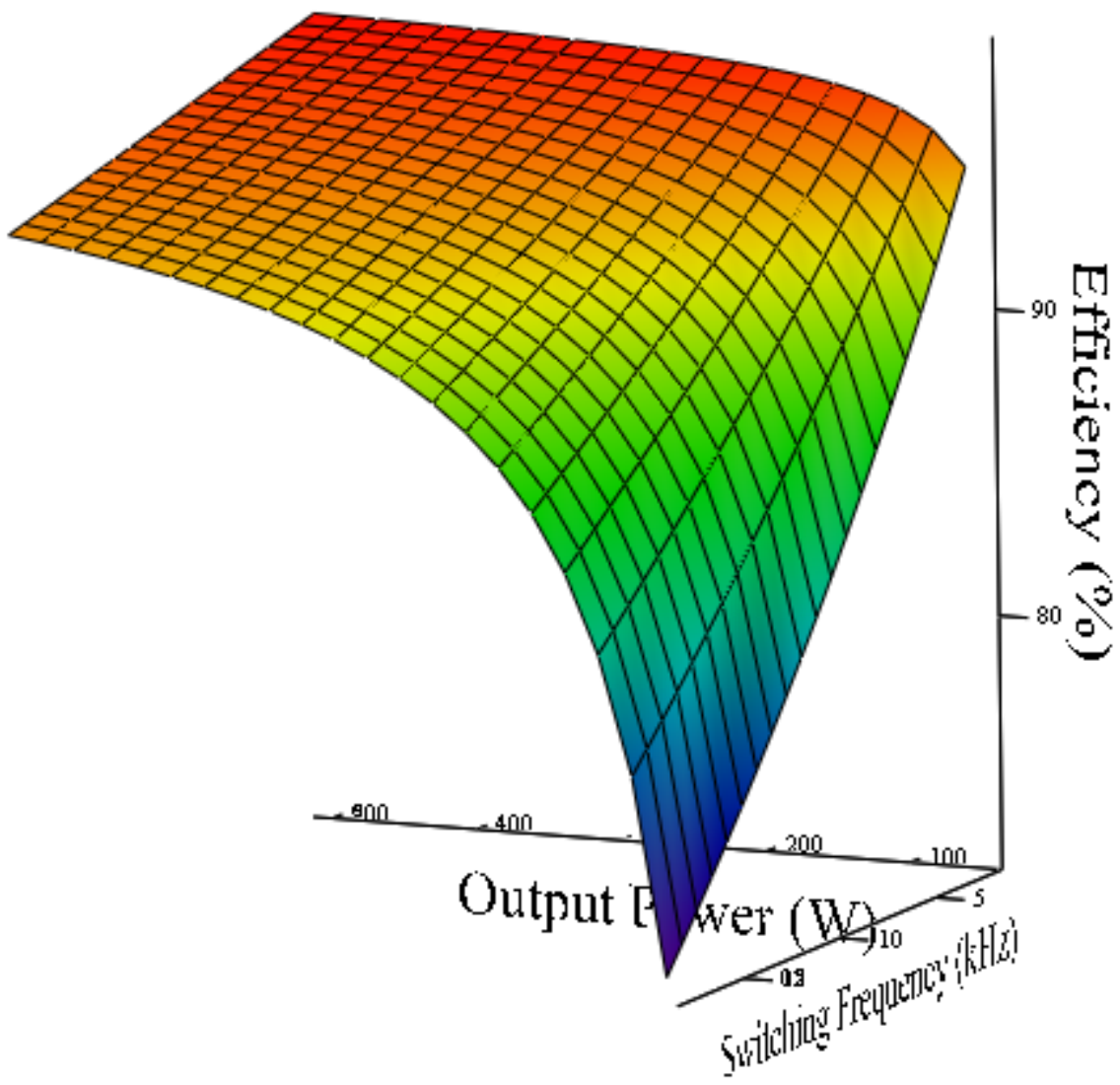

Figure 4-7 - Theoretical Efficiency vs. Output Power and Switching Frequency for a 200V Input

\subsection{Harmonic Distortion}

Total harmonic distortion can be calculated by determining the total rms voltage as well as the rms voltage of the fundamental component. However, this is not the way standard circuit simulation software determines THD. Circuit simulation software normally determines the first 50 harmonics and calculates THD as the ratio of the $2^{\text {nd }}$ through $50^{\text {th }}$ rms voltage with that of the fundamental component. This is rather limiting because at $60 \mathrm{~Hz}$ the highest harmonic frequency that can be measured is $3 \mathrm{kHz}$. Since the inverter is switching at frequencies up to $18 \mathrm{kHz}$, measuring only up to the $50^{\text {th }}$ 
harmonic neglects a lot of harmonic content that occurs at and around multiples of the switching frequency.

In this study no output filtering is performed and therefore it would seem that the total harmonic distortion is calculable by hand. However, due to the somewhat complicated switching performed, it is not as simple and would be far too complex to perform these calculations by hand. Mathcad serves as an intermediary between hand calculations and circuit simulation software. It allows for the true total harmonic distortion to be calculated in its pure mathematical form. The remainder of the section will show how an inverter was built in mathcad in order to perform the complex integrals necessary to find the THD.

First, a triangle wave has to be made since mathcad does not have this as a built in function. Using Fourier analysis the first harmonics of a triangle wave are summed up in order to produce a periodic triangle.

$$
V_{t r i}(t)=\left(\frac{8}{\pi}\right) \sum_{n=0}^{100}\left[\left[\frac{(-1)^{n}}{(2 n+1)^{2}}\right] \sin \left(2 f_{s w}(2 n+1) \pi t\right)\right]
$$

An example of the triangular waveform produced by the above equation was previously shown in Figure 2-2. Following the creation of the triangle wave the switching signals must be made. This involves comparisons of the triangle wave as well as a sine wave oscillating at $60 \mathrm{~Hz}$. A Type 2 Unipolar inverter switching topology will be used. These switching signals can then be used to determine the output voltage. 


$$
\begin{gathered}
V_{1}(t)=\mid \begin{array}{c}
1 \text { if } V_{\text {sin }}(t)>V_{\text {tri }}(t) \\
0 \text { otherwise }
\end{array} \\
V_{2}(t)=\mid \begin{array}{c}
1 \text { if }-V_{\text {sin }}(t)>0 \\
0 \text { otherwise }
\end{array} \\
V_{3}(t)=\mid \begin{array}{c}
1 \text { if } V_{\text {sin }}(t)<0 \\
0 \text { otherwise }
\end{array} \\
V_{4}(t)=\mid \begin{array}{c}
1 \text { if } V_{\text {sin }}(t)<V_{\text {tri }}(t) \\
0 \text { otherwise }
\end{array} \\
V_{\text {out }}(t)=\mid \begin{array}{c}
1 \text { if } V_{1}(t)^{\wedge} V_{2}(t) \\
-1 \text { if } V_{3}(t)^{\wedge} V_{4}(t) \\
0 \text { otherwise }
\end{array}
\end{gathered}
$$

Figure 4-8 shows the output waveform generated by the equations above. The amplitude of the sine wave can be adjusted to produce the desired output voltage at the fundamental frequency. This is necessary in order to produce $120 \mathrm{~V}_{\mathrm{rms}}$ at $60 \mathrm{~Hz}$ for varying switching frequencies and input voltages.

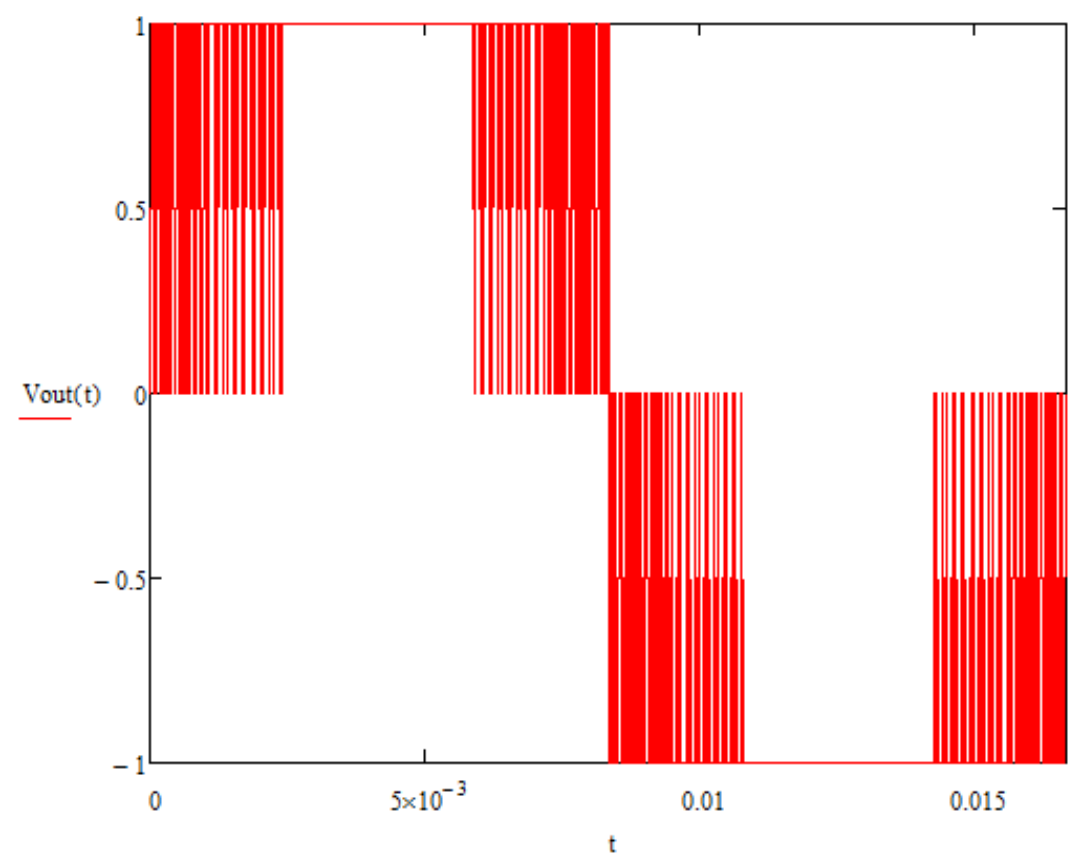

Figure 4-8 - Output Waveform for Mathcad THD Calculation 
Notice in Figure 4-8 how rapid switching occurs in the beginning. The pulse widths gradually increase until there is a $100 \%$ duty cycle at the sine wave's peak. From here the pulse widths decrease to almost zero upon which the voltage goes negative. Now the complicated integrals seen below can be performed in order to determine the THD.

$$
\begin{aligned}
& V_{r m s}=V_{d c} \sqrt{f_{\text {sin }} \int_{0}^{\frac{1}{f_{s i n}}} V_{\text {out }}(t)^{2} d t} \\
& a_{1}=2 f_{\text {sin }} \int_{0}^{\frac{1}{f_{\text {sin }}}} V_{\text {out }}(t) \cos \left(2 \pi f_{\text {sin }} t\right) d t \\
& b_{1}=2 f_{\text {sin }} \int_{0}^{\frac{1}{f_{\text {sin }}}} V_{\text {out }}(t) \sin \left(2 \pi f_{\text {sin }} t\right) d t \\
& V_{1, r m s}=V_{d c} \sqrt{\frac{a_{1}{ }^{2}+b_{1}{ }^{2}}{2}} \\
& T H D=100 \% * \frac{\sqrt{V_{r m s}{ }^{2}-V_{1, r m s}{ }^{2}}}{V_{1, r m s}}
\end{aligned}
$$

Through an iterative process all switching frequency and input voltage cases were performed. For each case the amplitude of the sine wave was adjusted to produce 120 $\mathrm{V}_{\mathrm{rms}}$ at $60 \mathrm{~Hz}$. Figure 4-9 shows how the THD varies. As the switching frequency varies, the THD remains relatively constant. This is because the total rms output voltage actually remains relatively constant for all switching frequencies while the fundamental component is fixed at $120 \mathrm{~V}$. This is most likely due to the total on time of each cycle being the same regardless of switching frequency. However, the THD does increase as 
the voltage increases. This is to be expected. As the input voltage gets further away from the desired peak output voltage of $170 \mathrm{~V}$, more switching has to occur at the peak of the output wave. This causes the output voltage to have more harmonic content away from $60 \mathrm{~Hz}$ increasing the THD. At $270 \mathrm{~V}$ and $280 \mathrm{~V}$ the THD seems to begin to level off from its linear increase. This is because at this input voltage the sine wave could not be adjusted to a small enough value to produce $120 \mathrm{~V}_{\mathrm{rms}}$ at $60 \mathrm{~Hz}$. So rather than being $120 \mathrm{~V}$, it actually varies from 121 to $126 \mathrm{~V}$ causing the THD to be less.

It is worth mentioning that the THD is not dependent on the load. This inverter should exhibit the same type of switching regardless. Since this output voltage remains the same regardless of loading, the THD will as well.

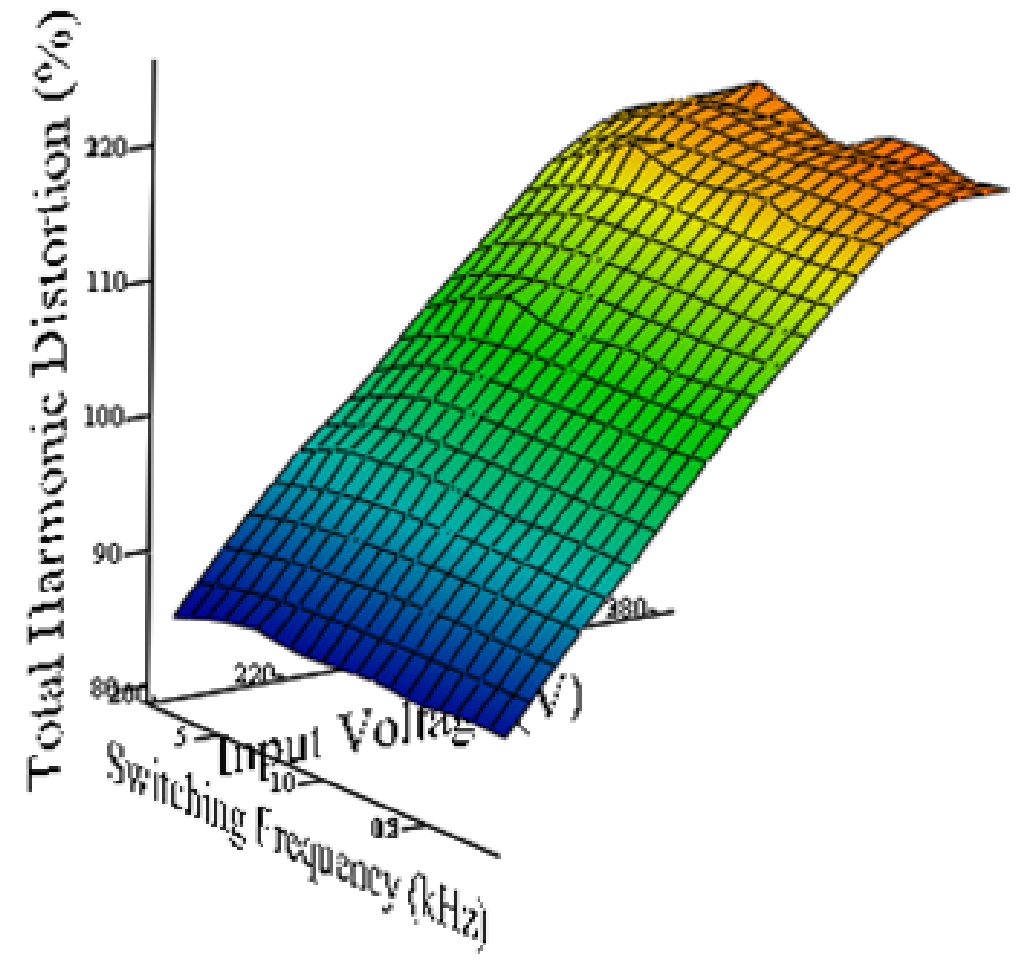

Figure 4-9 - Theoretical Total Harmonic Distortion vs. Switching Frequency and Input Voltage 


\subsection{Theoretical Calculation Summary}

This chapter helped to determine the expectations of the experimental portion of this thesis. With regards to efficiency, it is expected to decrease as both input voltage and switching frequency increase. However, this decrease should be more dependent on switching frequency. Also, the THD is expected to increase with input voltage, but remain relatively constant while switching frequency and load change. These findings are discussed further in Chapter 6. 


\section{Inverter Design and Laboratory Setup}

\subsection{Lab Procedure}

Table 5-1 shows a summary of the inverter parameters. Several conditions are listed as ranges because these parameters will be varied to determine the inverter's optimum operation. The input DC voltage will range from 200 to $280 \mathrm{~V}$. The minimum of the range was chosen because it is reasonably above the $170 \mathrm{~V}$ desired peak of the fundamental component. The maximum of $280 \mathrm{~V}$ was chosen because this is the limit at which the $60 \mathrm{~Hz}$ output of $120 \mathrm{~V}_{\mathrm{rms}}$ can be maintained. The load minimum was set at 50 $\mathrm{W}$ because anything below this would be impractical. The maximum was determined by the input voltage supply's output limit. The supply's maximum output power was found by multiplying its maximum current of $3.2 \mathrm{~A}$ by the maximum voltage of $280 \mathrm{~V}$. A value reasonably below the combined limit of $925 \mathrm{~W}$ was chosen to be $500 \mathrm{~W}$. The switching frequency minimum was set at $2 \mathrm{kHz}$ because, once again, anything less would be impractical. The maximum was set at $18 \mathrm{kHz}$, reasonably below the IPM's maximum switching frequency of $20 \mathrm{kHz}$.

Table 5-1 - Inverter Test Parameters

\begin{tabular}{|l|l|}
\hline Input Voltage $\left(\mathrm{V}_{\mathrm{dc}}\right)$ & $200-280$ \\
\hline $\begin{array}{l}\text { Fundamental Output Voltage } \\
\left(\mathrm{V}_{\mathrm{rms}}\right)\end{array}$ & 120 \\
\hline Load $(\mathrm{W})$ & $50-500$ \\
\hline Switching Frequency $(\mathrm{kHz})$ & $2-18$ \\
\hline Output Frequency $(\mathrm{Hz})$ & 60 \\
\hline
\end{tabular}

While collecting data, a three loop system will be implemented due to the three different ranges of Table 5-1. The primary loop will consist of the load. Bench resistors of $150 \Omega$ will be used in various configurations to get $300,150,75,50$ and $42.85 \Omega$. The 
secondary loop will consist of the input voltage ranging from 200 to $280 \mathrm{~V}$ in $10 \mathrm{~V}$ increments. The tertiary loop will consist of the switching frequency ranging from 2 to $18 \mathrm{kHz}$ in $2 \mathrm{kHz}$ increments. For example, data collection will begin with a $300 \Omega$ load, $200 \mathrm{~V}$ input, and $2 \mathrm{kHz}$. The control signals will be adjusted to produce $120 \mathrm{~V}_{\mathrm{rms}}$ at 60 $\mathrm{Hz}$ and the input current, output voltage, and output voltage THD will be recorded. Then the frequency will be adjusted to $4 \mathrm{kHz}$ and the process will repeat. At $18 \mathrm{kHz}$, the frequency will be adjusted to $2 \mathrm{kHz}$ and the input voltage to $210 \mathrm{~V}$. This process will be repeated until $280 \mathrm{~V}$ upon which the inputs will be reset and the load adjusted to $150 \Omega$. This process was chosen as the most optimum and time efficient method to collect such a large amount of data.

\subsection{Inverter Design}

Figure 5-1 shows the circuit design of the PWM controller. The circuit is supplied with a $15 \mathrm{~V}$ source and a $5 \mathrm{~V}$ reference is obtained with a simple voltage divider circuit. A comparator (TS3702) is supplied with the triangle and sine wave, both with a 5 $\mathrm{V}$ offset. The $5 \mathrm{~V}$ offset makes only one control power supply necessary. If the waveforms were oscillating about $0 \mathrm{~V}$ a negative supply would be required. A fast switching signal is created by comparing the sine and triangle waves and a slow switching signal is created by comparing the sine wave with the $5 \mathrm{~V}$ reference. The two outputs of the comparator are used to generate four switching signals with two separate half-bridge drivers (IR2111). These drivers were used to make the switching signals because they have a built in dead time to avoid inverter shoot through. While the IPM does have short circuit protection, the built in drivers do not have dead time and therefore it must be included in the PWM controller. 

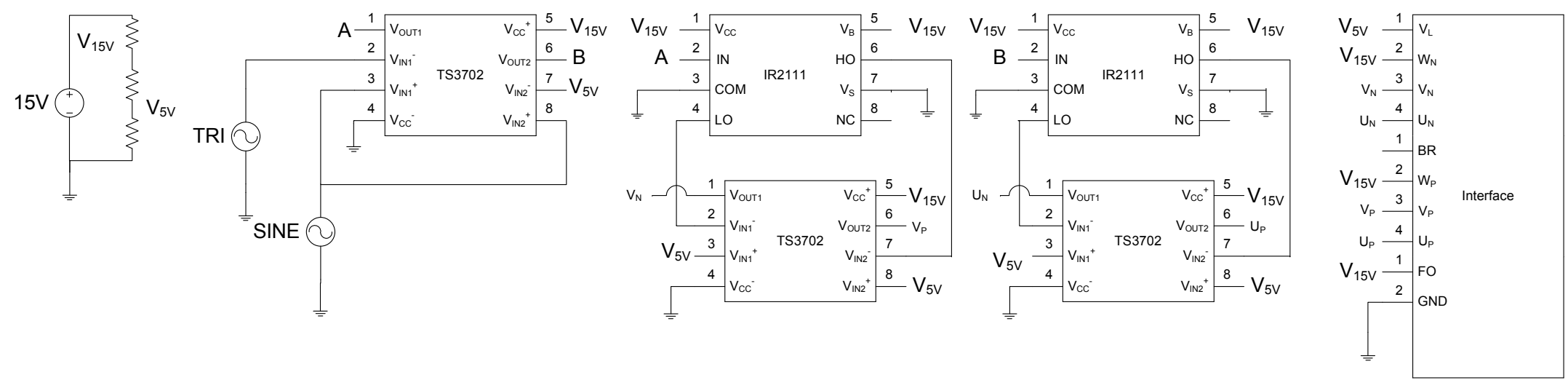

Figure 5-1 - PWM Controller Circuit Schematic 
The control signals fed to the IPM must also be active low while the outputs of the half bridge drivers are active high. This means that the drivers put the dead time before the low to high transition when they need to be from the high to low transition. To compensate for this the four signals are inverted using four comparators. It is made into an inverter by putting the $5 \mathrm{~V}$ reference in the non-inverting input and the signal to be inverted in the inverting input. When the signal is low, the $5 \mathrm{~V}$ will be higher and the output of the comparator will be high. Conversely, when the signal is high, the $5 \mathrm{~V}$ will be lower and the output of the comparator will be low. These four signals $\left(U_{N}, U_{P}, V_{N}\right.$, and $\left.\mathrm{V}_{\mathrm{P}}\right)$ are then fed to the interface circuit. The two unused switches $\left(\mathrm{W}_{\mathrm{N}}\right.$ and $\left.\mathrm{W}_{\mathrm{P}}\right)$ on the IPM must be turned off when not in use. As a result, these are connected to the $15 \mathrm{~V}$ supply.

While it may seem complicated, this design omits the use of a microcontroller. Instead, by using controllable input signals, the control signals can be quickly adjusted in amplitude and frequency using a function generator. With a microcontroller, the process would take much longer by requiring the constant reprogramming to meet testing requirements.

\subsection{Lab Setup}

A detailed block diagram of the system can be seen in Figure 5-2. The control consists of the PWM signal generator of Figure 5-1, a voltage source, two function generators, and two oscilloscopes. The GW GPR-6060D Power Supply supplies the 15 $\mathrm{V}$ needed for the control circuit. The sine and triangle wave are generated using two function generators, the Madell CA 1640-20 and the GWinstek GFG3015. Two 
oscilloscopes, the GWinstek GDS-2204 and the Agilent DSO3202A, are used to monitor the control signals.

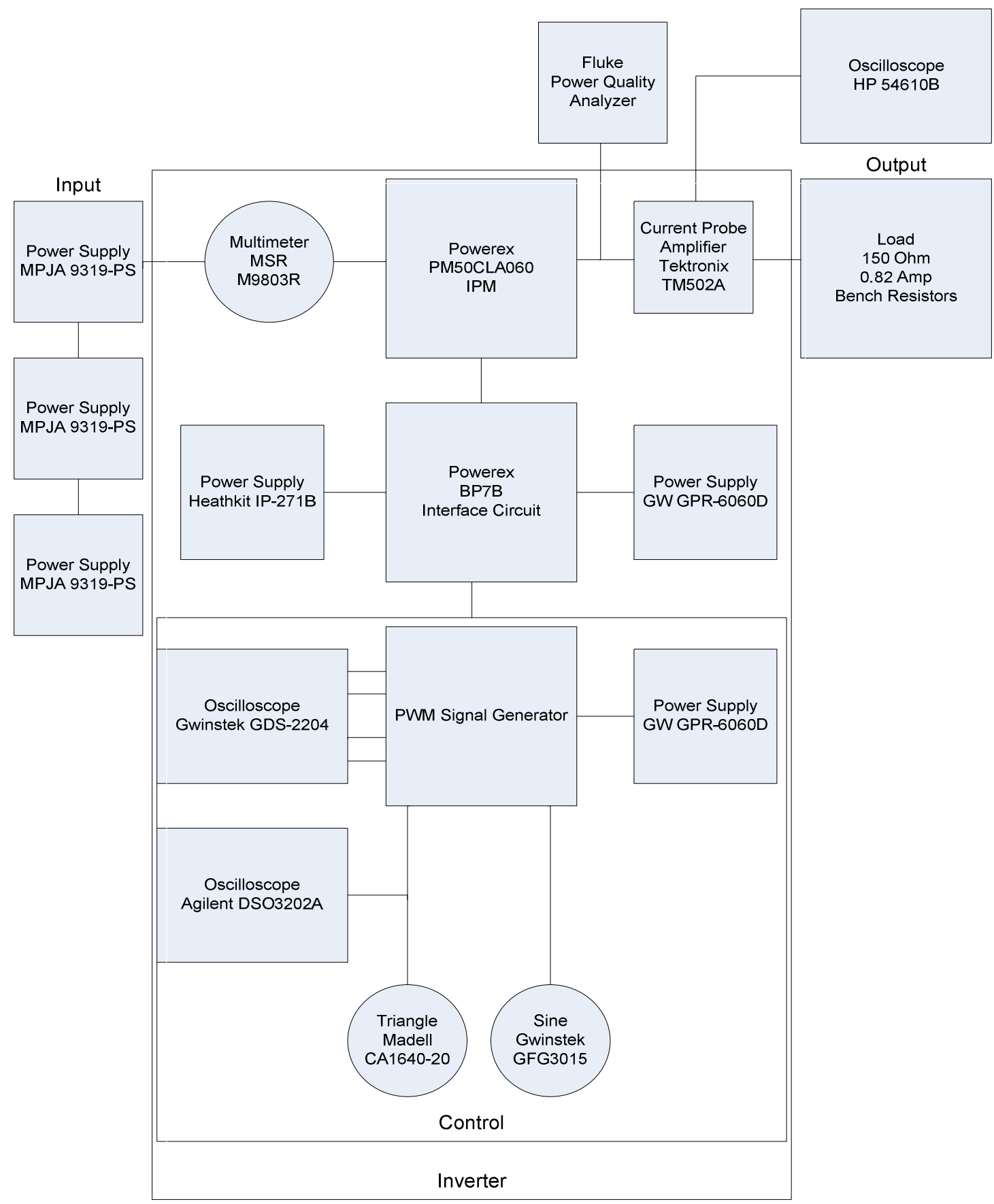

Figure 5-2 - Detailed Block Diagram of Test Setup 
Along with the control, the inverter consists of the interface circuit, the IPM, two power supplies, a multimeter, and current probe amplifier. The control feeds signals to the BP7B interface circuit, which in turn feeds these signals to the IPM. The interface is powered by the GW GPR-6060D at $24 \mathrm{~V}$ and also takes a $5 \mathrm{~V}$ reference from the Heathkit IP-271B. The input current is monitored with the MSR M9803 R multimeter and the output current is measured with the Tektronix TM502A Current Probe Amplifier connected to the HP 54610B Oscilloscope. The output voltage and voltage THD are measured using the Fluke Power Quality Analyzer.

The inverter also requires an input voltage. This comes from three MPJA 9319PS. These have a maximum output voltage of $120 \mathrm{~V}$ and, in order to obtain the maximum inverter input of $280 \mathrm{~V}$, three must be connected in series. The output of the inverter is fed to a load of $150 \Omega, 0.82$ A bench resistors. The actual lab set-up can be seen in Figure 5-3. Two benches are being used. One has the input and the inverter, while the other consists of the bench resistors. 


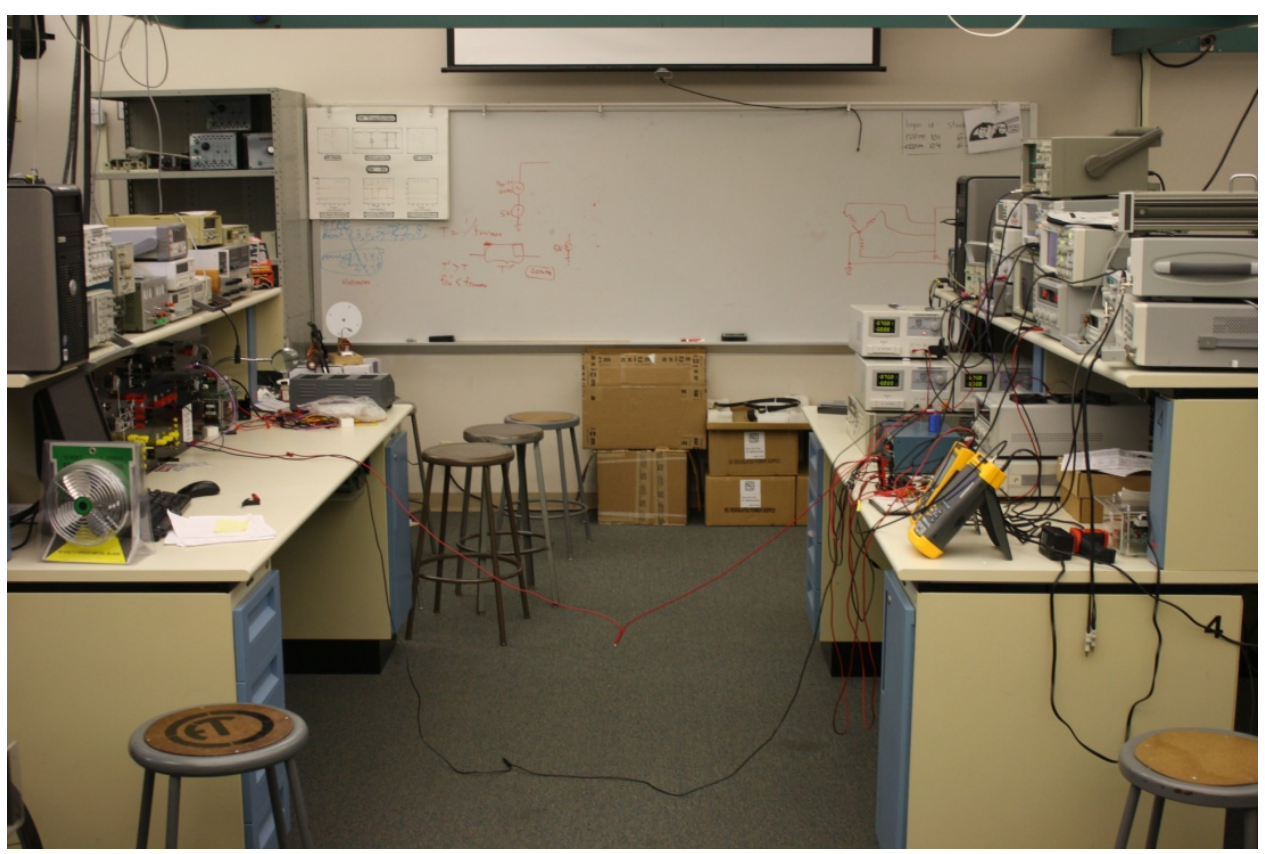

Figure 5-3 - Complete Test Set-Up

Figure 5-4 shows the primary bench consisting of the inverter and input voltage. The three input voltage supplies can be seen on the left, the inverter is shown in the front middle, and the no load output is being measured on the Fluke Power Quality Analyzer on the left. The three oscilloscopes can be seen on the top of the bench with the function generators on the right. 


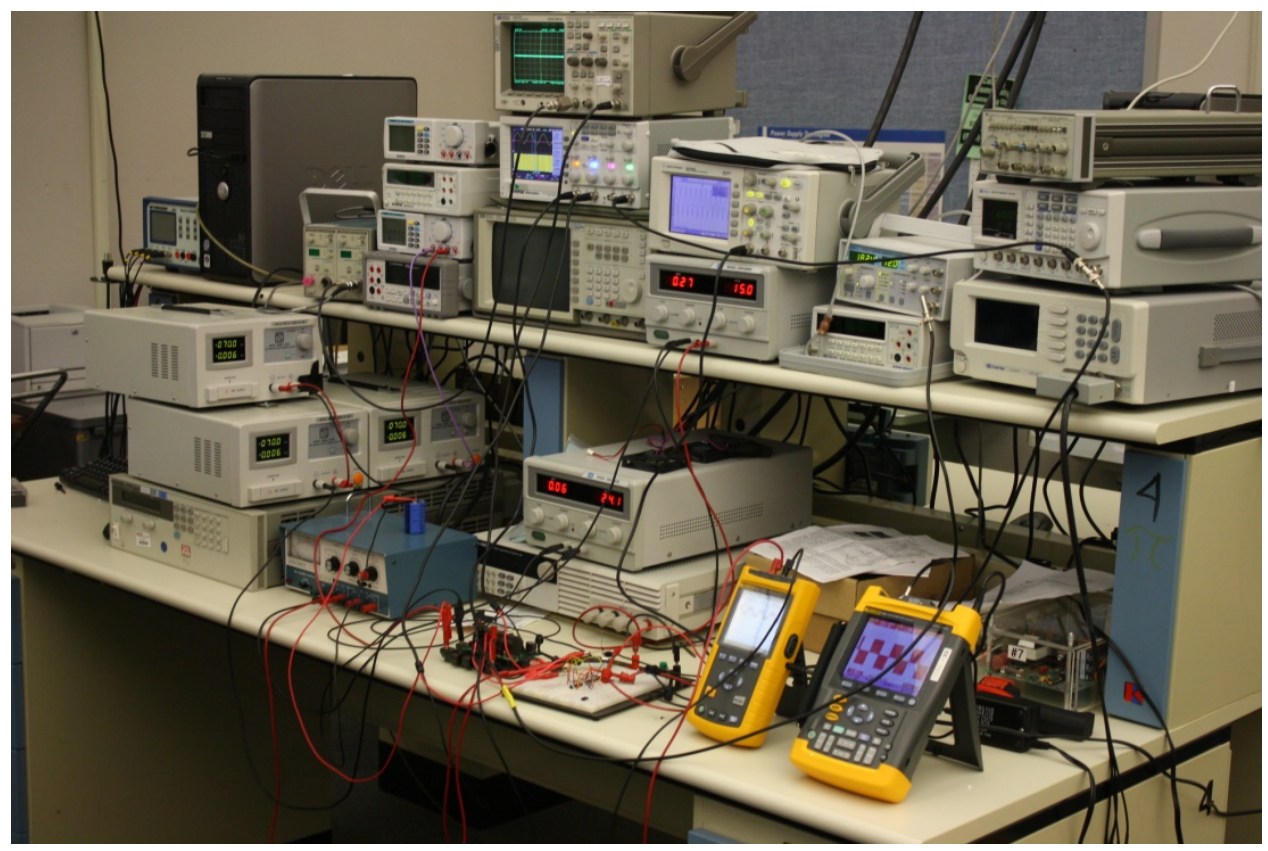

Figure 5-4 - Test Set-Up Primary Bench (Inverter)

Figure 5-5 shows a detailed picture of the three input voltage sources connected in series. Each of these has a 3.3 A current limit which will limit the scope of this study. Figure 5-6 shows the secondary bench consisting of the resistive loads. In the picture, the maximum load the input voltage sources can handle is shown. This is a $42.85 \Omega$ equivalent resistance that consists of three $150 \Omega$ resistors in parallel, which are in turn connected in parallel to two $150 \Omega$ resistors connected in series. This was the most complicated resistance to obtain. The others consisted of two $150 \Omega$ resistors in series, followed by one, two, and three in parallel for $300,150,75,50$, and $42.85 \Omega$ loads. 


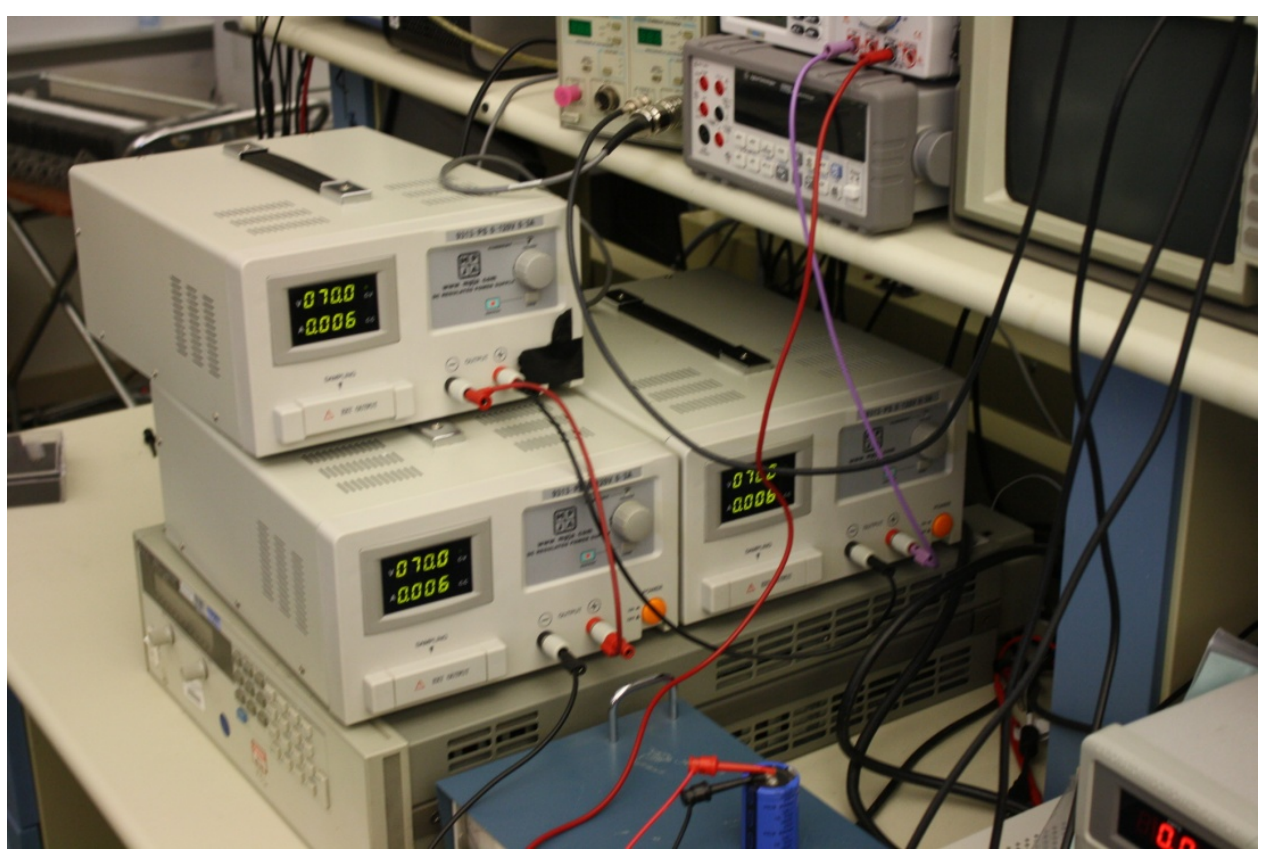

Figure 5-5 - Input Voltage Source

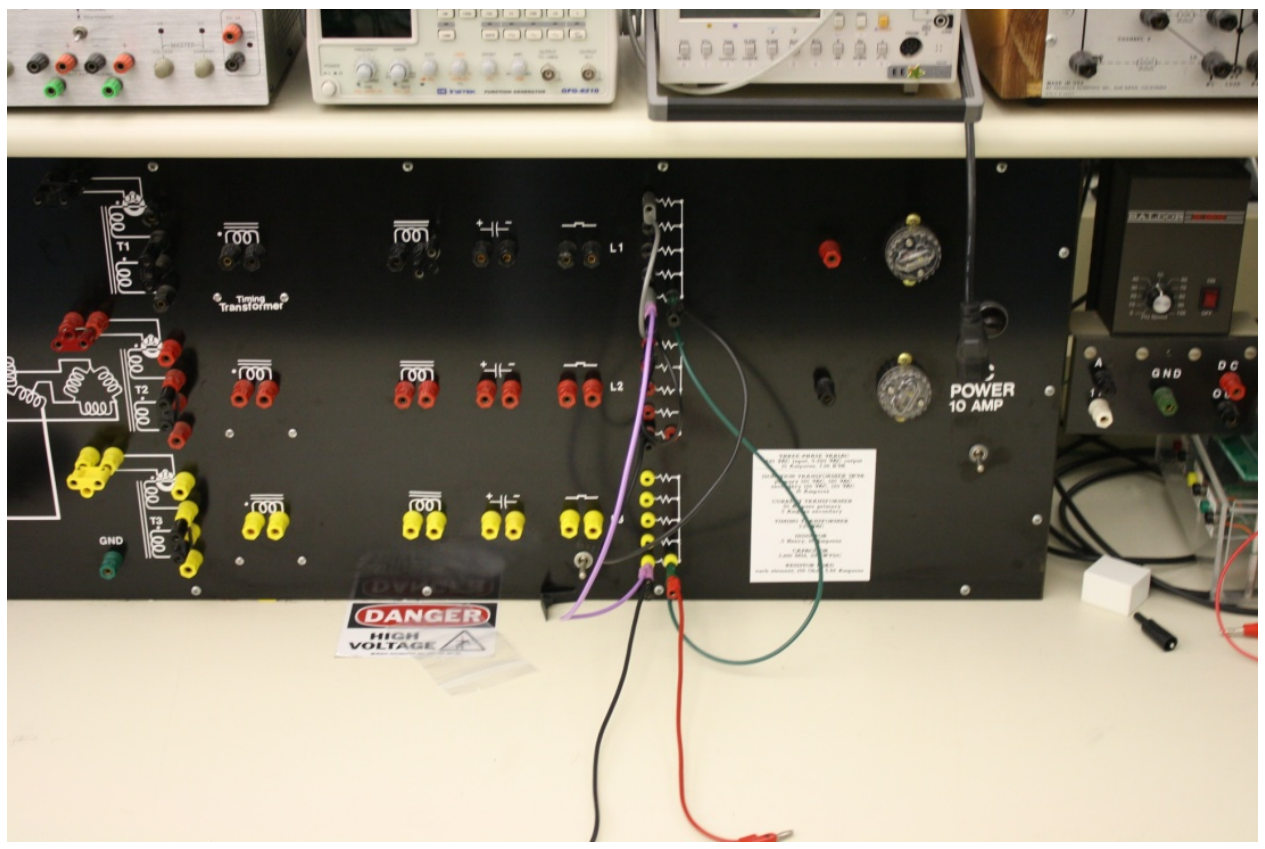

Figure 5-6 - Test Set-Up Secondary Bench (Load) 
Figure 5-7 shows a detailed view of the IPM, interface, and PWM controller. The PWM controller is on the bread board on the right. The ten signals can be seen feeding the interface through the red jumper cables. The interface sits atop the IPM and feeds these signals through the middle. In the following chapter this lab procedure, design, and set-up will be used for the measurement and analysis portion of this study.

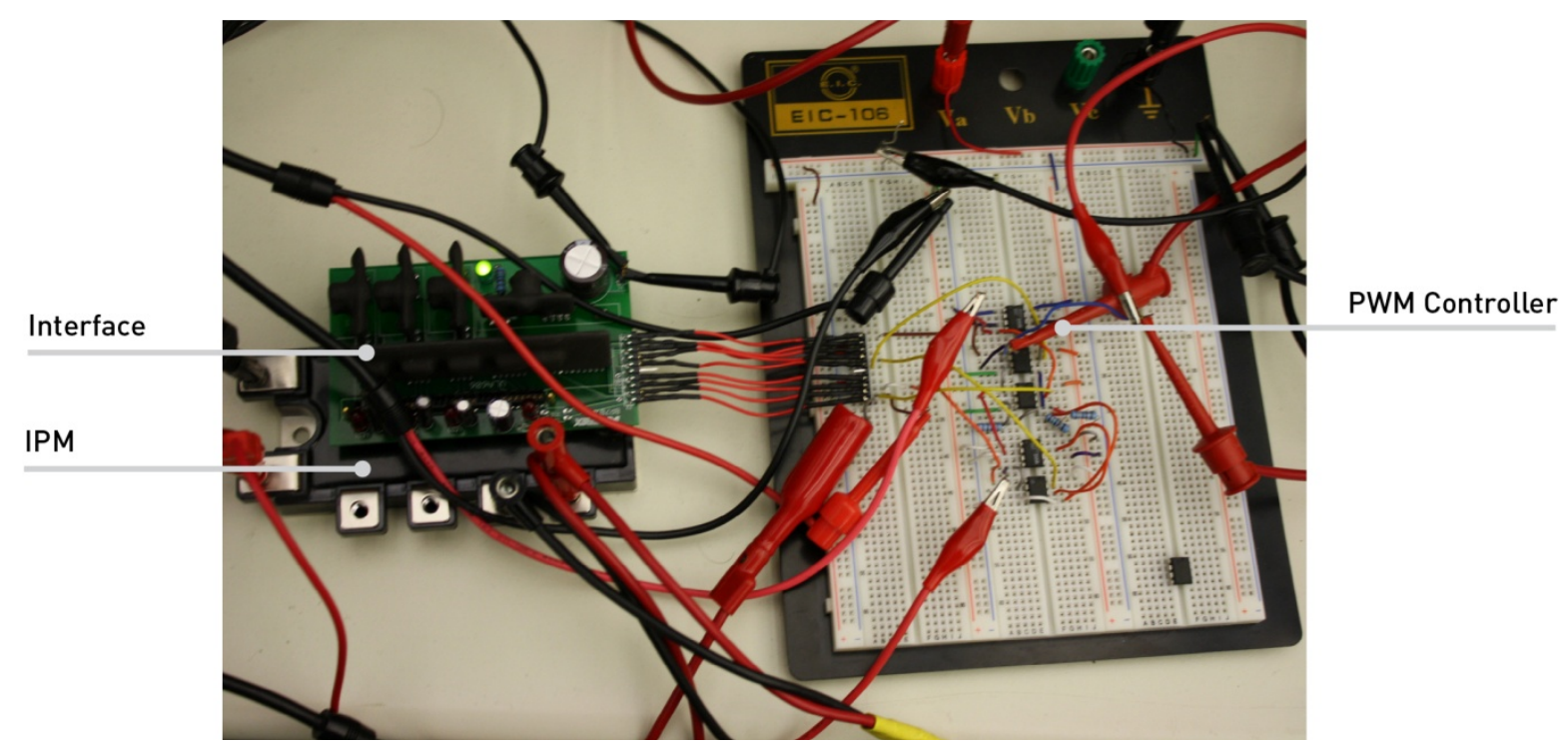

Figure 5-7 - Intelligent Power Module, Interface, and Control 


\section{Measurement and Analysis}

This chapter begins with an overview of the operation of the inverter. A demonstration of its operation as well as a discussion for each of the problems encountered is included. Following this the efficiency will be measured and analyzed. The trends will be compared to the theoretical results and the differences will be addressed and further analyzed. A similar study of the harmonic distortion will follow.

\subsection{Inverter Operation}

Figure 6-1 shows the inverter switching signals at a $2 \mathrm{kHz}$ switching frequency. Notice on the right of Figure 6-1 that the triangle wave of Channel 3 has a frequency of $1.998 \mathrm{kHz}$. The sine wave of Channel 4 is moving much slower. When the triangle wave is greater than the sine wave there is a pulse on Channel 1. Channel 1 shows the high frequency switching signal that generates two switching signals with the half bridge driver. Channel 2 pulses whenever the sine wave is greater than $5 \mathrm{~V}$. This is the low frequency switching signal that generates two of the switching signals with the half bridge driver as shown in Figure 3-1. 


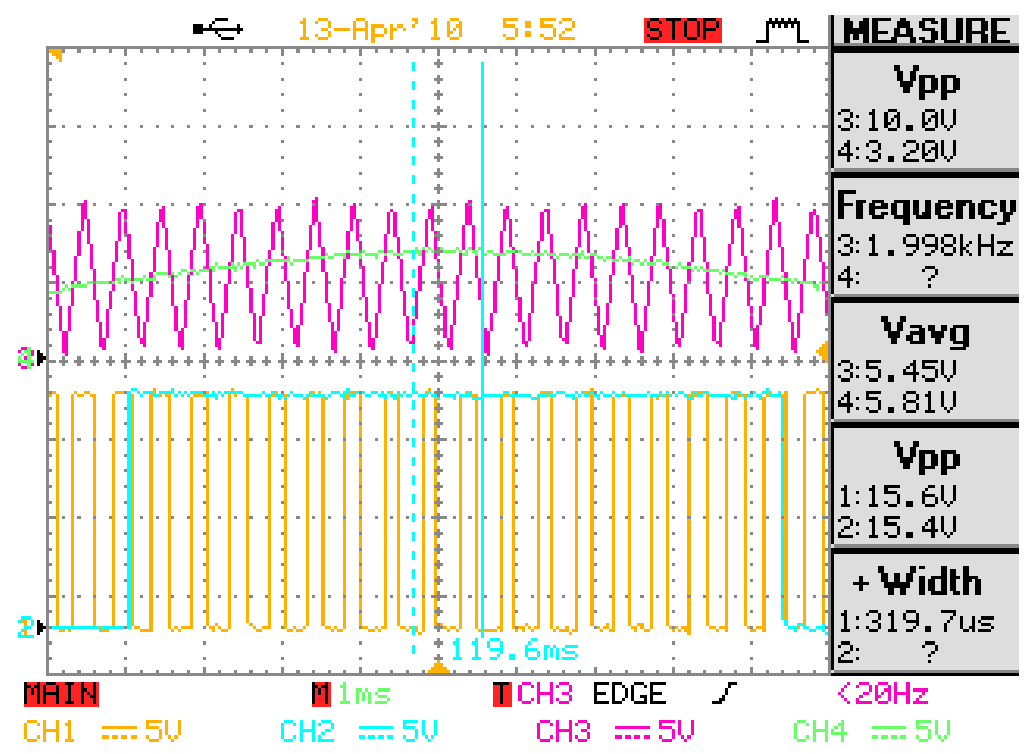

Figure 6-1 - Switching Signals at 2 kHz Switching Frequency

Figure 6-2 shows the output voltage waveform captured on the Fluke Scope Meter. This is for an input voltage of $200 \mathrm{~V}$ at no load. Notice that the pulses occur at positive and negative $200 \mathrm{~V}$. The period appears to be just over $15 \mathrm{~ms}$ or $60 \mathrm{~Hz}$. Since 2 $\mathrm{kHz}$ is the lowest switching frequency, the pulses can actually be seen at $5 \mathrm{~ms} / \mathrm{div}$. A more detailed capture can be seen in Figure 6-3 at $1 \mathrm{~ms} / \mathrm{div}$. It is harder to see at this frequency, but notice how the pulses get slightly wider in the middle of the negative half cycle. This is increasing the effective voltage. Much like a sine wave reaching its peak, the average voltage increases. 


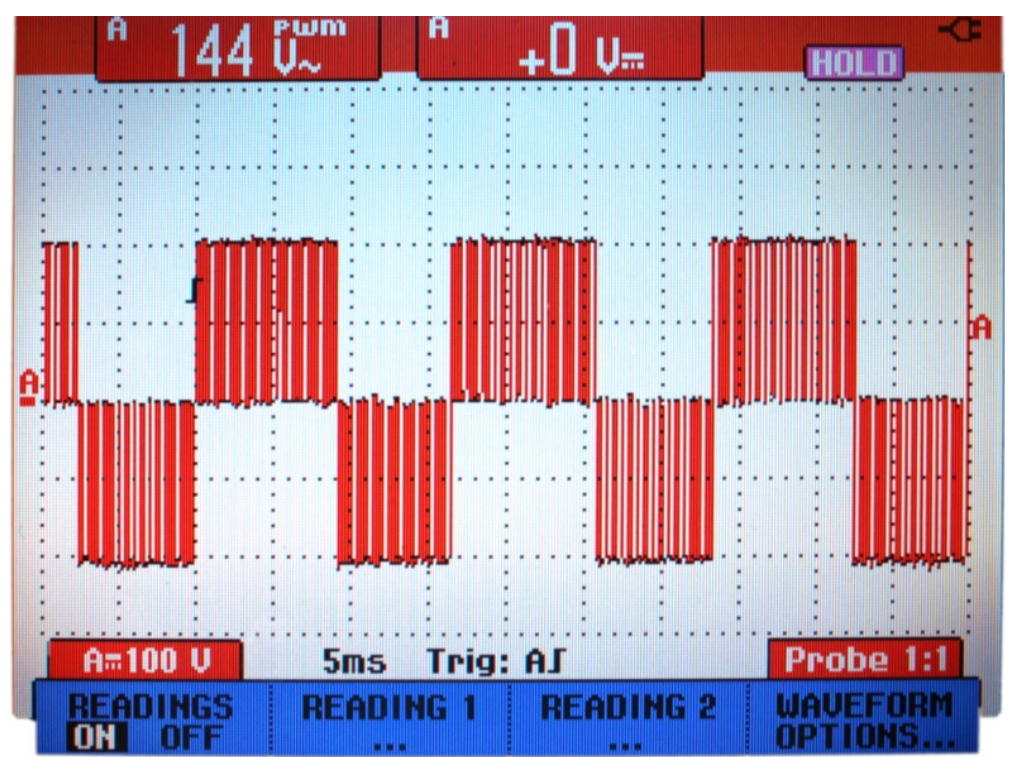

Figure 6-2 - Output Voltage at $2 \mathrm{kHz}$ Switching Frequency (5ms/div)

Figure 6-4 shows the inverter switching signals at $18 \mathrm{kHz}$ switching frequency. Similar to Figure 6-1, the high and low frequency switching signals can be seen on Channels 1 and 2 respectively. The switching frequency on Channel 3 can also seen as $18.02 \mathrm{kHz}$.

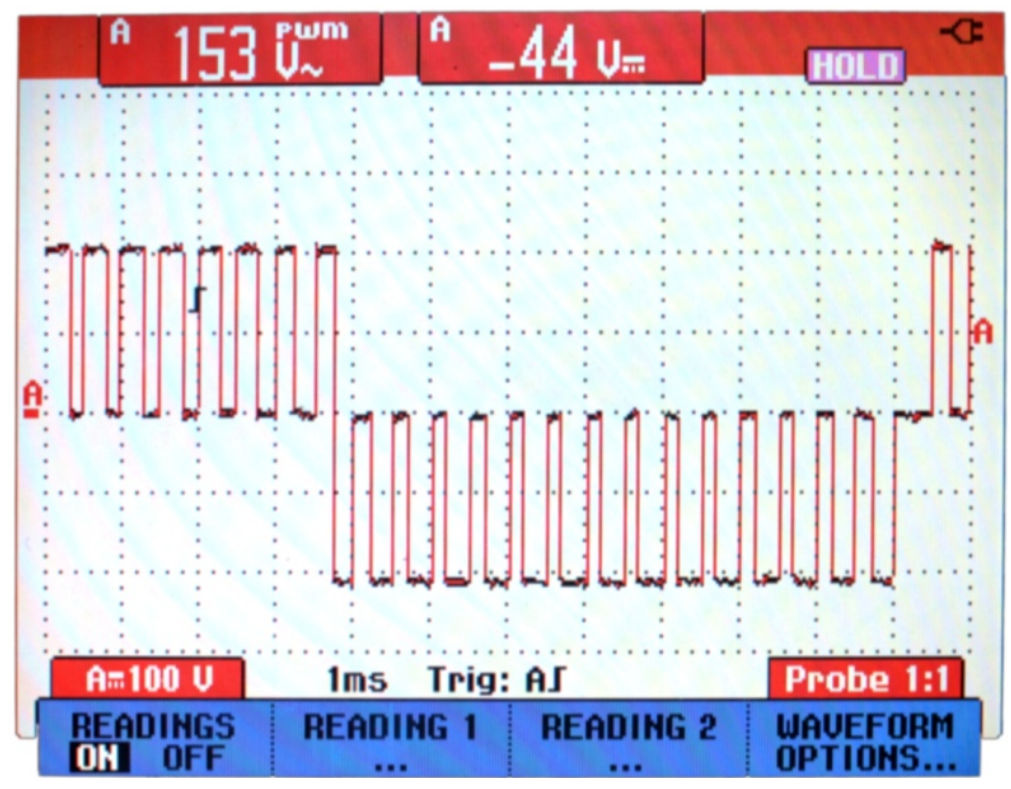

Figure 6-3 - Output Voltage at 2 kHz Switching Frequency (1ms/div) 


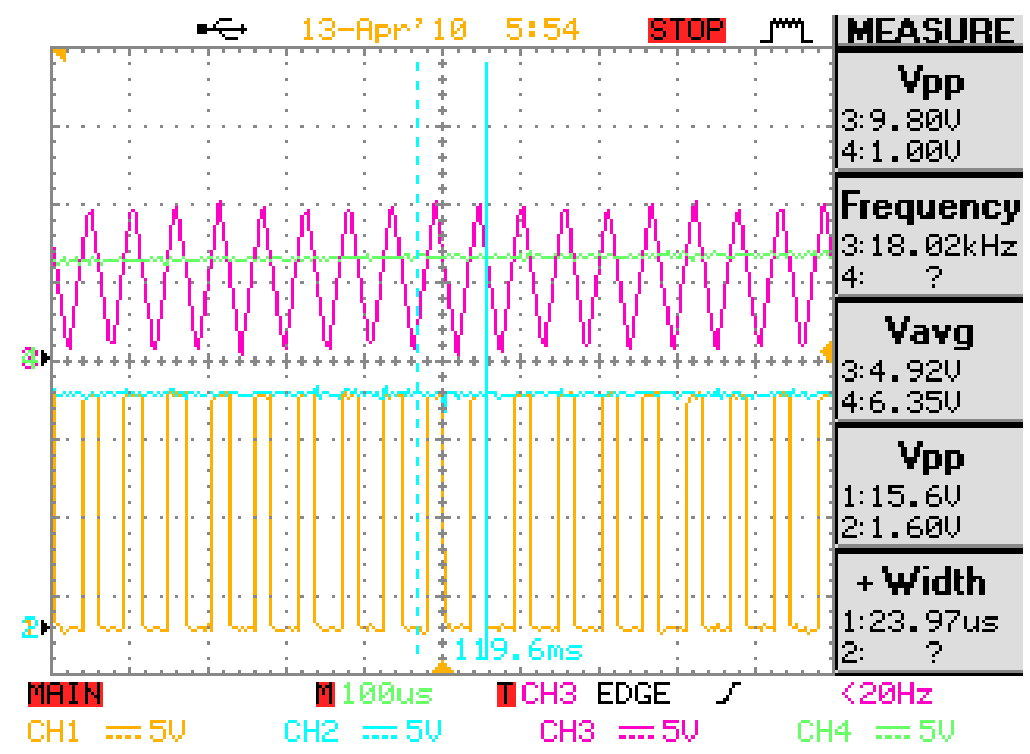

Figure 6-4 - Switching Signals at 18 kHz Switching Frequency

Figure 6-5 shows the output voltage waveform captured on the Fluke Scope Meter. Similar to before, this is for an input voltage of $200 \mathrm{~V}$ at no load. Since $18 \mathrm{kHz}$ is the highest switching frequency, the pulses are impossible to distinguish at $5 \mathrm{~ms} / \mathrm{div}$. A more detailed capture can be seen in Figure 6-6 at $1 \mathrm{~ms} / \mathrm{div}$. Unlike before, even at 1 $\mathrm{ms} / \mathrm{div}$ the pulses cannot be distinguished due to the lower relative resolution relative to the increased switching frequency. Figure 6-7 shows an even more detailed view at 200 $\mu s /$ div. Here the pulses are very short in duration, but increase with time. All of these figures demonstrate the proper operation of the inverter. 


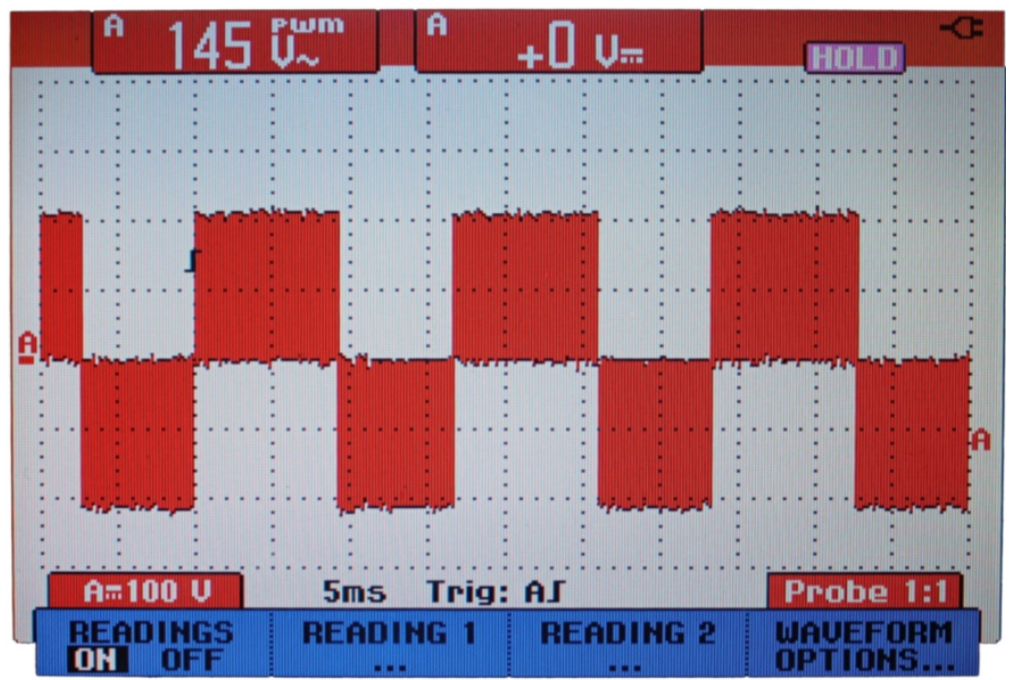

Figure 6-5 - Output Voltage at $18 \mathrm{kHz}$ Switching Frequency (5ms/div)

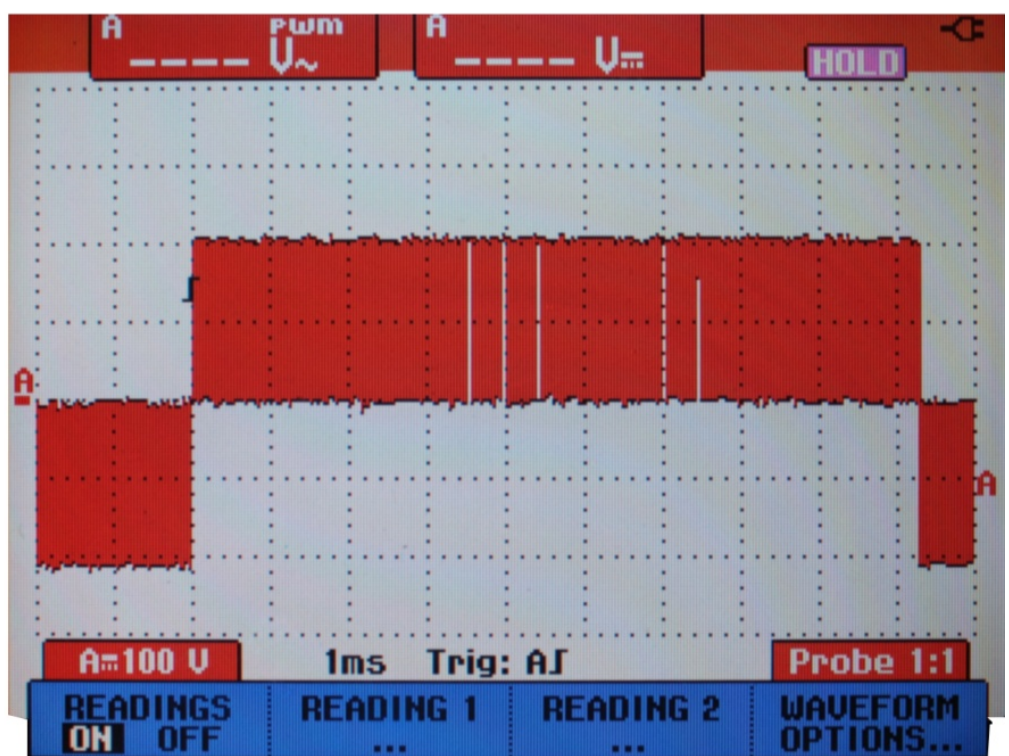

Figure 6-6 - Output Voltage at $18 \mathrm{kHz}$ Switching Frequency (1ms/div) 


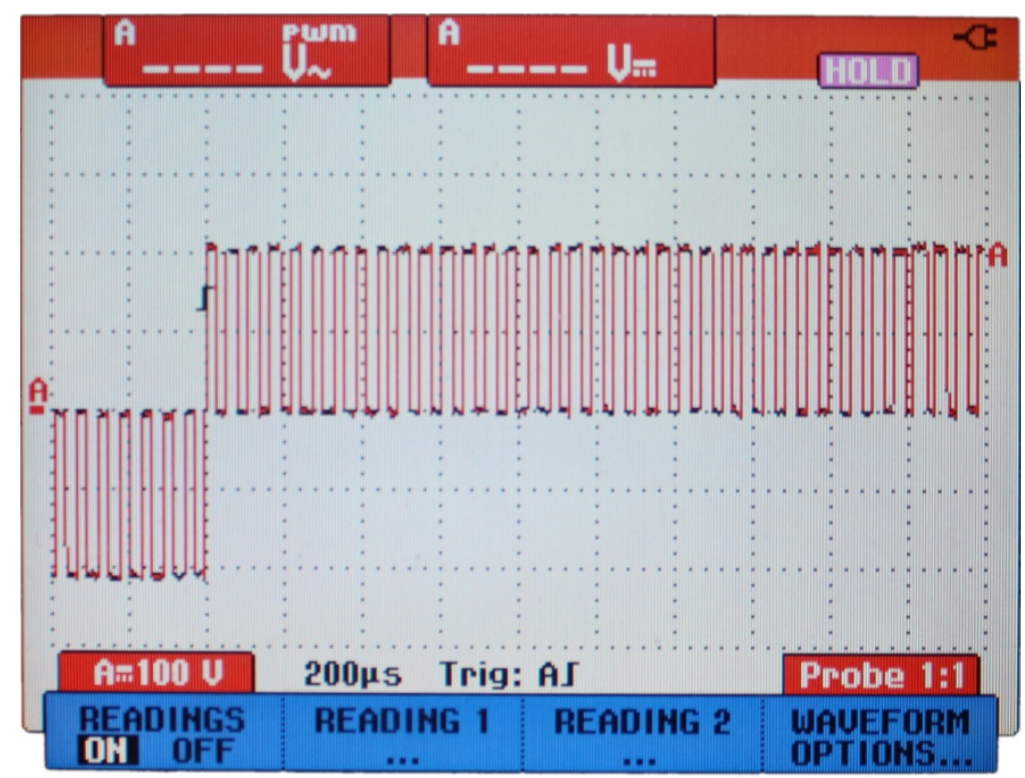

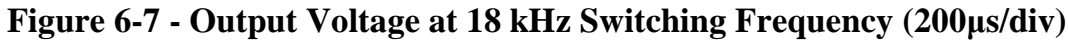

Initially, the inverter was not properly operating and was experiencing problems with shoot through where the input voltage source is shorted. This occurs when two switches on one half of the full-bridge inverter are on at the same time. They are supposed to always be opposites of each other in order to avoid shorting the constant voltage source and causing large current spikes. This can be a particularly harmful problem because, not only does it cause high currents to flow through switches causing increased stresses and heat, but it can damage the input capacitor with continual shorting and large $\mathrm{dv} / \mathrm{dt}$. The noise from the $\mathrm{dv} / \mathrm{dt}$ can even reach the control circuit in some cases and cause switching signals to inappropriately turn switches on.

Figure 6-8 shows the switching signals and input current for this problem. Notice that the input current shown on Channel 3 has spikes occurring when the inverter is switching. The particular case shown is for no load, therefore no input current should even be seen. The two switching signals of Channel 1 and Channel 2 should be the opposite of each other, however this is not always the case. Notice how when Channel 2 
is high, Channel 1 is low, but at two points goes high. This can cause two switches of a half bridge to be on, shorting the input voltage source. Also, noticeable distortion can be seen on the sine wave of Channel 4. This could be one of the causes of current and future problems.

This problem was remedied by using the IR2111 half-bridge driver to create two pairs of opposite switching signals. The driver adds $650 \mathrm{~ns}$ of dead time preventing this shoot through from occurring. However, the driver is active high and that is why the four switching signals are inverted in the design section to change it to active low and place the dead time on the appropriate transition.

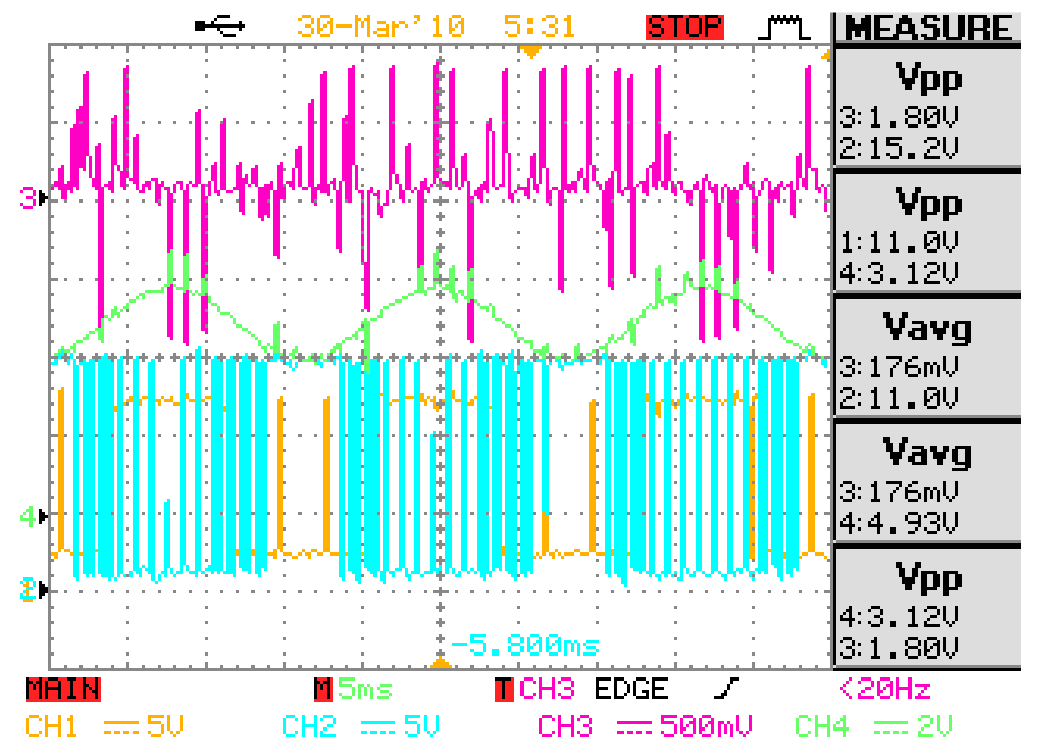

Figure 6-8 - Switching Signals and Input Current of Inverter Shoot Through 


\subsection{Efficiency}

With the inverter operating properly, measurements and an analysis of the inverter efficiency can follow. For five different loads of various combinations of series and parallel $150 \Omega$ resistors, input voltage, input current, and output voltage were recorded while the input voltage and switching frequency were varied. The efficiency was calculated as follows.

$$
\begin{aligned}
& P_{\text {in }}=V_{\text {in }} I_{\text {in }} \\
& P_{\text {out }}=\frac{V_{\text {out }}^{2}}{R} \\
& \eta=\frac{P_{\text {out }}}{P_{\text {in }}}=\frac{V_{\text {out }}^{2}}{V_{\text {in }} I_{\text {in }} R}
\end{aligned}
$$

Figure 6-9 shows the theoretical and experimental efficiency for a load of $300 \Omega$. After a brief look, the two can be seen to closely correlate. They have similar downward slopes as efficiency and switching frequency increase. Some inspection suggests that the optimum parameters at this load are the lowest input voltage and lowest switching frequency. This is to be expected since a lower switching frequency means less switching losses. While less obvious, a lower input voltage is better for the same reason. With higher voltages, more switching has to occur to reduce the effective voltage. This increases the losses, decreasing the efficiency. 


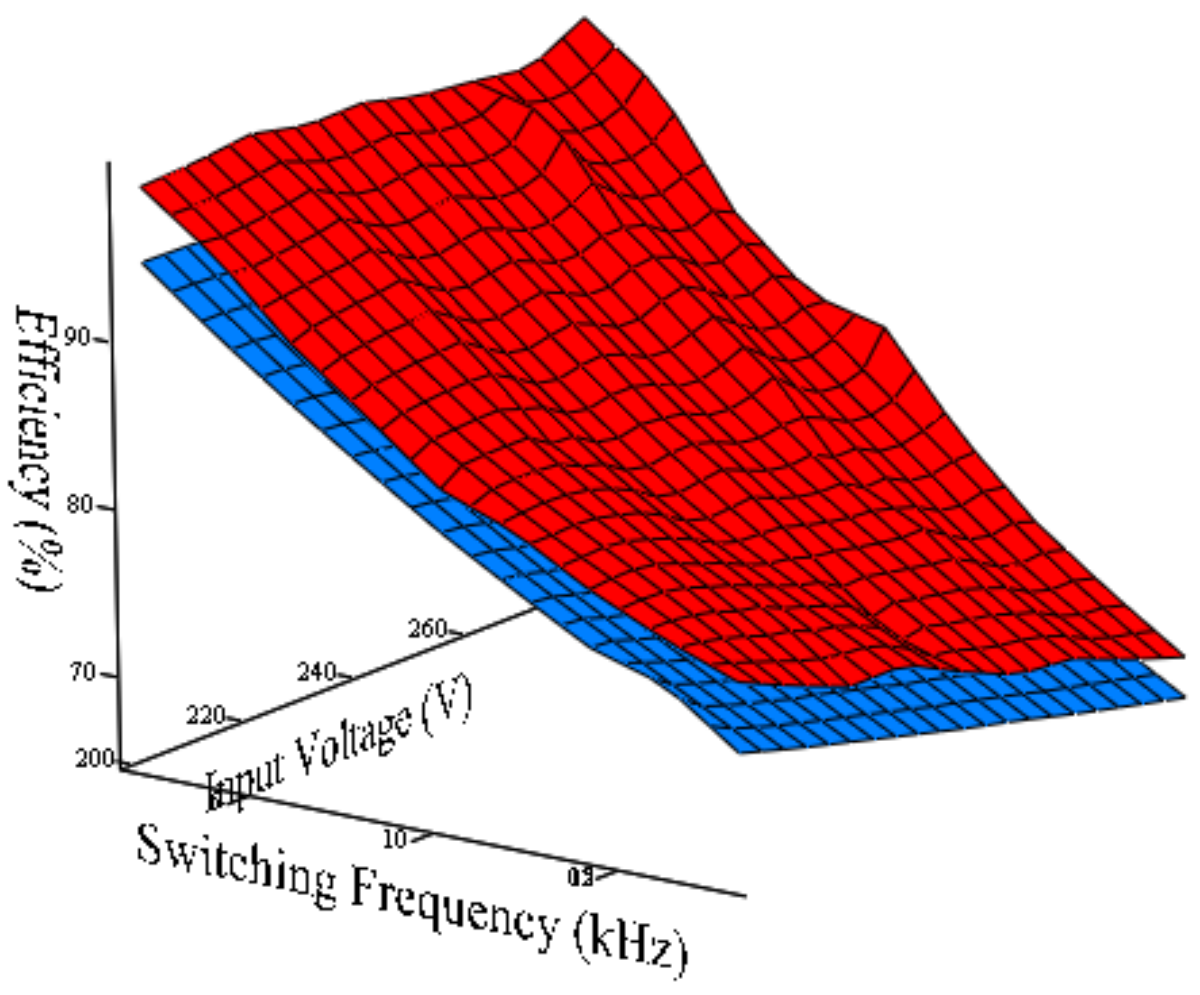

Figure 6-9 - Theoretical (Blue) and Experimental (Red) Efficiency for a $300 \Omega$ Load

It is important to note that, while the input voltage and load resistance are fixed, the input current and output voltage are not. The fundamental component of the output voltage remains $120 \mathrm{~V}$, however the harmonic content is constantly changing with the various conditions. This changing output voltage causes the output power to be a dynamic quantity over the varying conditions. Figure 6-10 shows how the output power changes over these conditions. The orientation of the axis maximizes the visibility of the output power relationship with input voltage and switching frequency. As the input voltage decreases and the switching frequency increases the output power decreases. This is a result of the output voltage changing. At a higher input voltage, more harmonic content is present causing a higher voltage. The switching frequency affects this 
condition less and its change is most likely attributed to the measurement instruments as will be discussed later.

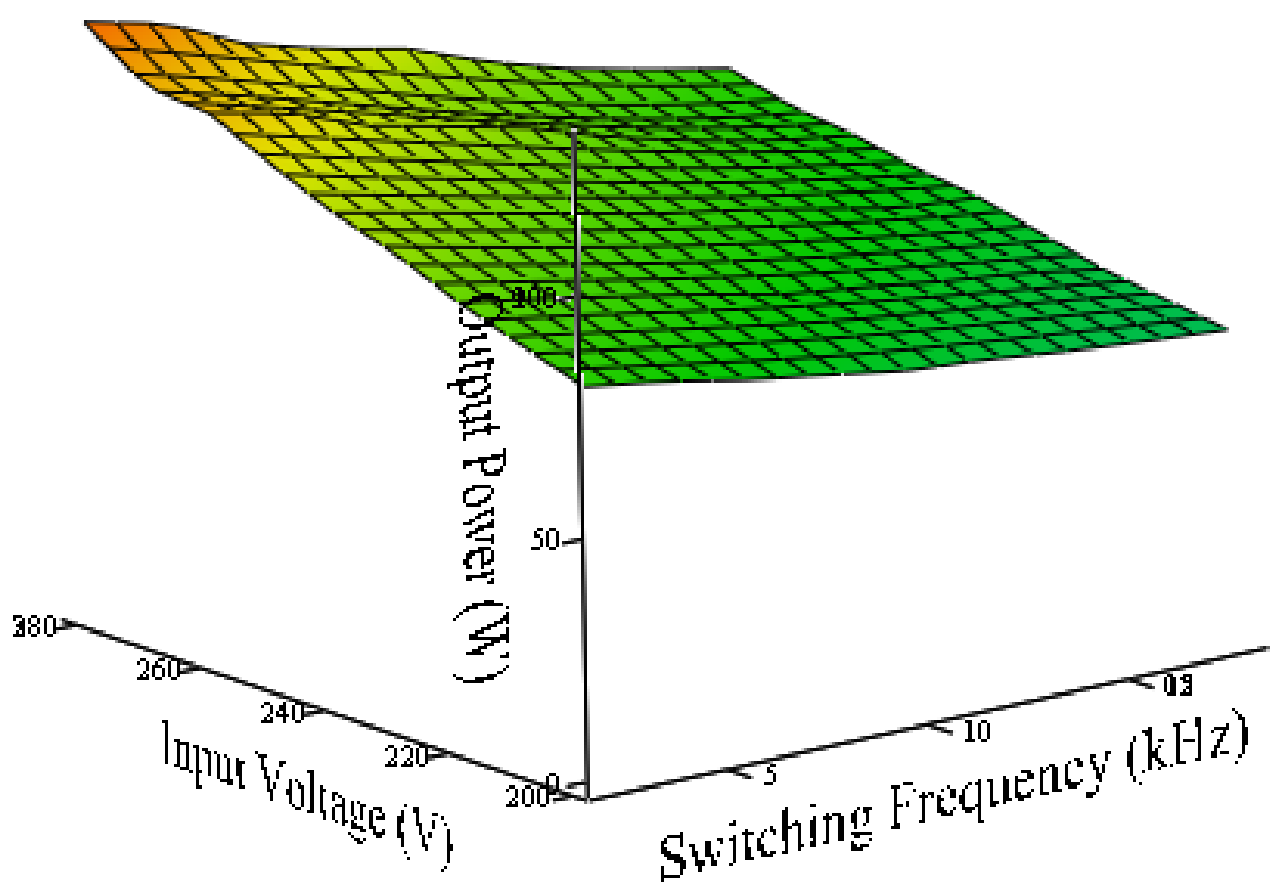

Figure 6-10 - Experimental Output Power for a $300 \Omega$ Load

Figure 6-11 through Figure 6-14 show the efficiency for 150, 75, 50, and $42.85 \Omega$ respectively. Starting at Figure 6-11 the experimental efficiency begins to lower than the theoretical efficiency. As load resistance decreases and load increases, this difference grows. This is because, while the slope of the experimental efficiency increases, the theoretical efficiency decreases. Regardless of this difference, from each load the highest theoretical and experimental efficiency is obtained when the input voltage and switching frequency are at the lowest value of $200 \mathrm{~V}$ and $2 \mathrm{kHz}$. This is not dependent on the load and could be a fixed static set of parameters. 


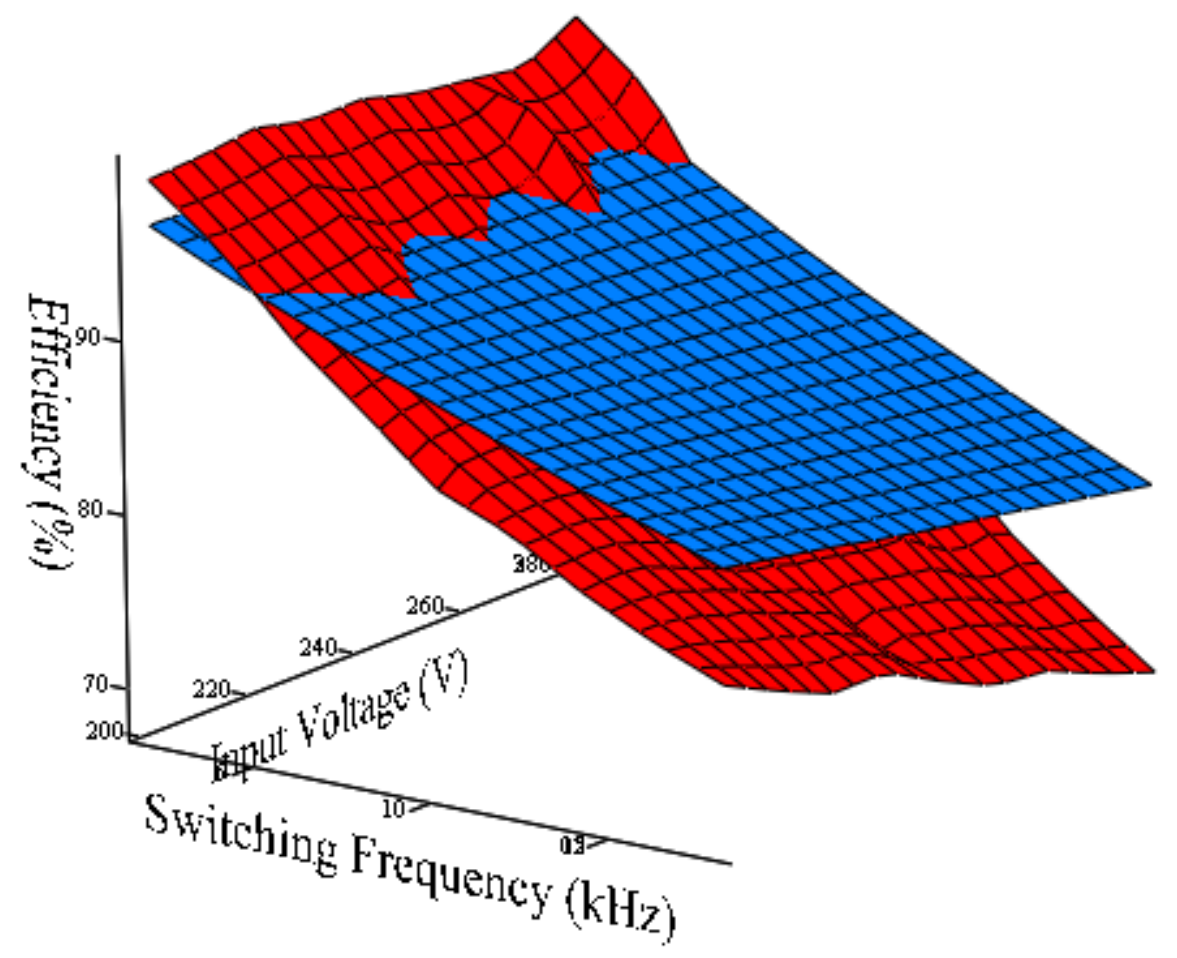

Figure 6-11 - Theoretical (Blue) and Experimental (Red) Efficiency for a $150 \Omega$ Load

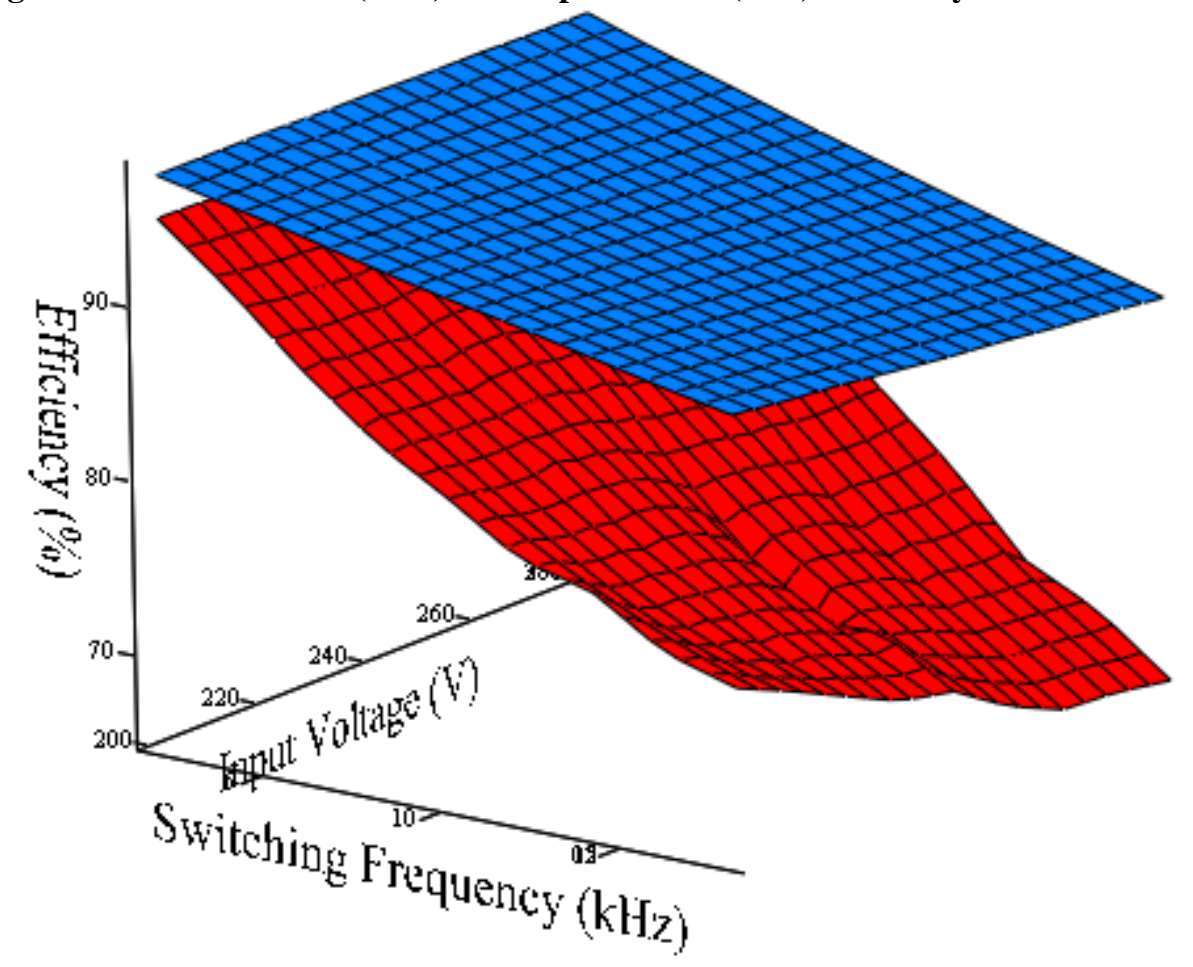

Figure 6-12 - Theoretical (Blue) and Experimental (Red) Efficiency for a $75 \Omega \mathrm{Load}$ 


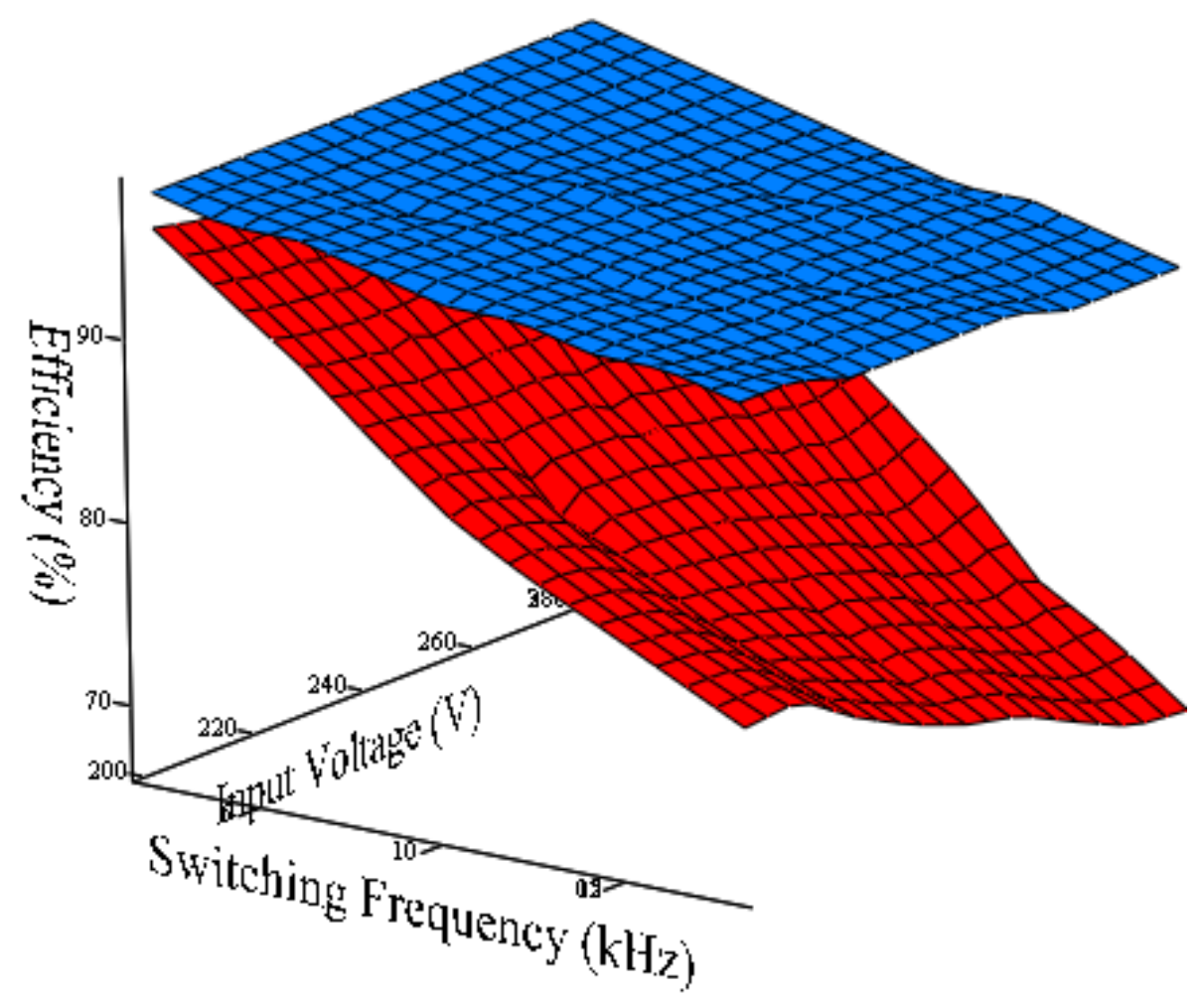

Figure 6-13 - Theoretical (Blue) and Experimental (Red) Efficiency for a $50 \Omega$ Load

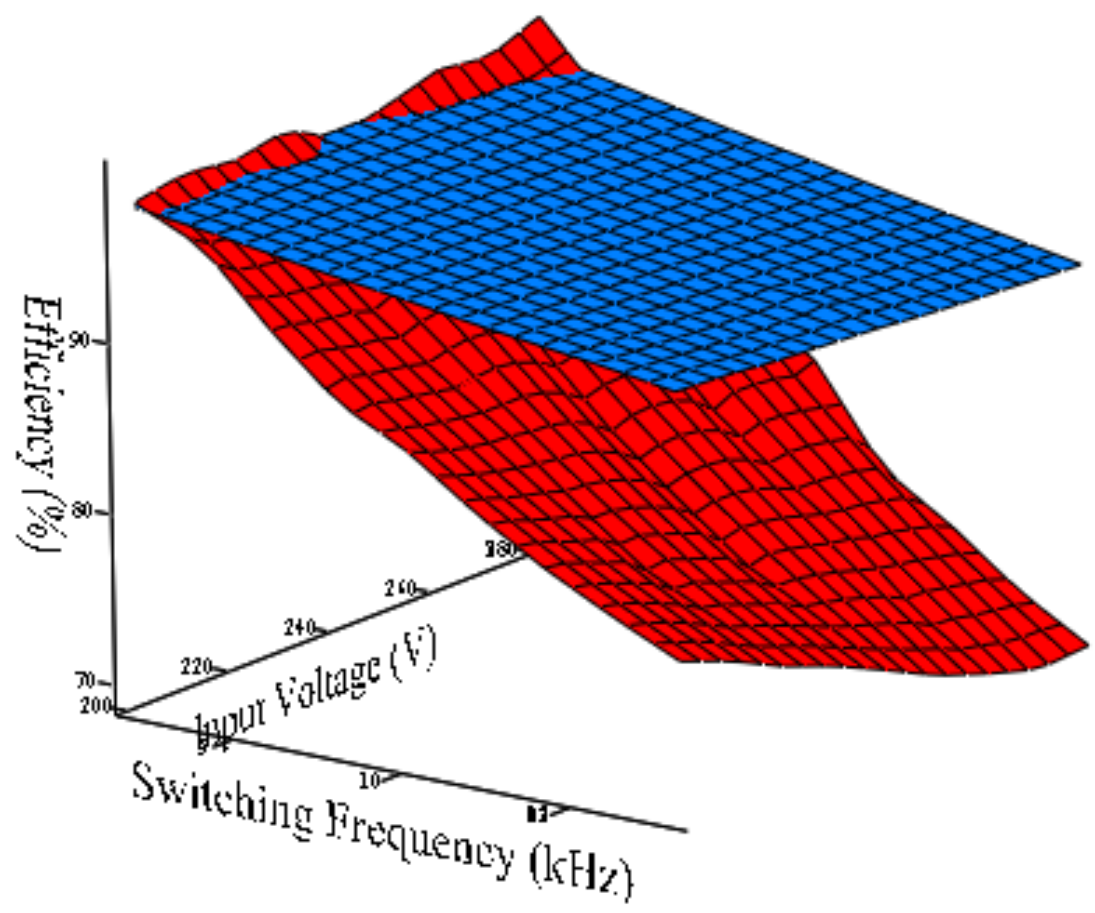

Figure 6-14 - Theoretical (Blue) and Experimental (Red) Efficiency for a $42.85 \Omega$ Load 
Even though, despite the difference, both experimental and theoretical results suggest the same operational characteristics for different parameters, it is important to note possible reasons for the discrepancy. There are a number of possible sources of error, but one of the easiest explanations could be to question the measuring instrument. While the Fluke Power Quality Analyzer does measure harmonics and is supposed to be able to properly measure the voltage of non-sinusoidal waveforms, the high switching could pose a problem. If the device does not have a high enough sampling rate, it could under measure the output voltage and lead to a lower measured efficiency. To investigate this possible cause, a more accurate device was used to measure the output voltage for a particular case. The current probe analyzer was used to measure the output current. It was connected to an HP oscilloscope with a sampling rate of $500 \mathrm{Mhz}$. At the highest switching frequency of $18 \mathrm{kHz}$, almost 30,000 samples per period are measured leading to a very accurate reading. The rms voltage was measured on the scope and converted to the appropriate current based on the amplifier settings. This current was then multiplied by the load resistance to get the output voltage. Using the Mathcad simulated inverter, the theoretical output voltage was also recorded along with the measurements from the Fluke Power Quality Analyzer. All three output voltages are compared in Figure 6-15.

At first glance, part of the efficiency problem is immediately verified. Notice the linear slope of the Fluke measurements that contrast the almost constant HP and Mathcad measurements. At $2 \mathrm{kHz}$ and even $4 \mathrm{kHz}$, the Fluke seems to be able to accurately measure the output voltage, but as the frequency increases this changes. As the frequency increases, more harmonic content in the voltage is ignored. This is most likely 
a result of the device not having a high enough sampling rate to measure the higher frequency content. When the switching frequency increases, more of the input voltage is pushed to these high frequencies that the Fluke cannot measure. It is this difference in voltage measurements that could cause a discrepancy in the measurement of efficiency.

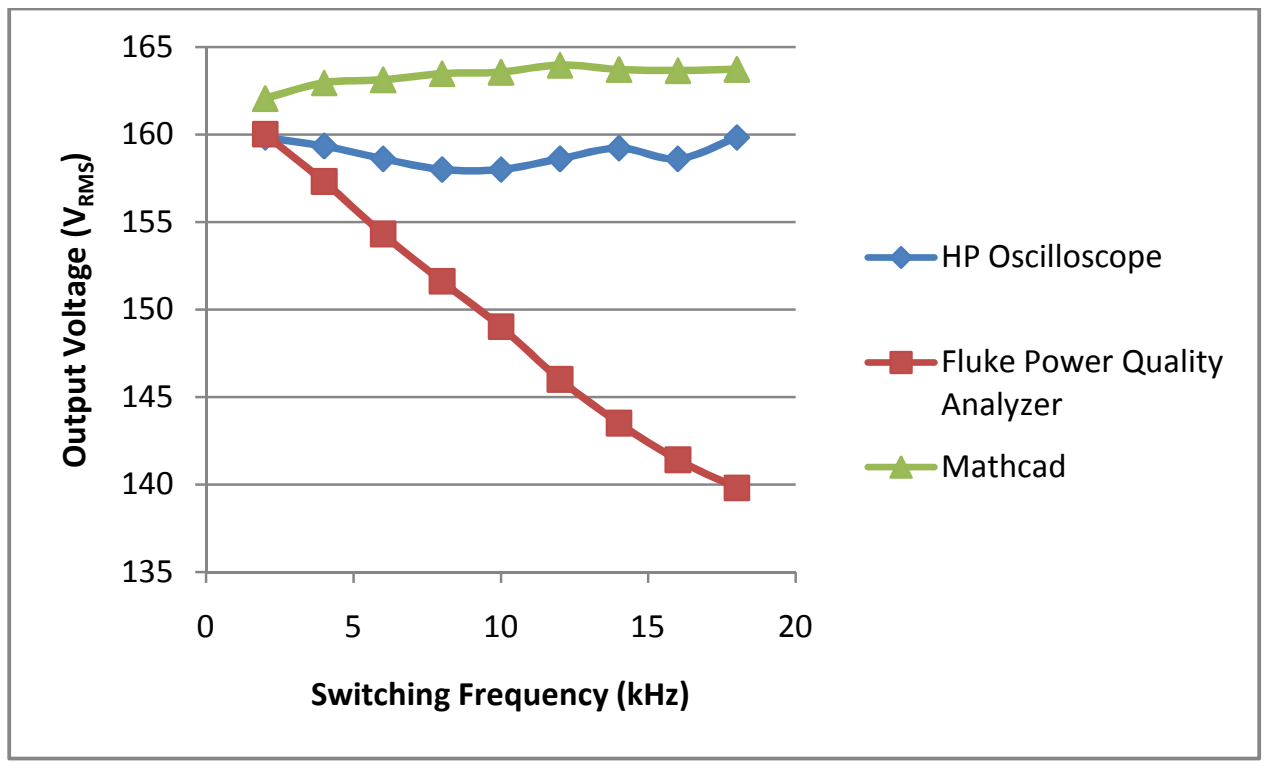

Figure 6-15 - Comparison of Different Output Voltage Measurements at $300 \Omega$ and $210 \mathrm{~V}$

While the voltage measurements do point out a large source of error, they do not explain why this difference with theoretical results increases with load. As the load increases, the efficiency should level off. This is why looking through Figure 6-9 and Figure 6-11 through Figure 6-14 the theoretical efficiency slope gets flatter. While this decreasing slope as load increases does behave theoretically, the decreasing slope with respect to switching frequency could be to blame. From the experimental results, it can be seen that as the load increases the slope of efficiency with respect to switching frequency increases. This points at a potential flaw with the theoretical results. In the Mathcad simulation of efficiency, a fixed switching energy was assumed for turning the IGBTs on and off. This however is not the case. As load increases, the collector current 
through each IGBT increases causing a larger switching energy and larger efficiency slope with respect to switching frequency.

The assumption with regard to increasing load does not only affect the switching energy. As the collector current of each IGBT increases, the collector-emitter saturation voltage and forward voltage drop of the freewheeling diode increase leading to increased conduction losses. This could explain the offset between the theoretical and experimental results. Lastly with respect to the Mathcad simulations, a fixed $120 \mathrm{~V}$ output was used to calculate collector currents and losses. This, however, is only the fundamental component of the voltage and would only be accurate in calculating losses if the output was filtered. There is actually harmonic content that adds significantly to the fundamental component. This content increases with input voltage and could cause the theoretical slope of efficiency with respect to input voltage to correlate accurately with experimental results.

Now that the discrepancies have been discussed, it is worth mentioning the results of the efficiency portion of this study. At the highest load of $42.85 \Omega$ and highest input voltage of $280 \mathrm{~V}$, a total output power of $817.6 \mathrm{~W}$ was measured. This significantly exceeds the requirements of $500 \mathrm{~W}$ and points out why care should be taken with adding a large margin with the $925 \mathrm{~W}$ limit of the input voltage source. It would be easy to assume that, with an output voltage of $120 \mathrm{~V}$ and resistance of $42.85 \Omega$, only $336 \mathrm{~W}$ is output, but this neglects all of the unfiltered harmonic content. The output power exceeded the requirements and it was determined that, in order to obtain the highest efficiency regardless of load, the lowest switching frequency and input voltage should be used. Obviously there is a limit to this input voltage, and it would more be accurate to 
say that an input voltage just above the desired peak of the fundamental output voltage should be used.

\subsection{Harmonic Distortion}

Following the efficiency measurements, the total harmonic distortion was measured. This was originally done using the Powersight 3000 however, at higher frequencies it had difficulty measuring the output THD and voltage. Instead, the Fluke Power Quality Analyzer was used. Figure 6-16 shows the theoretical and experimental THD for a $300 \Omega$ load. As previously mentioned, the THD of the output voltage should not change with load, so all measurements are compared to the same theoretical case. With the exception of the $2 \mathrm{kHz}$ case, the THD remains relatively constant as switching frequency changes. This is a result of the output voltage remaining relatively constant as switching frequency increases and can most likely be attributed to the total on time of the switches being roughly the same for changing conditions. A slight increase in experimental THD can be seen as the input voltage increases. This is due to the total output voltage increasing while the fundamental component remains fixed. As the voltage increases, more harmonic content is being added in order to maintain a fixed 120 V output at $60 \mathrm{~Hz}$.

While their major differences will be discussed later, there are some similarities between theoretical and experimental results. They both exhibit a slight increase in THD as voltage increases with the theoretical results being larger. For the most part, they both do not change with respect to switching frequency. If the major differences were removed and they did not have the offset between them, they would look rather similar with the exception of the steep increase at $2 \mathrm{kHz}$. 


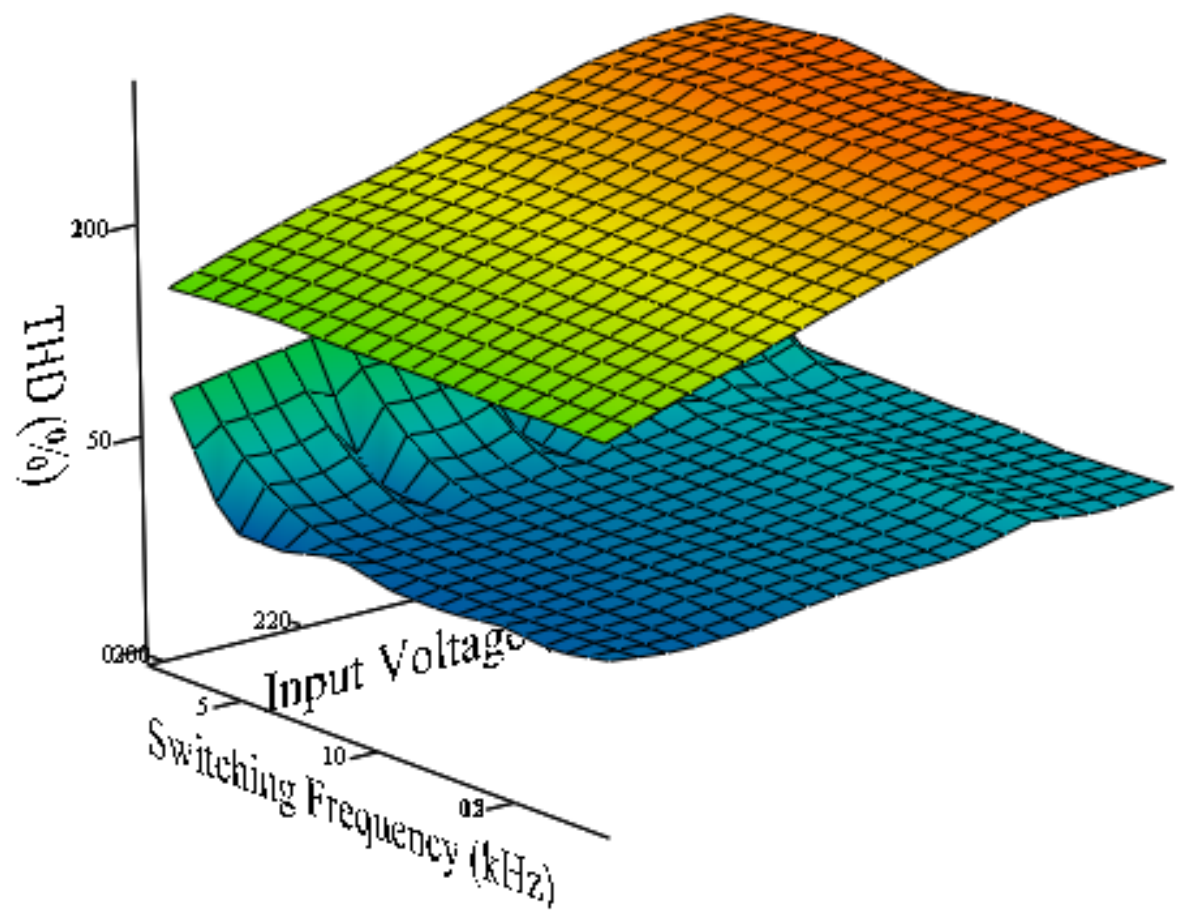

Figure 6-16 - Theoretical (Top) and Experimental (Bottom) THD for a $300 \Omega \mathrm{Load}$

Figure 6-17 through Figure 6-20 show the THD for loads of 150, 75, 50, and $42.85 \Omega$ respectively. They show the same overall trend as before. There is a steep slope downward at $2 \mathrm{kHz}$ upon which the THD remains relatively flat, but increases with input voltage. This increase is still less than the increase the theoretical results have with increasing voltage. All four results seem to start above $50 \%$ at $2 \mathrm{kHz}$ and roll-off to somewhere between $30 \%$ and $40 \%$. At several points in the different figures, there are some imperfections in the smooth nature of the trend. This can be attributed to a measurement error at that point. The THD can fluctuate when being measured and sometimes a bad reading can be taken. This reading is then estimated by the graphing program to roll off in all directions showing a small bump in the smooth curve. This is evident in Figure 6-18 around $18 \mathrm{kHz}$ and $210 \mathrm{~V}$. 


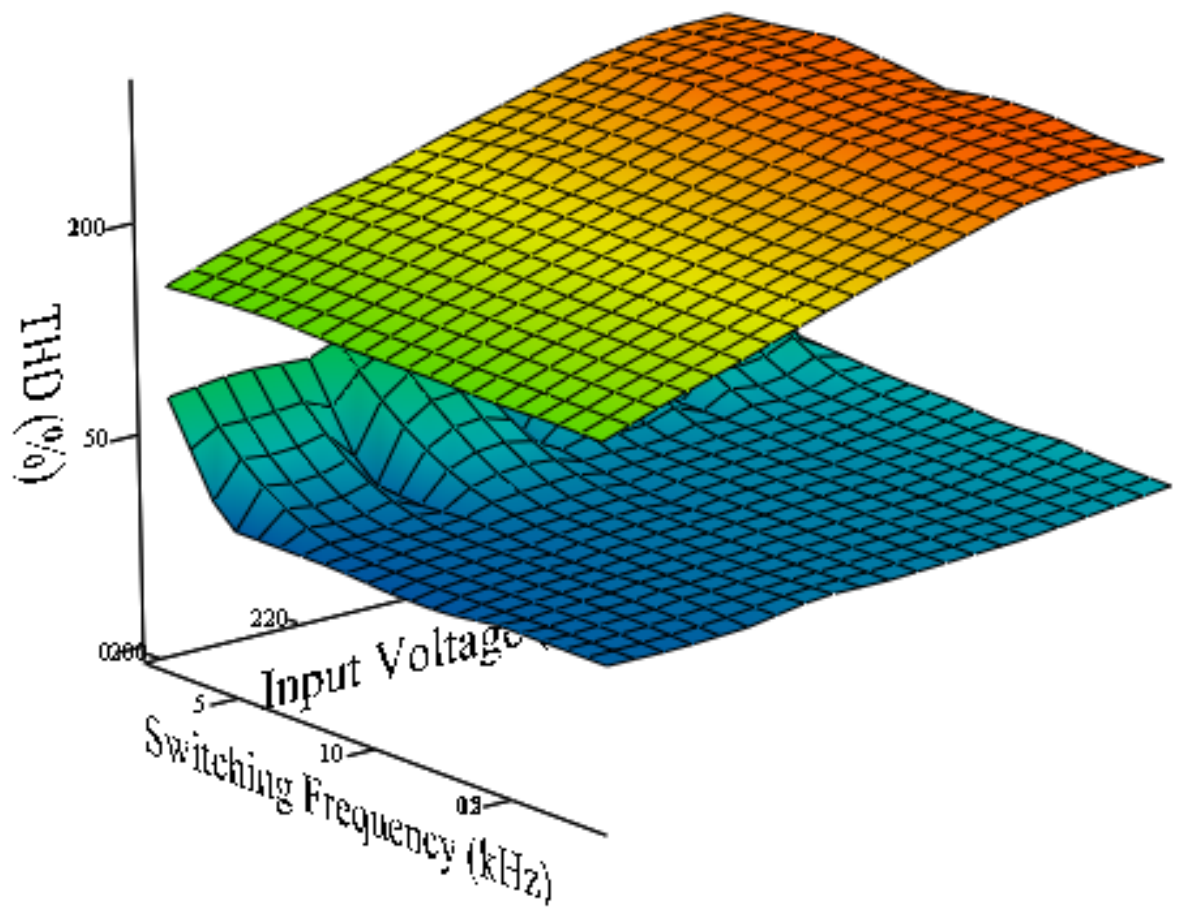

Figure 6-17 - Theoretical (Top) and Experimental (Bottom) THD for a $150 \Omega$ Load

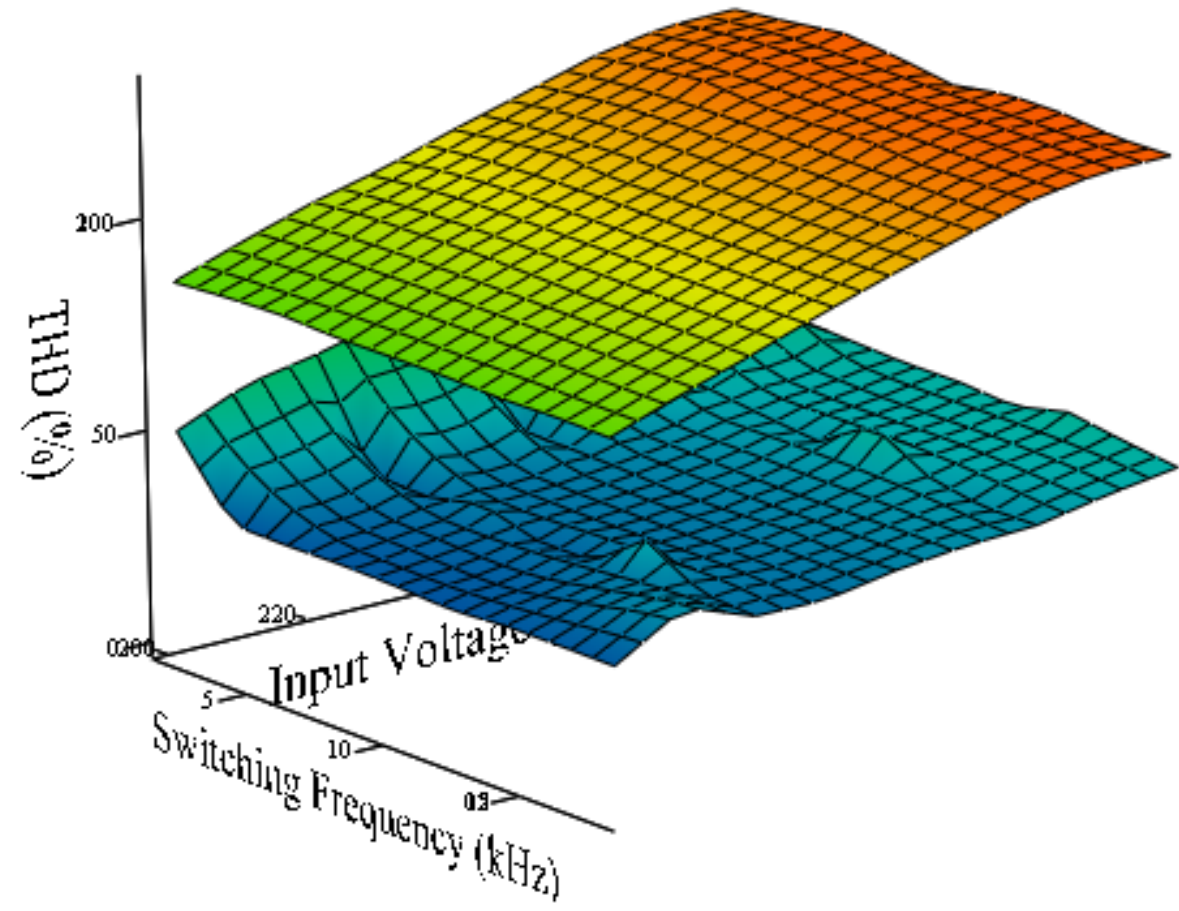

Figure 6-18 -Theoretical (Top) and Experimental (Bottom) THD for a $75 \Omega \mathrm{Load}$ 


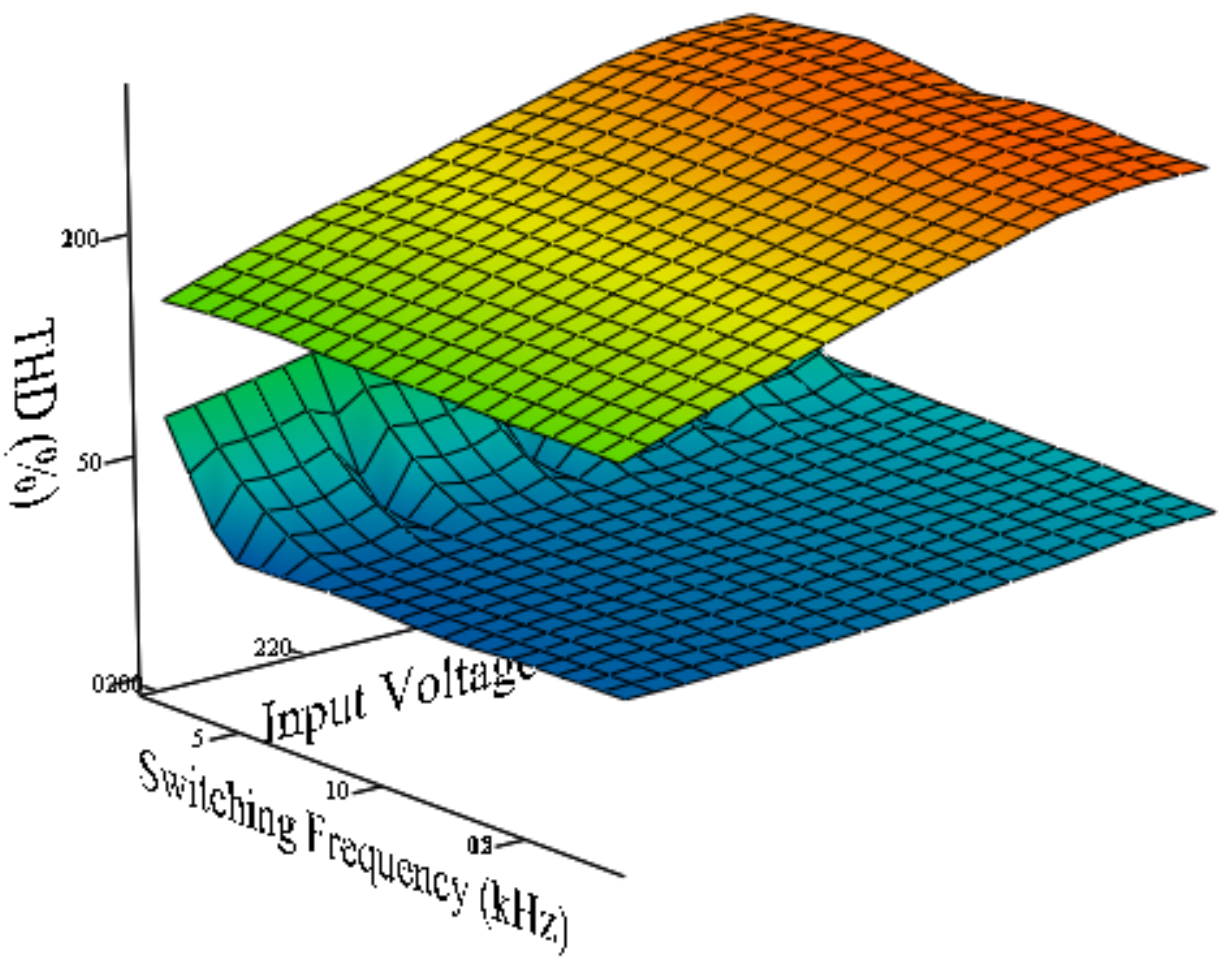

Figure 6-19 - Theoretical (Top) and Experimental (Bottom) THD for a $50 \Omega \mathrm{Load}$

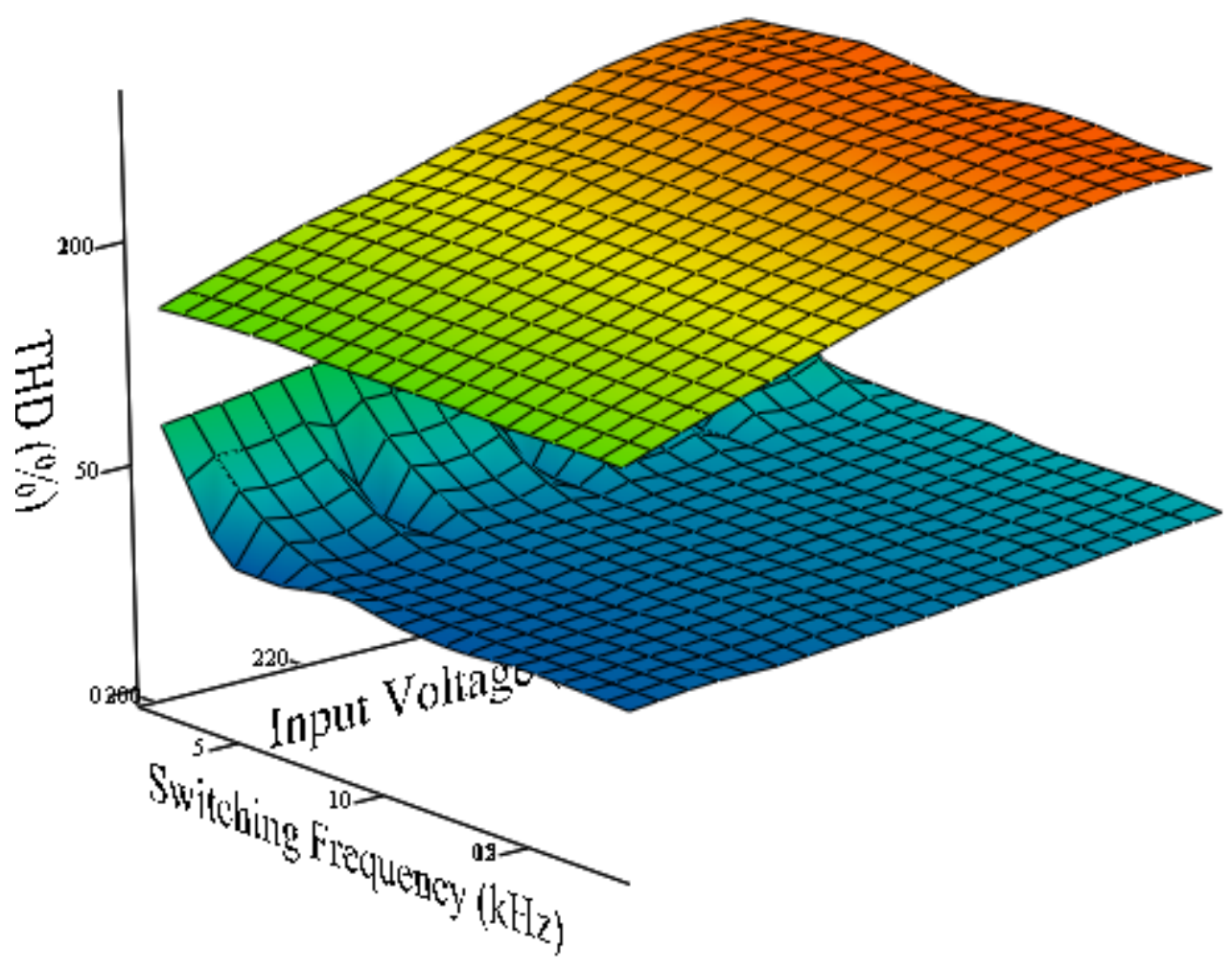

Figure 6-20 - Theoretical (Top) and Experimental (Bottom) THD for a $42.85 \Omega \mathrm{Load}$ 
Before investigating the reasons for the differences between theoretical and experimental results, it is worth verifying that the THD does not change with load. Figure 6-21 shows the THD for all five loads superimposed on each other. Notice that, with the exception of a few imperfections due to measurement errors, all five THD trends are identical and it is difficult to distinguish one from the other. This demonstrates that the THD will remain constant despite the loading. This is helpful to know because now the inverter parameters do not have to change with loading to achieve optimum THD.

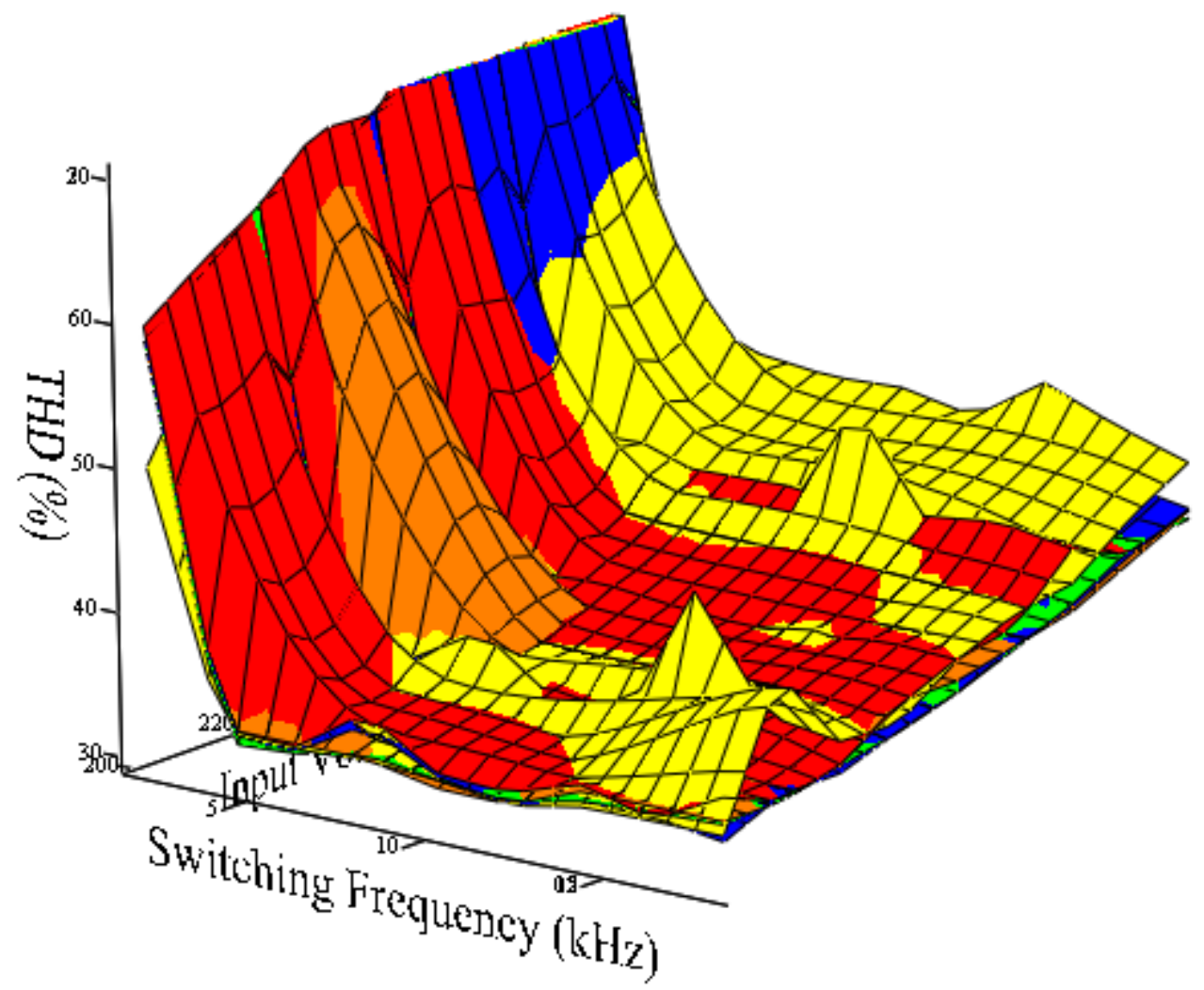

Figure 6-21 - Experimental THD for 300 (Red), 150 (Orange), 75 (Yellow), 50 (Green), 42.85 (Blue) $\Omega$ Loads

There were several correct assumptions with respect to the experimental THD trend. The assumption that the THD is constant as the load and switching frequency change was correct. As well as the slight increase in THD as voltage increases. These 
suggest that the approach taken to predict THD was correct; however, there are still two major differences in the offset between theoretical and experimental results as well as the larger THD at $2 \mathrm{kHz}$. These can be attributed to the measurement of the THD, and a fundamental flaw in the THD measurement using power quality analyzers is evidenced by this error.

The Fluke Power Quality Analyzer, the Powersight 3000, and most other power quality measurement devices measure the THD by measuring the first 50 harmonics. The THD is then displayed as the ratio of the 2 nd through 50 th harmonic with the 1 st. For most situations, this is an accurate measurement of THD because the harmonic content after the 50th harmonic is negligible. However, for an unfiltered inverter this is not the case. Most of the harmonic content occurs at multiples of the switching frequency. At 2 $\mathrm{kHz}$, this occurs at and around the 33rd harmonic. A power quality measurement device measures the first 50 harmonics and for the $2 \mathrm{kHz}$ would measure the first harmonic peak at 33, but neglect those at increased multiples of 33. For frequencies higher than $2 \mathrm{kHz}$, the switching harmonics are completely ignored by the measurement device and the THD is noticeably under-measured. This is demonstrated in Figure 6-22 where the frequency spectrum of a particular $2 \mathrm{kHz}$ case was captured using the Powersight 3000 . The calculated and measured frequency spectrum seem to follow each other very closely including the two having almost identical peaks at $2 \mathrm{kHz}$ (33). The calculated THD for the first 50 harmonics is $81 \%$ while it was measured to be $71 \%$. This small difference between the two could be attributed to measurement inaccuracies. Figure 6-23 shows the entire frequency spectrum. There are four distinct peaks that are completely ignored in experimental results. A similar analysis was performed at $18 \mathrm{kHz}$ and the THD of the 
first 50 harmonics was calculated to be $37 \%$ while the experimental results were measured to be $37.4 \%$. This analysis of the power quality measurement inaccuracy explains the major difference in theoretical and experimental results.

This measurement inaccuracy can also explain why the slope of the THD with respect to input voltage is not as steep for the experimental results. As the input voltage increases, the switching has to increase in order to maintain the constant $120 \mathrm{~V}$ at the fundamental frequency. This increased switching causes increased harmonic content. Some of this content occurs in the first 50 harmonics which is why there is a slight increase, but most of it occurs at harmonics greater than 50 that go unmeasured in the experimental results.

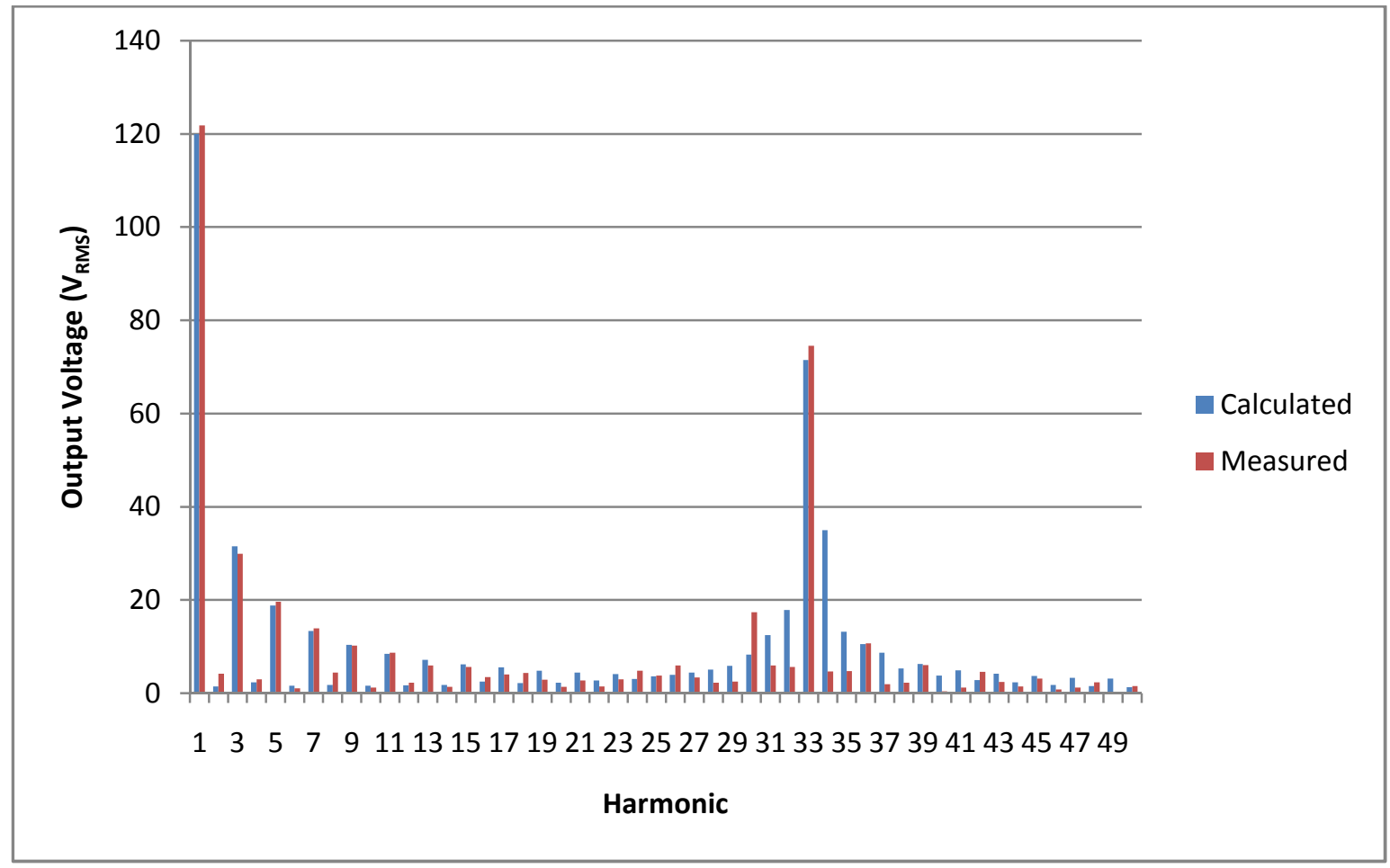

Figure 6-22 - Calculated and Measured Frequency Spectrum of Output Voltage at $210 \mathrm{~V}$ and $2 \mathrm{kHz}$ up to 50th Harmonic 


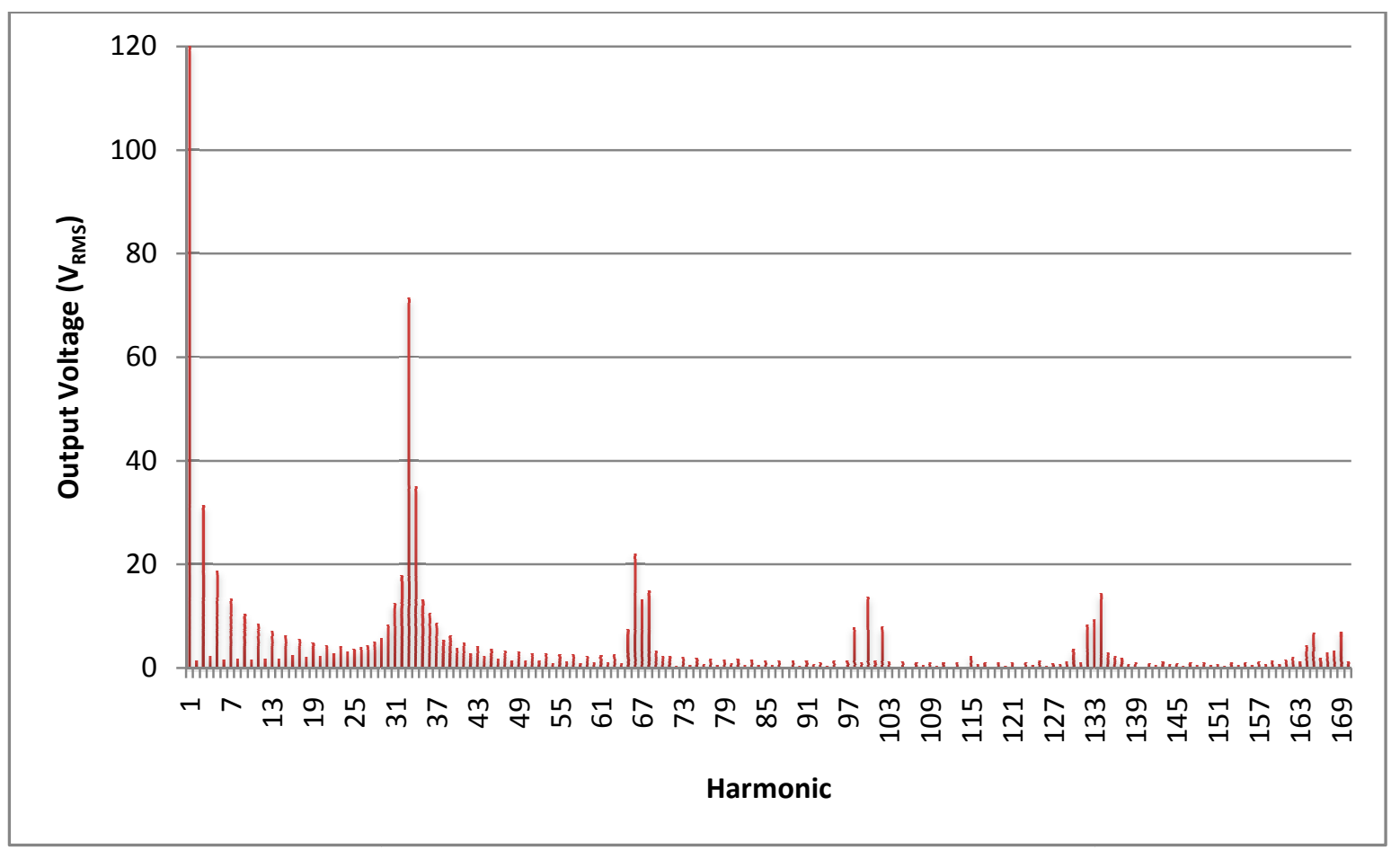

Figure 6-23 - Calculated Frequency Spectrum of Output Voltage at $210 \mathrm{~V}$ and $2 \mathrm{kHz}$

The results of the THD measurement and analysis portion of this study suggest using the lowest input voltage regardless of load and switching frequency. An input voltage just above the desired peak of the fundamental frequency at the output should be used. Care should also be taken when trusting what power quality measurement devices say about the unfiltered output. 


\section{Conclusions}

In this report, a power quality study was performed on a unipolar PWM inverter topology. The inverter was simulated and theoretical calculations were made using Mathcad. The inverter was then built using a Powerex IPM and data was collected as the input voltage, switching frequency, and load were changed. The efficiency and THD for every case were evaluated and compared to theoretical results.

The results of this study suggest particular steps that should be taken in designing the most optimum inverter and photovoltaic system. In order to maintain the highest efficiency, the lowest switching frequency should be used as well as a DC input voltage that is just above the desired peak of the output voltage. This is the case regardless of load. With respect to harmonic distortion, similar conditions apply. The lowest possible input voltage should also be used with the best case being that of the peak of the desired fundamental output voltage. Without filtering, THD is not dependent on switching frequency and any value could be used. With filtering, higher switching frequencies are most likely preferred. This is a result of higher frequencies being easier to filter because of the harmonic content being further away from the fundamental frequency as well as the smaller size of components. However, there exists a trade-off here between efficiency and harmonic filtering. If a higher frequency is chosen because of filtering ease, the efficiency will suffer. The importance of each of these should be evaluated before a decision is made. Not only has this study suggested optimal inverter design parameters, but it has also pointed out a deficiency in power quality measurement devices. When high frequency harmonics are present caution should be taken when trusting the reading of these devices. 
The most difficult problem encountered in this study was with inverter shootthrough. It is recommended that appropriate dead time should be designed for. The first sign of this problem is if current is present for no load. While power supplies do have current limits, this current limit is on the average and not the instantaneous current. Current peaks greater than 20 A were seen and, without the higher ratings and protection circuitry of the Powerex IPM, devices could have been destroyed. It is also recommended that appropriate devices are used to measure particular quantities. Problems were encountered with the measurement of output voltage and THD at high frequencies.

Future work could be done by performing a similar analysis of different inverter topologies including bipolar and type 1 unipolar PWM. It may seem obvious that these studies would come to the same conclusion, however this cannot be assumed without further analysis. Performing these studies would be rather simple in that only a few changes to the control circuitry need to be made before data can begin to be collected. This study could also be applied to make the most optimum inverter for a particular case and its results are a valuable asset to design engineers. Another study could be performed with a different IPM that has a break circuit. The effect of controlling the output with a thyristor could investigated in detail.

Overall, this study was a success in its pointing out the best input parameters for the optimum operation of a type 2 unipolar PWM inverter. Expected results with theoretical and experimental calculations and measurements were obtained and the differences between the two were explained, investigated, and verified in detail. 


\section{BIBLIOGRAPHY}

[1] Owen, E.L., "History [origin of the inverter]," Industry Applications Magazine, IEEE, vol.2, no.1, pp.64-66, Jan/Feb 1996

[2] Edelmoser, K.H.; Himmelstoss, F.A., "Analysis of a new high-efficiency DC-toAC inverter," Power Electronics, IEEE Transactions on , vol.14, no.3, pp.454460, May 1999

[3] Meksarik, V., Masri, S., Taib, S., Hadzer, C.M., "Development of high efficiency boost converter for photovoltaic application," Power and Energy Conference, 2004. PECon 2004. Proceedings. National, vol., no., pp. 153- 157, 29-30 Nov. 2004

[4] Chien-Ming Wang, "A novel single-stage full-bridge buck-boost inverter," Applied Power Electronics Conference and Exposition, 2003. APEC '03. Eighteenth Annual IEEE, vol.1, no., pp. 51- 57 vol.1, 9-13 Feb. 2003

[5] Uematsu, T., Tanaka, K., Takayanagi, Y., Kawasaki, H., Ninomiya, T., "Utility interactive inverter controllable for a wide range of DC input voltage," Power Conversion Conference, 2002. PCC Osaka 2002. Proceedings of the , vol.2, no., pp.498-503 vol.2, 2002

[6] Zargari, N.R., Ziogas, P.D., Joos, G., "A two-switch high-performance current regulated DC/AC converter module," Industry Applications, IEEE Transactions on , vol.31, no.3, pp.583-589, May/Jun 1995

[7] Edelmoser, K.H., Himmelstoss, F.A., "Improved $1 \mathrm{~kW}$ solar inverter with wide input voltage range," Signals, Circuits and Systems, 2003. SCS 2003. International Symposium on, vol.1, pp. 201- 204 vol.1, 10-11 July 2003

[8] Shireen, W., Kulkarni, R.A., "A soft switching inverter module with modified DC-link circuit for high frequency DC-AC power conversion," Applied Power Electronics Conference and Exposition, 2003. APEC '03. Eighteenth Annual IEEE, vol.1, pp. 507- 511 vol.1, 9-13 Feb. 2003

[9] Guan-Chyun Hsieh, Chun-Hung Lin, Jyh-Ming L,; Yu-Chang Hsu, "A study of series-resonant DC/AC inverter," Power Electronics Specialists Conference, 1995. PESC '95 Record., 26th Annual IEEE, vol.1, no., pp.493-499 vol.1, 18-22 Jun 1995

[10] Hui, S.Y.R., Gogani, E.S., Jian Zhang, "Analysis of a quasi-resonant circuit for soft-switched inverters ," Power Electronics, IEEE Transactions on, vol.11, no.1, pp.106-114, Jan 1996 
[11] Maswood, A.I., Yusop, A.K., Rahman, M.A., "A novel suppressed-link rectifierinverter topology with near unity power factor," Power Electronics, IEEE Transactions on, vol.17, no.5, pp. 692- 700, Sep 2002

[12] Zue, A.O., Chandra, A., "Simulation and stability analysis of a $100 \mathrm{~kW}$ grid connected LCL photovoltaic inverter for industry," Power Engineering Society General Meeting, 2006. IEEE, vol., no., pp.6 pp., 0-0 0

[13] Naik, R., Mohan, N., "A novel grid interface for photovoltaic, wind-electric, and fuel-cell systems with a controllable power factor of operation," Applied Power Electronics Conference and Exposition, 1995. APEC '95. Conference Proceedings 1995., Tenth Annual, no.0, pp.995-998 vol.2, 5-9 Mar 1995

[14] Oliva, A.R., Balda, J.C., "A PV dispersed generator: a power quality analysis within the IEEE 519," Power Delivery, IEEE Transactions on , vol.18, no.2, pp. 525- 530, April 2003

[15] Kjaer, S.B., Pedersen, J.K., Blaabjerg, F., "A review of single-phase gridconnected inverters for photovoltaic modules," Industry Applications, IEEE Transactions on , vol.41, no.5, pp. 1292-1306, Sept.-Oct. 2005

[16] Tria, L.A.R., Escoto, M.T., Odulio, C.M.F., "Photovoltaic array reconfiguration for maximum power transfer," TENCON 2009 - 2009 IEEE Region 10 Conference, pp.1-6, 23-26 Jan. 2009

[17] Imhoff, J., Pinheiro, J.R., Russi, J.L., Brum, D., Gules, R., Hey, H.L., "DC-DC converters in a multi-string configuration for stand-alone photovoltaic systems," Power Electronics Specialists Conference, 2008. PESC 2008. IEEE, pp.28062812, 15-19 June 2008

[18] Myrzik, J.M.A., Calais, M., "String and module integrated inverters for singlephase grid connected photovoltaic systems - a review," Power Tech Conference Proceedings, 2003 IEEE Bologna, vol.2, no., pp. 8 pp. Vol.2, 23-26 June 2003

[19] Steimer, P.K., "Power Electronics, a Key Technology for Energy Efficiency and Renewables," Energy 2030 Conference, 2008. ENERGY 2008. IEEE, pp.1-5, 1718 Nov. 2008

[20] Taufik, "Introduction to Power Electronic," Lecture Notes, $6^{\text {th }}$ revision 2008.

[21] Milanovic, J.V., Negnevitsky, M., "Power quality problems and solutions: current understanding," Harmonics And Quality of Power, 1998. Proceedings. 8th International Conference on, vol.1, pp.30-35 vol.1, 14-18 Oct 1998 
[22] Rashid, Muhammed H. Power Electronics Handbook. San Diego, California: Academic Press, 2001.

[23] "IEEE Recommended Practices and Requirements for Harmonic Control in Electrical Power Systems." no. IEEE Std 519-1992, 1993

[24] Rash, A., "Harmonics-what are they, how to measure them and how to solve the problem (in connection with standards IEEE 1159-1995 and IEEE 519-1992) ," Electrical and Electronics Engineers in Israel, 1996., Nineteenth Convention of, pp.83-86, 5-6 Nov 1996

[25] Taufik, "Advanced Power Electronic," Lecture Notes, $3^{\text {rd }}$ revision 2009.

[26] Mitsubishi Electric. "Using IGBT Modules". Mitsubishi Semiconductors Power Modules MOS.

[27] "L-Series Power Devices Application Note." Powerex, Inc., 2007.

[28] "PM50CLA060 Datasheet." Powerex, Inc.

[29] "BP7B Application Notes." Powerex, Inc.

[30] Franke, W.-T., Mohr, M., Fuchs, F.W., "Comparison of a Z-source inverter and a voltage-source inverter linked with a DC/DC-boost-converter for wind turbines concerning their efficiency and installed semiconductor power," Power Electronics Specialists Conference, 2008. PESC 2008. IEEE, pp.1814-1820, 1519 June 2008 